\title{
NAVY SEAL PROSTHETIC HAND
}

\author{
A Thesis \\ presented to \\ the Faculty of California Polytechnic State University, \\ San Luis Obispo
}

\author{
In Partial Fulfillment \\ of the Requirements for the Degree \\ Master of Science in Biomedical Engineering
}

by

Devon Patrick Augustus

June 2013 
(C) 2013

Devon Patrick Augustus

ALL RIGHTS RESERVED 
Committee Membership

TITLE:

Navy SEAL Prosthetic Hand

AUTHOR:

Devon Patrick Augustus

DATE SUBMITTED:

June 2013

COMMITTEE CHAIR:

Dr. Lily Laiho

Biomedical Engineering

California Polytechnic State University San Luis Obispo

COMMITTEE MEMBER: Dr. David Clague

Biomedical Engineering

California Polytechnic State University San Luis Obispo

COMMITTEE MEMBER: Dr. Robert Crockett

Biomedical Engineering

California Polytechnic State University San Luis Obispo 


\section{Abstract \\ Navy SEAL Prosthetic Hand \\ Devon Patrick Augustus}

Prosthetic development recently has focused mainly on myoelectrically controlled electric hands despite a majority of upper extremity amputees actively choosing body powered devices. Myoelectric hands utilize a small electric pulse generated in muscles when flexing as a signal to the hand to close. Finger flexion in these devices is controlled by electromechanical servos, requiring no strength input from the user. Body powered devices use a cable attached to a shoulder harness which causes mechanical closure of the device via tension placed on a control cable by a shoulder shrug motion or arm extension. Outfitting of active duty service personnel has recently tended to follow the electronic hands which have fragile electronics, have a poor response to user input, and are not fit for harsh outdoor environments. This report will detail the current development of a re-design of a custom left hand prosthesis for an active duty Navy SEAL and the transition from electronic controls to full body power function.

Keywords: Prosthetic Hand, Body Powered Hand, Outdoor Prosthetic, Locking Prosthetic 


\section{Acknowledgements}

I would especially like to thank Mr. Jon Monett and Mr. Scott Monett along with all the staff at Quality of Life Plus that make projects like these possible. Thank you for the work you do to better the lives of those who have been injured in service to this great country.

I would like to thank Dr. Lily Laiho for advising this project and imparting excellent insight and guidance from inception to prototype completion. This project would not have been possible without her help and guidance.

I would also like to thank Jordan Gamble and all the tech staff in the Industrial and Manufacturing Engineering Advanced Machining Lab for their immense help in producing parts on the computer controlled mill. 


\section{Contents}

Tables viii

Figures ix

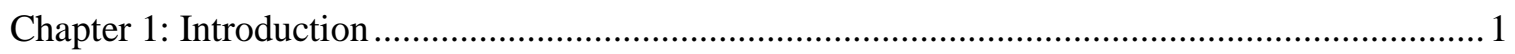

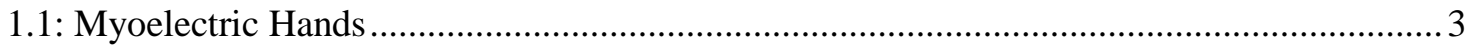

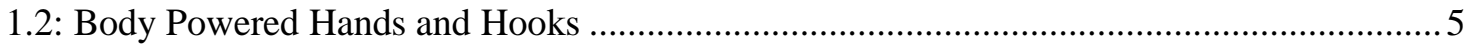

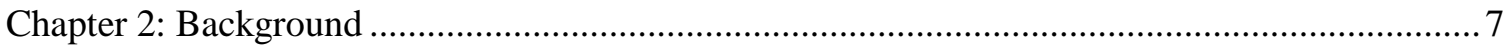

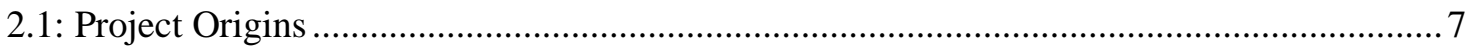

2.2: Reasons for Project Continuation and Re-Design ......................................................... 9

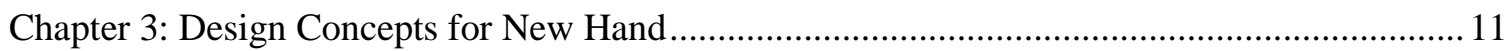

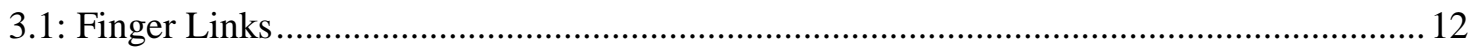



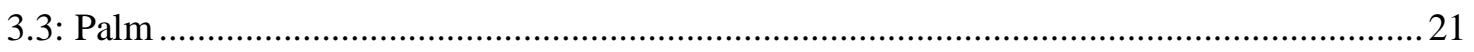

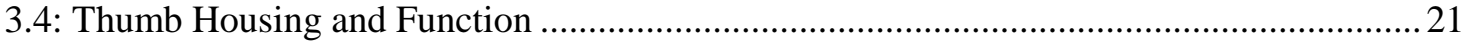

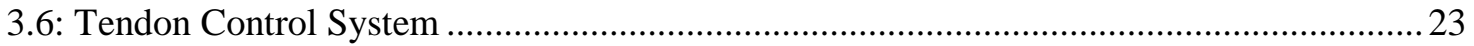

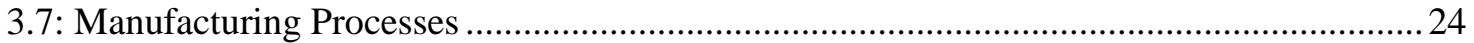

Chapter 4: Mathematical Simulations and Physical Testing Results ..........................................25

4.1: Maximum Tendon Tension Model and Physical Testing ................................................25

4.2.1: Finite Element Modeling of Transverse Phalanx Failure ................................................ 33

4.2.2: Physical Verification of Transverse Loading.......................................................... 41

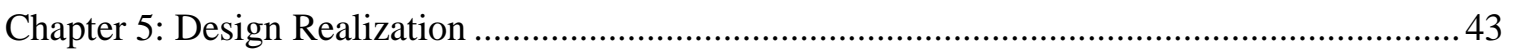

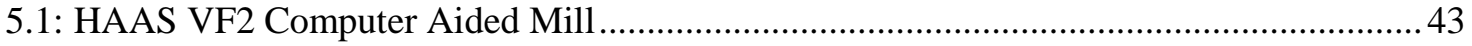

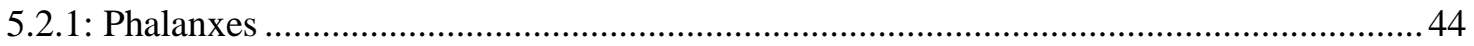

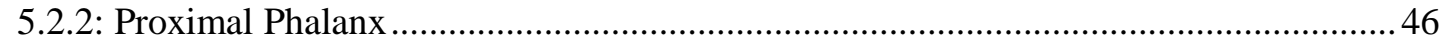

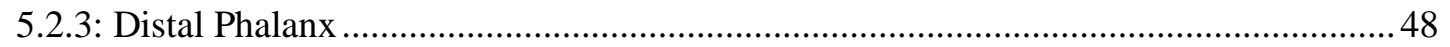

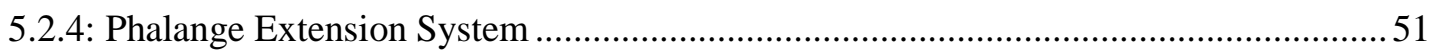

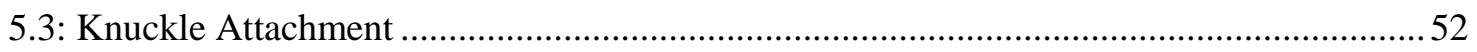

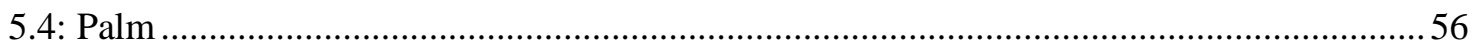



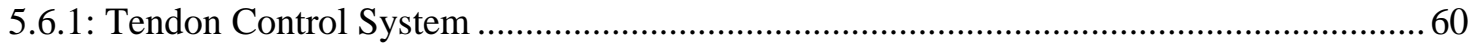

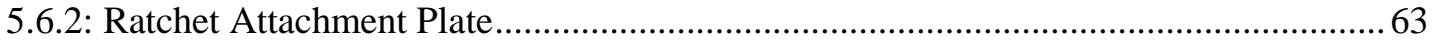

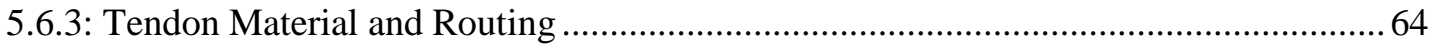

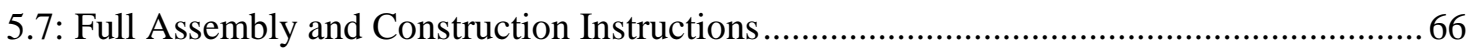


Chapter 6: Future Work

6.1: Knuckle Bar Redesign

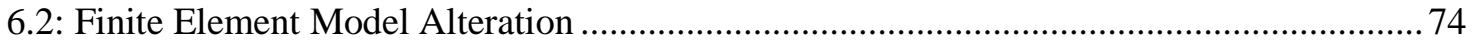

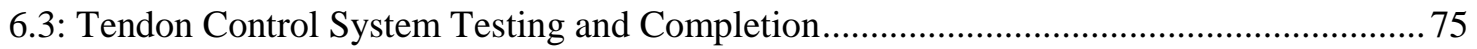

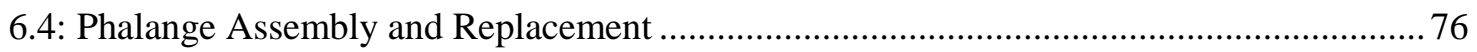

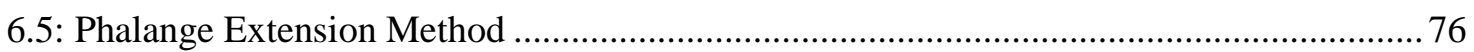

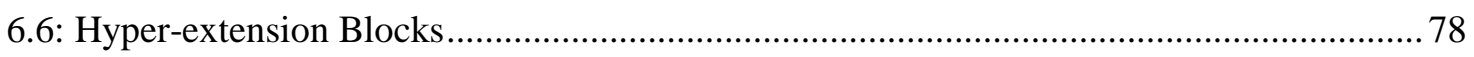

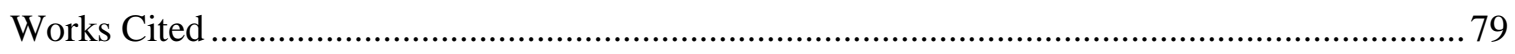

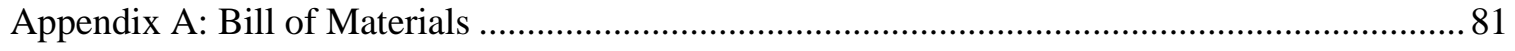

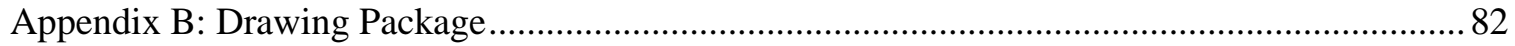




\section{Tables}

Table 1: Tendon Tension Model Results for Varying Angles ................................................29 


\section{Figures}

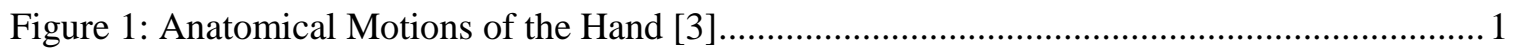

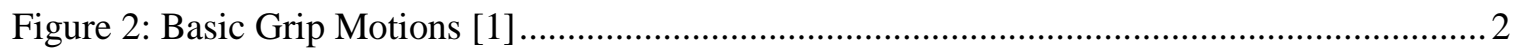

Figure 3: A) Touch Bionics iLimb Ultra [11] B) RSLSteelerBebionic Hand [12] ........................ 4

Figure 4: A) Otto Bock 8K22 Pasive Open Single Cable Hand [13] B) Otto Bock 10A70

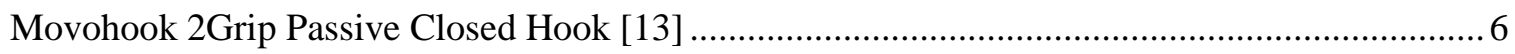

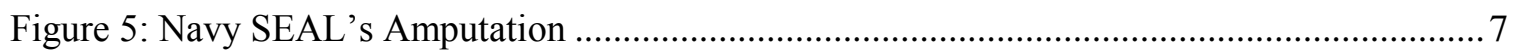

Figure 6: Typical Trans-Radial Device used by Navy SEAL during active duty ........................... 7

Figure 7: A) BETA II Device Prototype, Inferior Side B) BETA II Device Prototype, Superior

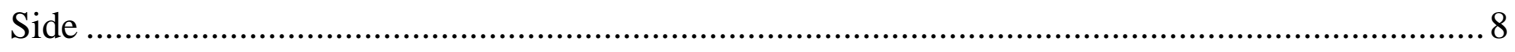

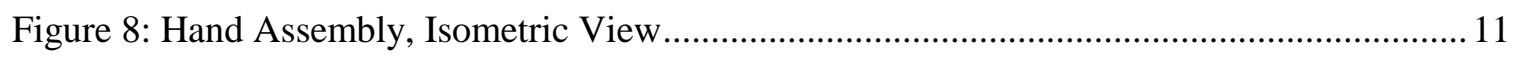

Figure 9: IOWA Hand Prototype Model created by group at the University of Iowa [7] ............. 12

Figure 10: de Visseret. al. Phalanx Design and Predicted Force Distribution [10] ...................... 13

Figure 11: Anatomic Phalanx Proportions ............................................................................. 14

Figure 12: Proximal Phalanx, Isometric View ..................................................................... 14

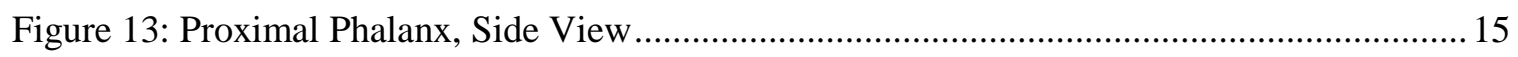

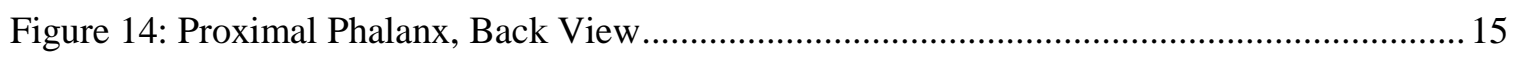

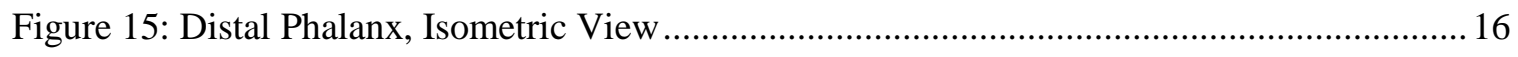

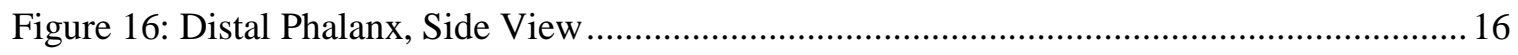

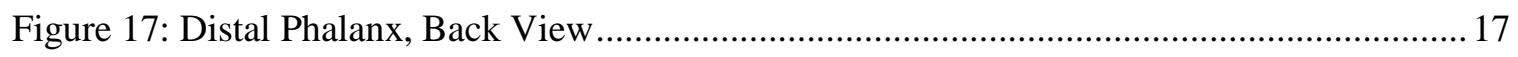

Figure 18: Phalange Assembly, Isometric View................................................................... 17

Figure 19: Transverse Loading of a Phalange and Expected Failure Point, Top View ................ 18

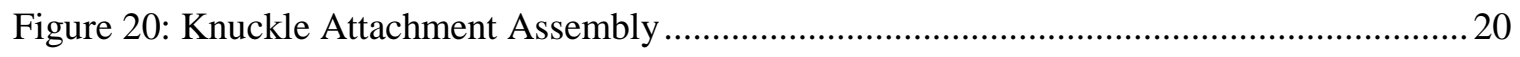

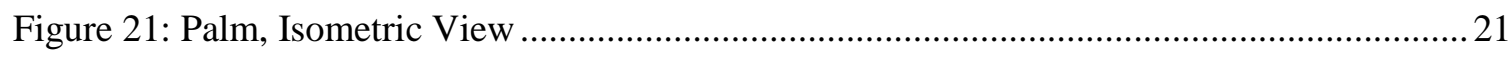

Figure 22: Thumb Housing Attachment Tab, Isometric View ...............................................22

Figure 23: Thumb Housing and Bar Model, Isometric View ................................................. 22 


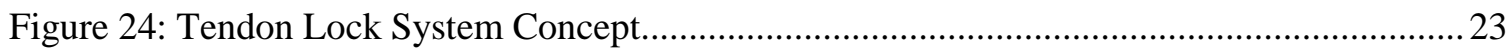

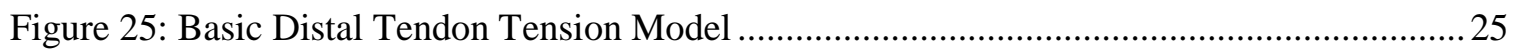

Figure 26: Full Finger Tendon Tension Model with Rotating Coordinate Systems ......................26

Figure 27: Coordinate Transforms for Cable Tension Model..................................................2

Figure 28: Tendon Tension Model Results as a Function of Proximal and Distal Bend Angle .... 30

Figure 29: Alpha Finger Assembly for Testing of Tendon System .......................................... 31



Figure 31: Force Scale Reading for Tendon force Physical Testing .......................................... 32

Figure 32: Finite Element Models and Meshes of Finger Components....................................... 34

Figure 33: Finite Element Model Boundary Condition and Force Placement.............................. 35

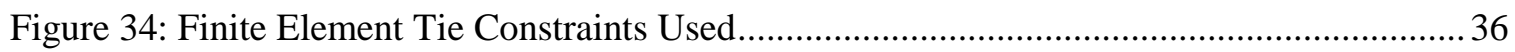

Figure 35: Finite Element Convergence Study Node Location ............................................... 37

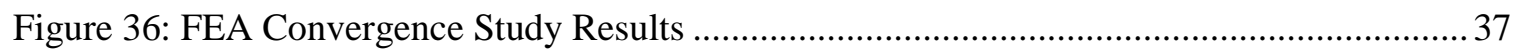

Figure 37: Locations of High Stress on Finite Element Model ................................................. 39

Figure 38: Aluminum Knuckle Finite Element von Mises Stress Results with 10lb Transverse

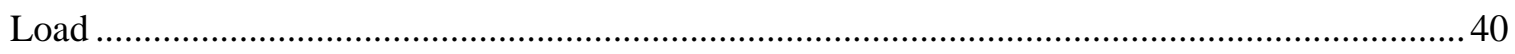

Figure 39: Titanium Knuckle Finite Element von Mises Stress Results with 10lb Transverse Load

Figure 40: Transverse Finger Failure Physical Verification ................................................... 41

Figure 41: Physical Transverse Load Testing, 16lb Weight Deflection Image ............................. 42

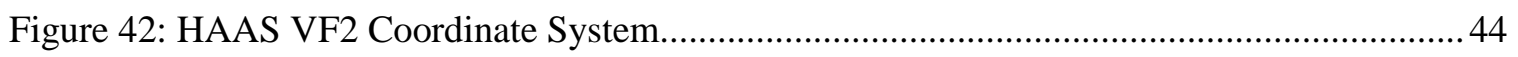

Figure 43: Proximal and Distal Phalanx Final Design Solidworks Rendering .............................. 46

Figure 44: Proximal Phalanx CNC Operation 1 Fixturing ...................................................... 47

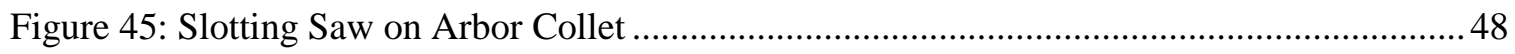

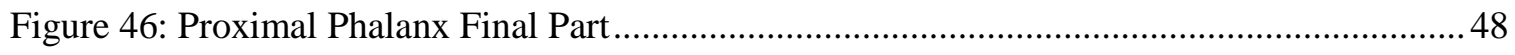

Figure 47: Distal Phalanx CNC Operation 1Fixturing ............................................................. 49 


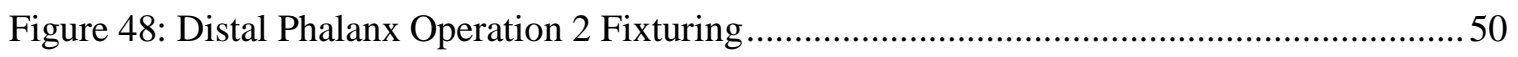

Figure 49: Distal Phalanx Failed Part and Correct Part ..............................................................50

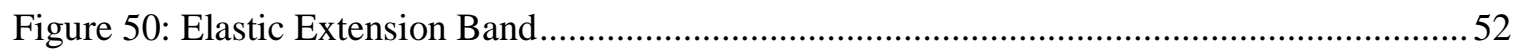

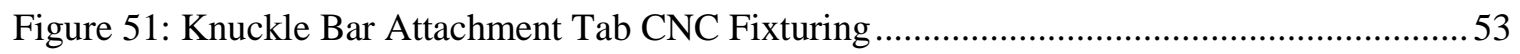

Figure 52: Knuckle Bar Hole Drilling Operation Fixturing.....................................................55

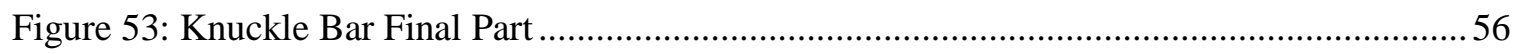

Figure 54: Palm Cut Line Layout and Cut Order....................................................................5

Figure 55: Palm with Distal Holes Drilled and Hole Guides for Leather Brace Attachment Laid

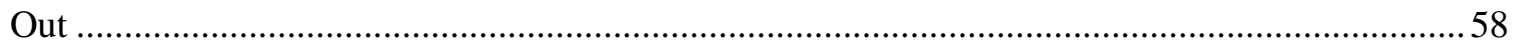

Figure 56: Thumb Housing Attachment Tab Final Part .......................................................... 60

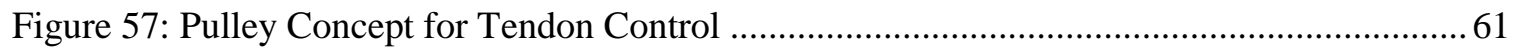

Figure 58: Cyclic Tie Down Ratchet in Closed and Open States ............................................63

Figure 59: Tendon Ratchet Mounting Plate Final Part ............................................................ 64

Figure 60: Multifilament Tendon with End Loop............................................................... 65

Figure 61: Cable Stops to Control Tendon Tension at the Ratchet............................................. 66

Figure 62: A) Complete Hand Prototype, Side View B) Complete Hand Prototype, Top View.. 66

Figure 63: Palm Plate Attachment to Leather Brace................................................................. 67

Figure 64: A) Ratchet Mounting Plate with Ratchet Mounting Screw Placed B) Ratchet

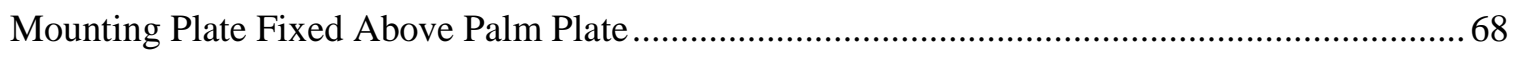

Figure 65: Thumb Housing Attachment Tab Connected to Palm............................................... 68

Figure 66: Thumb Mechanism from Previous Iteration Attached to Device................................69

Figure 67: A) Assembled Phalange Top View B) Assembled Phalange Side View .................... 70

Figure 68: Medial Phalange Attached to Knuckle Bar ............................................................. 71

Figure 69: Phalanges Attached to Knuckle Bar ....................................................................... 72

Figure 70: Tendons Run Through Knuckle Bar once it was Attached to the Assembly ............... 73 


\section{Chapter 1: Introduction}

The human hand is an amazingly complex set of mechanisms. It can be said that the hand is the brain's ultimate tool, and loss of even one of these amazing tools has a profound impact on a person's life. The human hand has a full 22 degrees of freedom [1] which are created by 27 unique bones and 30 muscles [2]. Muscle groups include both extrinsic muscles that are located in the trunk of the forearm and inserted into the hand via tendons, and intrinsic muscles which originate and terminate within the anatomy of the hand itself. Extrinsic muscles are responsible for hand flexion and extension as well as supination, pronation, abduction, and adduction about the wrist as shown in Figure 1 below. Intrinsic muscles originate from between the metacarpals and are responsible for fine motor control of the phalanges.

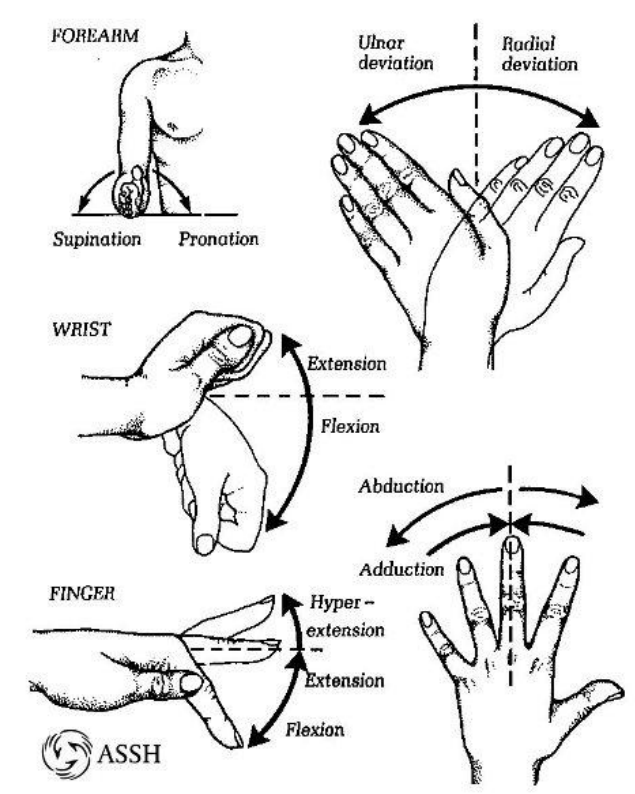

Figure 1: Anatomical Motions of the Hand [3]

Attempting to re-create the function of a hand for amputees is a daunting task due to limitations on comfortable device weight, actuation methods available, device grip strength, and adhering to cosmetic norms while keeping the device affordable. In addition, the complex motion 
of the phalanges allows for a wide variety of grip styles that is difficult to re-create in an artificial device.
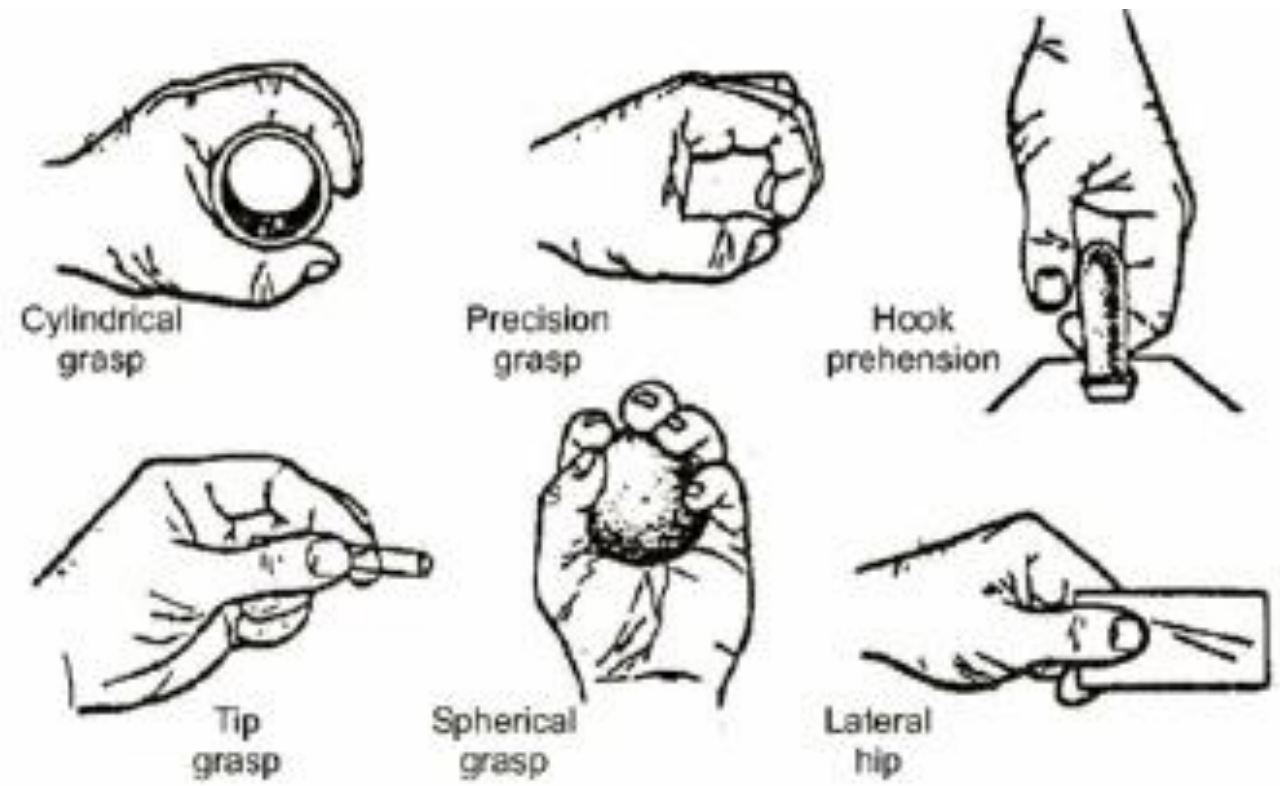

Figure 2: Basic Grip Motions [1]

When designing a hand prosthesis, it is desirable to mimic as closely as possible gestures made by a natural hand during gripping. Mimicking simple gestures such as the cylindrical grasp or hook prehension are simple tasks since they require basic planar motion of the fingers with no supination or pronation of the wrist, however designing a device capable of creating all of the gestures depicted above in Figure 2 becomes challenging while working within the mechanical and aesthetic constraints discussed above. The difficulty lies mainly with how mechanical joints are created and targeted actuation of specific parts. For example, hand prostheses typically use pinned joints for knuckle interfaces, allowing for relative motion in two planes, but locking motion in the third. In other words, a pinned joint can swivel up and down, but not side to side. The human phalange is capable of limited motion side to side unlike the pinned joint due to the nature of the anatomical articulating surface. To recreate this gesture with a prosthesis, a secondary joint is required to allow motion in that direction with an individual actuator for each joint. Sum this complexity over all possible joints in the hand, and an impossible number of 
individually controllable actuators becomes necessary. Prosthesis designers are limited in the manners of actuation and joint number due since a balance must be struck between size and weight of the device with component strength and life expectancy.

For a device to have a high adoption rate in the amputee community the design must meet the user's expectation in all of the design categories discussed above [4]. Typically in order to succeed in one section of design, the device in question must ultimately fail in another criterion. The prosthetics market is riddled with examples of this "give and take" style device. When selecting a device, amputees must decide which aspects of the device are most important to them and deal with short comings in other categories.

When it comes to choosing upper limb prostheses, amputees have two major options; electrically powered myoelectric prostheses or body powered prostheses.

\section{1: Myoelectric Hands}

New amputees are attracted to myoelectric devices due to their increased return to normalcy given by the high degrees of freedom. While electronic hands do not reach the full 22 degrees of freedom seen in a natural human hand, fully articulated fingers and programmable gestures make myoelectrically controlled hands like the Touch Bionics iLimb or the RSLSteeplerBeBionic hand the center of attention for research and development efforts. These devices are pictured below in Figure 3. 


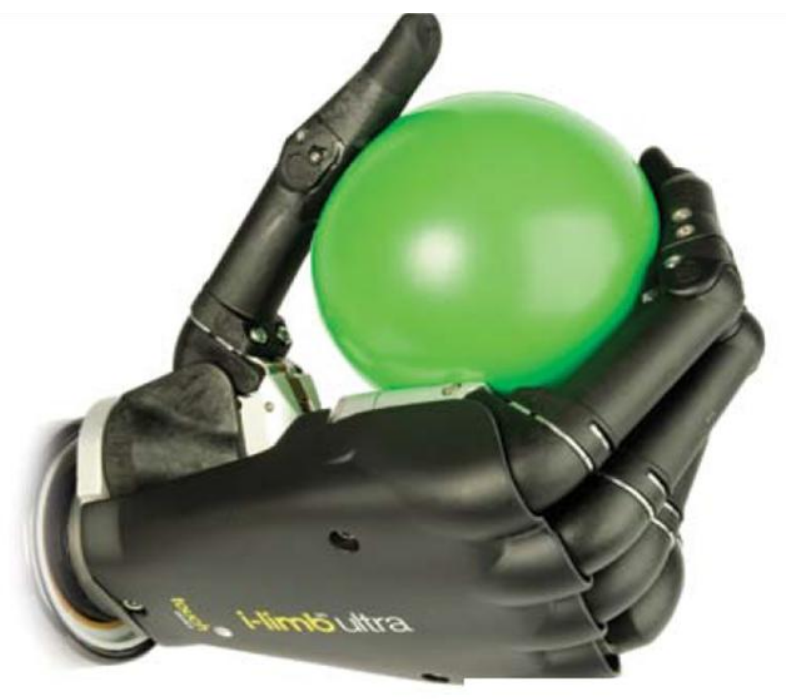

A

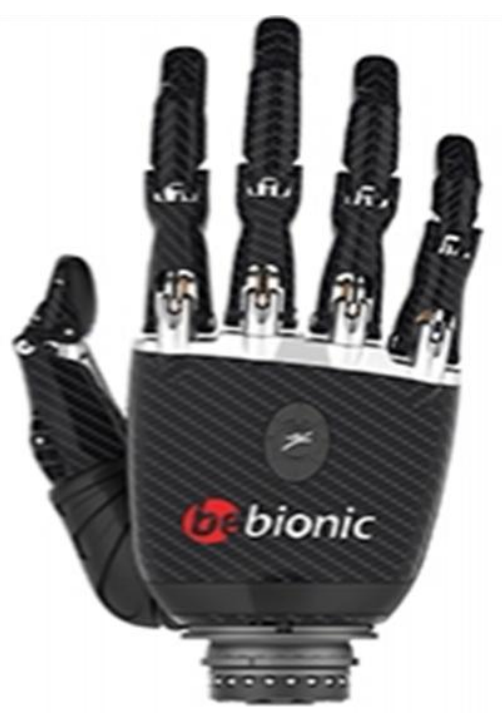

B

Figure 3: A) Touch Bionics iLimb Ultra [11] B) RSLSteelerBebionic Hand [12]

Myoelectrics describes a system which detects the electric impulse generated in a muscle (myo) during contraction. This faint impulse can be detected on the surface of the skin using sensors similar to those used for electrocariograms which is fed into a microcontroller computer in the device. The microcontroller then uses the myoelectric signal as an 'on switch' telling it to cause electromechanical servos in the hand to activate, causing the hand to close. Release of the muscle contraction removes the 'on' signal, causing the hand to open again. Application of programming logic allows for gestures to be programmed into the device which are activated with a specific series of flex and release of targeted muscle groups. For example, two quick flexes of a muscle could tell a hand to give a thumbs up gesture, allowing the user to cause complex motion of the multi-fingered device with a simple input.

While the technology contained in such devices is truly spectacular, amputee review of the device falls far short of what would be expected. Reasons for this vary from user to user, but typical complaints focus on device weight caused by battery packs, servo motors, and electronics 
packages necessary for device operation, poor charge time on the device battery, and poor response to user input to the device. Poor response of the device is due to myoelectric signals being very faint and needing high levels of amplification and filtering out of invasive electrical noise to be usable. This is coupled with the relatively fragile nature of the electrode connection to the skin and alterations in signal amplitudes based on physiological changes in the muscle leads to the need for complex microcontroller logic and patient customized programming [5]. This controller system is not perfect however, meaning users can become frustrated with the device if it does not behave as expected. In a study performed via internet survey, myoelectic hand users were asked to discuss their current device and their satisfaction level in a variety of categories. It was found that $77 \%$ of males and half of females surveyed answered that the device was either slightly or much too heavy [6]. All females and $76 \%$ of males rate the grip closing speed as "too slow" for their daily use [6]. At least one quarter of each group admitted to being distracted by the sound of the electric motors as the device actuates and over half of each group was "not content" with the cosmetics of the device [6].

\section{2: Body Powered Hands and Hooks}

This focus on myoelectrics means that the majority of recent development on upper limb prostheses has been in the field of electrically powered devices, meaning no significant design breakthroughs have occurred in body powered devices since the 1960's [7]. This is unfortunate for the amputee community since in the U.S., $70 \%$ of upper limb amputees choose body powered hooks over electrically powered hands [7]. Reasons for this seemingly counterintuitive statistic mainly include lower cost compared to electric hands, proprioceptive feedback through cable tension, more durability, mechanical reliability, and lower weight as compared to the more technologically advanced electric hands [8]. 
When compared to more expensive myoelectric devices, cable driven devices offer low cost and easy to use options; however they do not have as powerful of an aesthetic appeal or grip ergonomics presented by electronic hands. Body powered devices come in either simple hook shapes, or can be manufactured in the shape of a hand similar to the electronic hands.

Additionally, these devices are either passive open or passive close, describing the state of the grip mechanism when no tension is applied by the user. Two examples of body powered devices produced by Otto Bock can be seen below in Figure 5. For both of these devices, a cable is run from a shoulder harness to an actuation lever which is most visible in part B of Figure 5. By applying tension to the cable via a shoulder shrug or arm extension at the elbow, tension is applied to the cable causing the devise to close if it is passive open such as part A of Figure 5, or open if it is passive closed like part B of Figure 5.

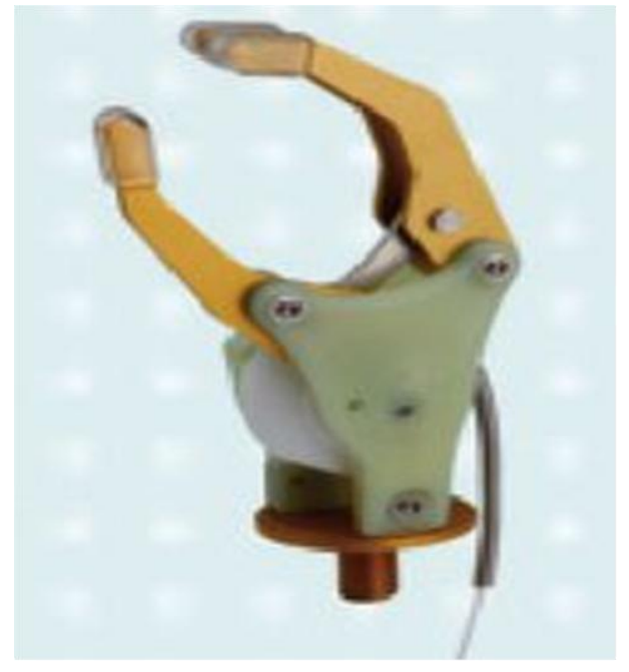

A

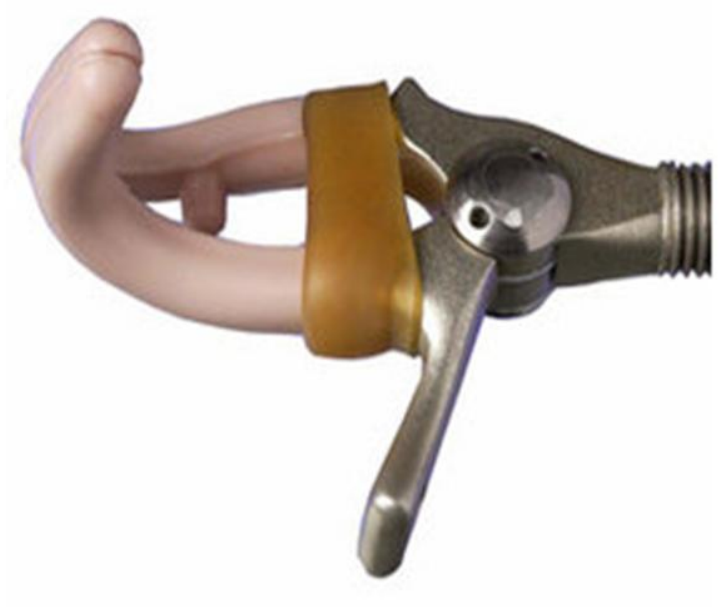

B

Figure 4: A) Otto Bock 8K22 Pasive Open Single Cable Hand [13] B) Otto Bock 10A70 Movohook 2Grip Passive Closed Hook [13] 


\section{Chapter 2: Background}

\section{1: Project Origins}

This project is a continuation of the first Navy SEAL hand project for a Navy SEAL Sharpshooter who remains in active duty. The challenger has an unusual amputation which includes most of his left hand but does not include a small section of the palm and the wrist. This presents a challenge since many hand prostheses are developed for trans-radial amputees where amputation occurs through the radius and ulna resulting in total loss of the hand, wrist, and part to the forearm. Use of trans-radial devices causes limited mobility of the challenger's existing wrist which he utilizes to perform tasks such as reloading, cocking, and firing weapons.

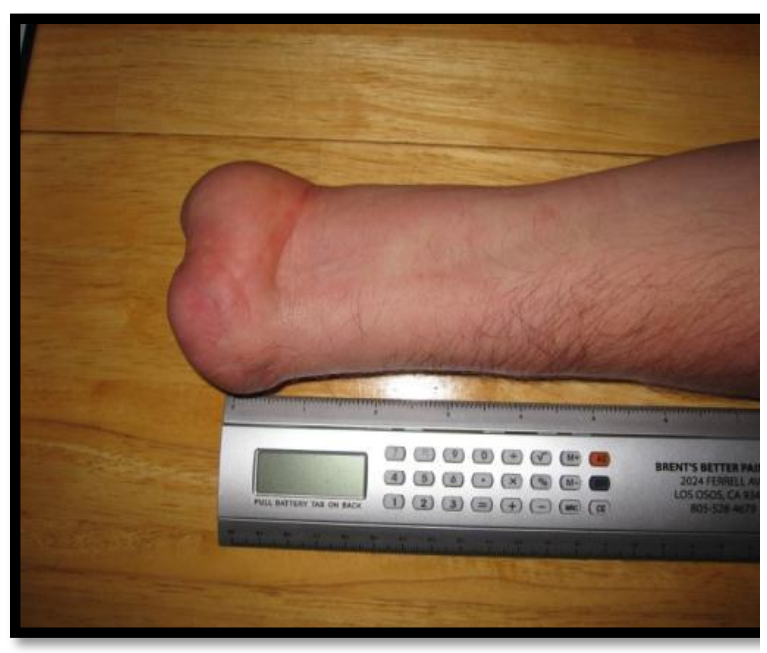

Figure 5: Navy SEAL's Amputation

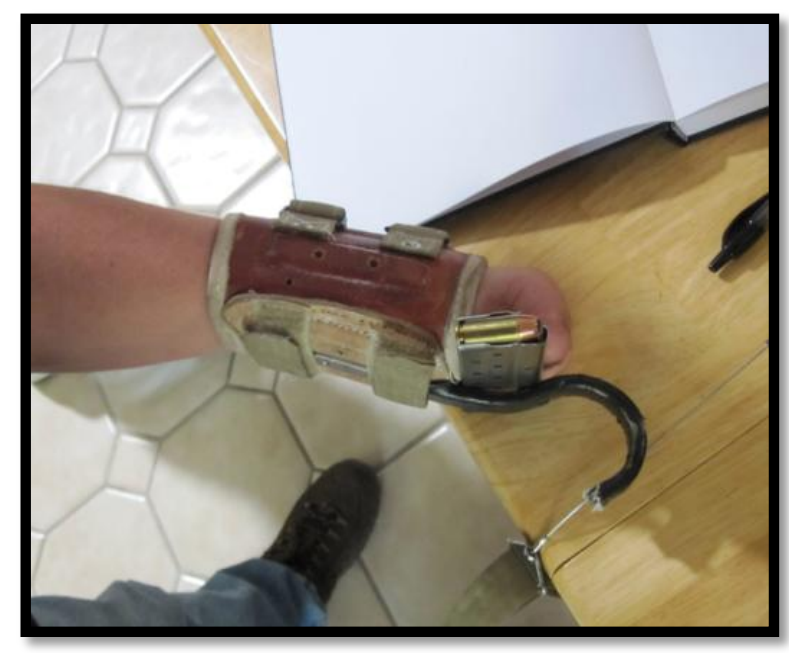

Figure 6: Typical Trans-Radial Device used by Navy SEAL during active duty 
As part of the previous project to give the challenger mobility of his wrist while wearing the prosthesis, a custom leather wrist strap was developed with custom tendon actuated finger and knuckle interfaces as shown below in Figure 7. This device utilizes two methods of actuation: myoelectric control circuitry to activate the servo seen in part B of Figure 7, as well as manual actuation using residual palm flexion on the palm strap seen in part A of Figure 7. By combining these features, the challenger would have the ease of use given by the myoelectric controller while having a back up manual actuation necessary for finesse motions and use in harsh combat environments. Device longevity on the battlefield was an important consideration that led to the high strength aluminum parts of considerable size, limiting the number of allowable digits to three to maintain the challenger's ergonomic hand size.

It is interesting to note that of device adoption in developing countries, amputees choose hand shaped devices over hooks despite their extra cost and weight. This is due to a heavy emphasis being placed on cosmetic appearance and anatomical correctness caused by stigma on physical disabilities [9]. This becomes relevant to the challenger since he might be operating in these types of communities.

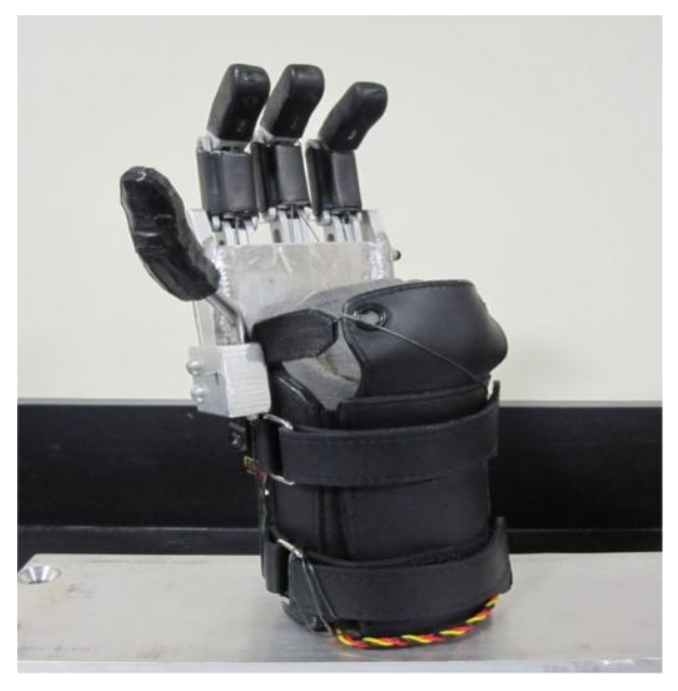

A

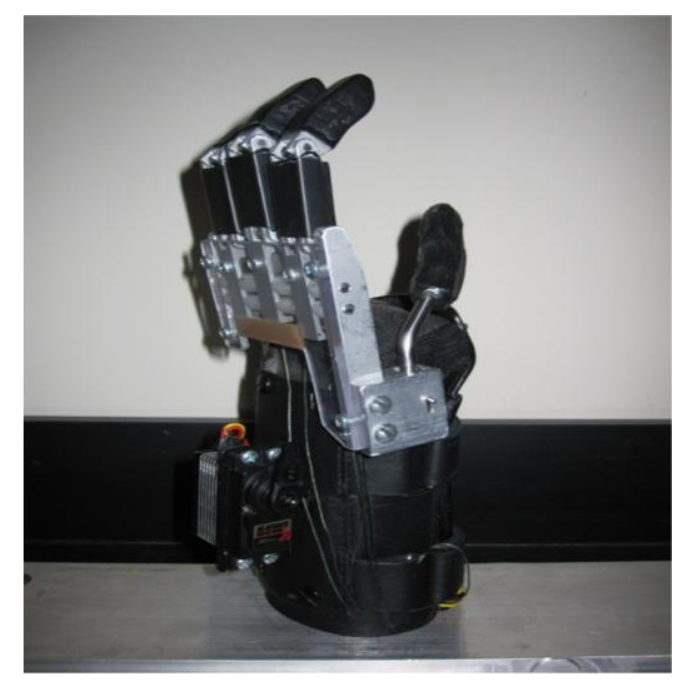

B

Figure 7: A) BETA II Device Prototype, Inferior Side B) BETA II Device Prototype, Superior Side 


\section{2: Reasons for Project Continuation and Re-Design}

Overall previous the device was met with approval from the challenger; however, a few key features were inadequate or required reworking for him to feel comfortable training with the device. Key among these issues were:

1. Tendon tension was not easily alterable to improve grip output strength and response.

2. Myoelectirc system was unreliable, bulky, and a liability in a hostile environment.

3. Palm actuation was not viable due to limited range of motion as a primary actuation method.

4. Device would be required to fit into a cosmetic covering to hide it due to reassignment into a covert operation in hostile territory.

5. Digits did not have a feature allowing them to lock into a position.

Based on the challenger's feedback on the previous device and discussions with him about how the hand is to be used and carried, the following specifications and goals for design were created:

1) While the total weight of the device is not important to the challenger, weight should be minimized as much as possible without sacrifice of strength. In addition, the bulk of the fingers and hand should be as close to in line with his existing bone structure to minimize awkward feeling dynamic effects caused by having a device center of gravity offset from the neutral axis of the ulna.

2) Device should be disassemble able in order to replace broken section individually rather than replacing large portions of the device when a specific section breaks. Additionally, replacement parts should be designed such that they utilize a minimal volume in carried packs in order to not displace essential equipment the challenger will be required to carry into the field. 
3) Device should use the wrist brace from the previous hand since the challenger liked the fit and it is similar in construction to a brace he has already used in the field and found satisfactory.

In addition, the four fingers of the device will be split into two functional categories. The two lateral fingers (little and ring fingers) will be the power finger while the two medial fingers (middle and index) will be finesse fingers. Power fingers describe finger that have the ability to create very high grip forces, while finesse fingers describe finger which can be finely controlled for delicate motions. While both sets of fingers will have the same tendon actuation via shoulder harness, the power fingers will have a ratchet mechanism that causes them to maintain position at the end of the shoulder shrug, allowing for increasing grip strength with subsequent shoulder shrugs. Once the task is completed these fingers will be releasable with a separate movement causing them to return to the open state. 


\section{Chapter 3: Design Concepts for New Hand}

Mechanical design of the finger system and tendon system as it relates to actuating the fingers will remain very similar to the old beta prototype. These aspects had relatively few short comings in the original design and will be changed simply to reflect the altered hand geometry which includes increasing the number of fingers to four and removing the wrist flexion actuation method. Focus in design ideation is placed in part repair and replacement, ease of assembly using one hand, and durability necessary for a combat environment. An image of the hand assembly concept can be seen below in Figure 8. As individual parts of the assembly are discussed below, please reference this image for insight on how they will fit together.

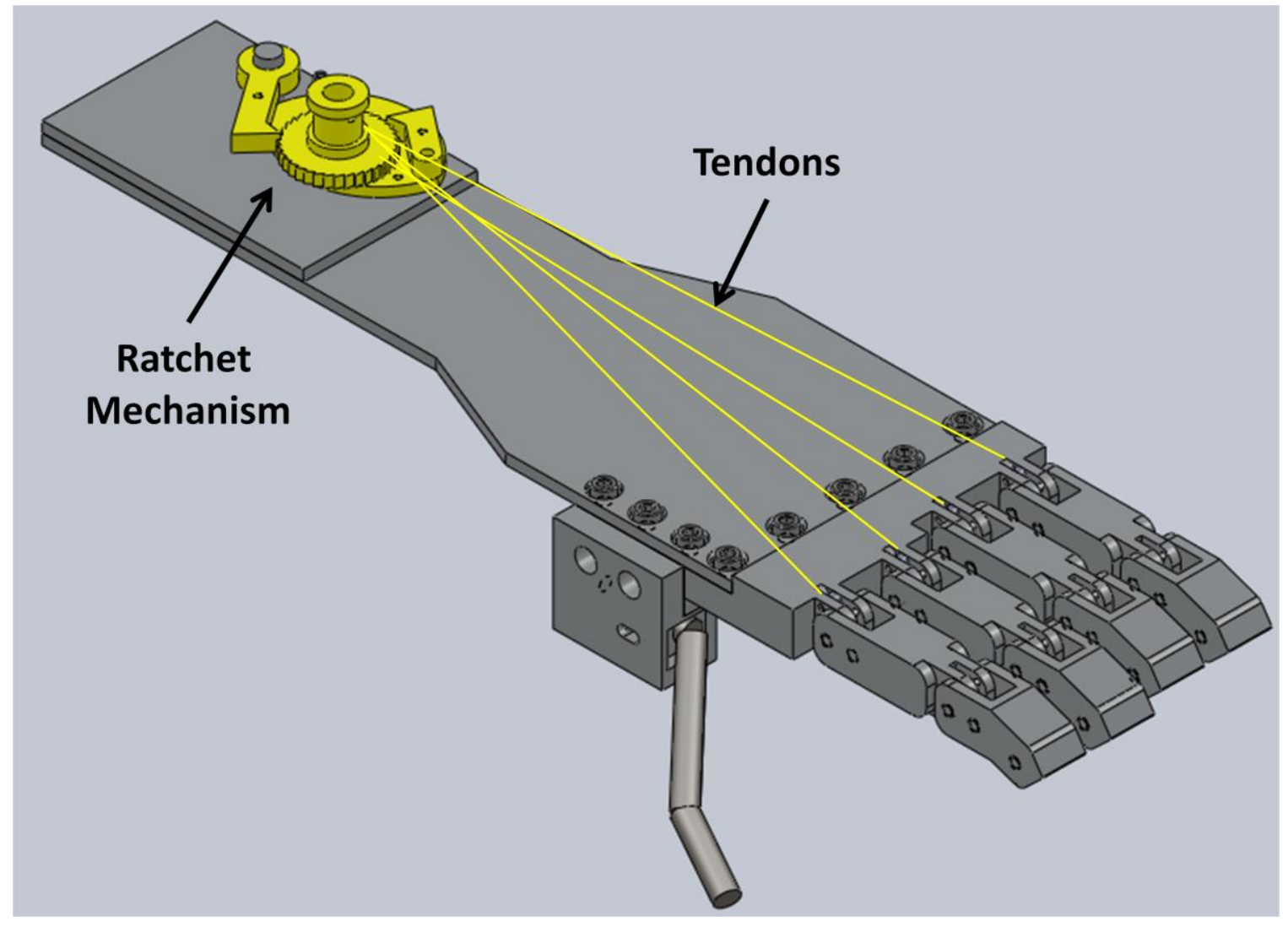

Figure 8: Hand Assembly, Isometric View 


\section{1: Finger Links}

The finger attachments are typically the weak link in prostheses since they are the object interacting portion of the device and are prone to failure caused by transverse loads due to thin beam cross sections by long beam lengths. Various finger designs have been attempted in prosthesis development in an attempt to merge natural form and movement with optimum physical function and grip characteristics with objects to varying degrees of success. An especially novel approach to finger design was approached by a group at the University of Iowa in the IOWA Hand. This hand utilizes solid blocks at the knuckles and coil springs as the main links in the fingers as shown below in Figure 9 [7]. While ergonomics and grip conformity for this design is promising, the fingers are not limited in transverse planes creating a difficult to control grip force since objects have the ability for force the fingers into strange conformations

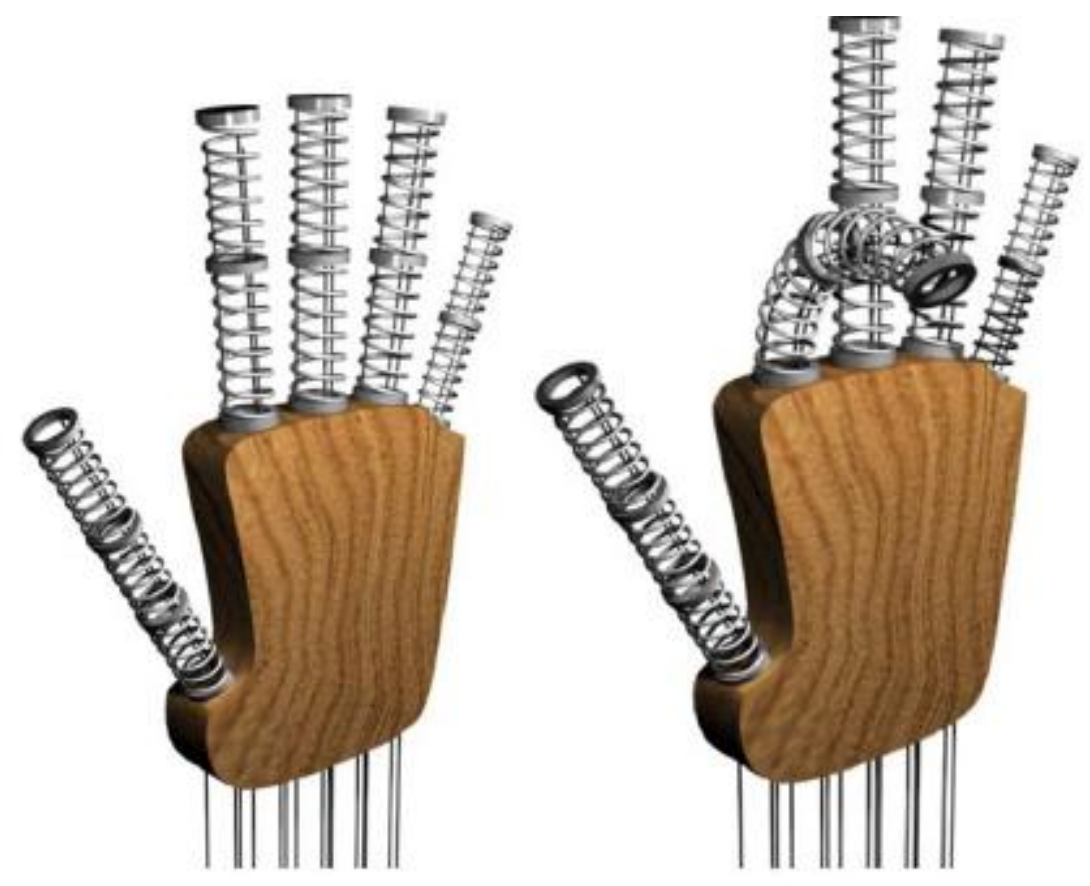

Figure 9: IOWA Hand Prototype Model created by group at the University of Iowa [7] 
One design point that has been present in all iterations of this prosthesis is the presence of two finger links rather than the anatomically correct three links. This decision was made based on tendon actuation since two tendons in a staggered alignment are needed to actuate the distal link before actuation of the two proximal links as was the case in PolyGrasp 1.0. To actuate the distal phalanx first, it must be attached to its own tendon which is pulled first. After acceptable flexion of the distal phalanx has occurred, a second tendon attached to the middle phalanx is pulled, causing the middle and proximal phalanx to bend as the distal phalanx continues to bend. This creates an anatomically correct flexion of the finger, however the additional tendon and phalanx adds complexity and potential failure points to the system which are unacceptable for an outdoor use prosthesis. By using only two links, one tendon is sufficient per finger to actuate flexion, but also reduces joint number which limits potential points of failure. This design is further supported by de Visseret. Et. al. which showed that in natural finger flexion, the most distal link rarely bends and does not add significant grip surface area to the hand [10]. Additionally, in their proposed phalanx design, the distal phalanx contains an angled section to improve grip characteristics as show in Figure 10 below from the paper.
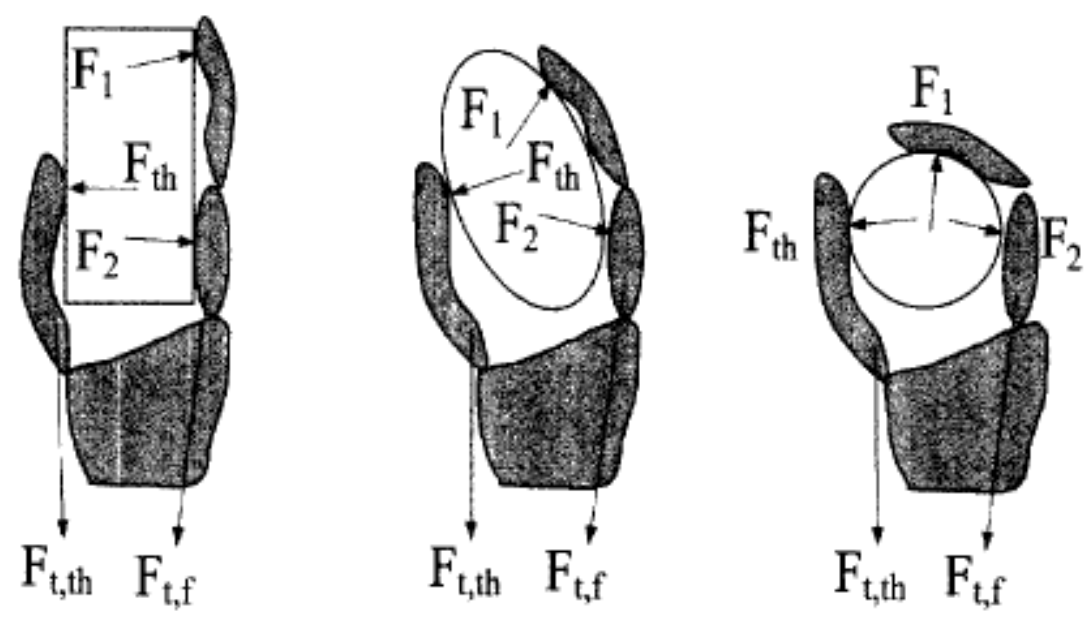

Figure 10: de Visseret. al. Phalanx Design and Predicted Force Distribution [10] 
When sizing the phalanxes, ergonomic data was used to determine the ratio of finger phalanx length as compared to each other. The following proportions were determined from data obtained in Ergonomic Design for People at Work published by Wiley in 2003 [11] and can be seen in Figure 11. In Figure 11, ' $\mathrm{X}$ ' represents the total length of the distal phalanx. By creating the ratios seen below, these anatomical proportions can be scaled to match any finger size.

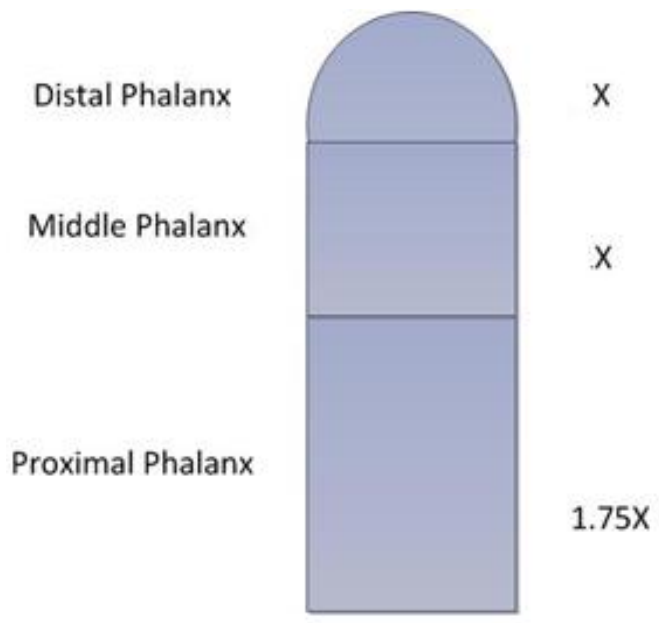

Figure 11: Anatomic Phalanx Proportions



Figure 12: Proximal Phalanx, Isometric View 


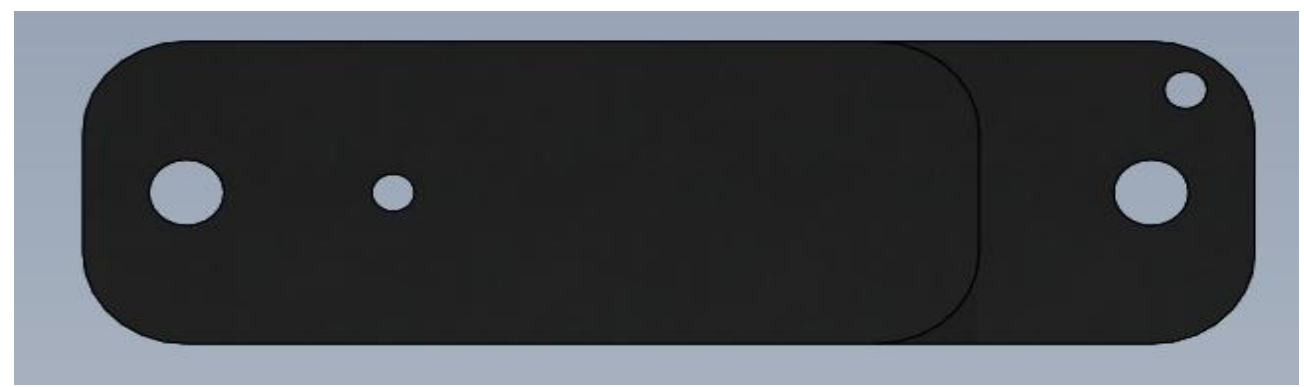

Figure 13: Proximal Phalanx, Side View

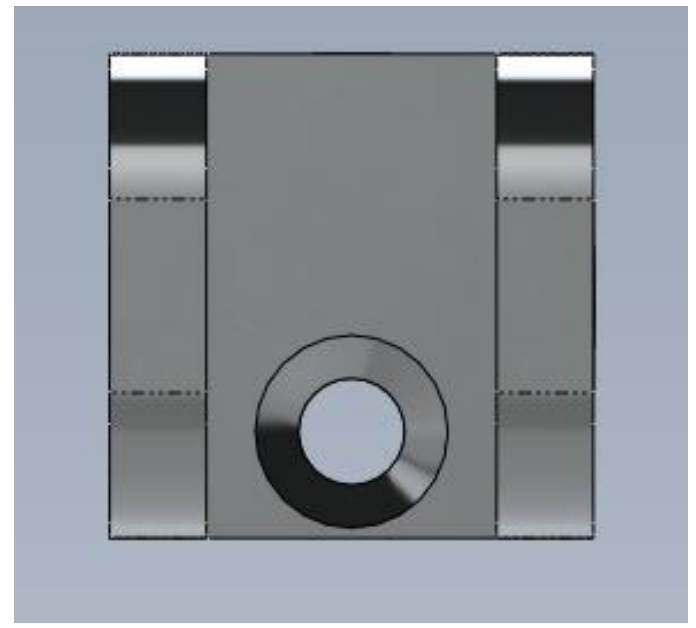

Figure 14: Proximal Phalanx, Back View

Due to these considerations, the design for the phalanges will deviate slightly from the original phalanx design. The proximal phalanx will be machined from $1 / 2$ inch bar stock 6061 aluminum alloy. This material was chosen primarily for its easy machinability, corrosion and wear resistance, and relative low cost. An isometric representation of the proximal phalanx concept can be seen above in Figure 12. Knuckles pins with e-clip restrictors will connect the proximal and distal sections together through the larger holes visible in the side view of Figure 13. The tendon will be routed in a through hole located near the bottom of the phalanx and run longitudinally as shown in the back view of Figure 14 . The additional smaller holes in the side view will contain pins that hole linear extension springs used for phalanx return when tension on the tendon is released. Extension springs were chosen over torsion springs due to space limitations. A torsion spring would have a limited number of coils based on tendon groove width, 
making the strength of the spring insufficient to return the phalanx due to material weight. The linear spring will have more coils, meaning force generation will be sufficient to return the phalange to open.



Figure 15: Distal Phalanx, Isometric View

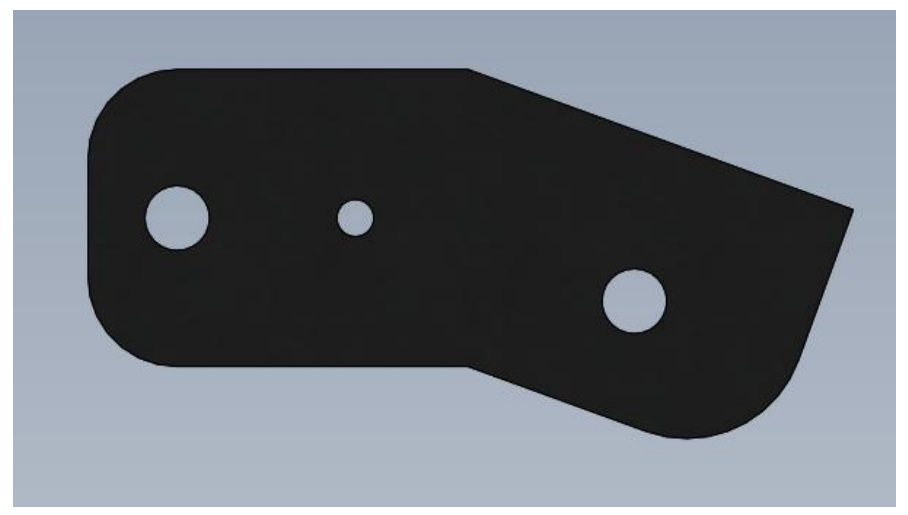

Figure 16: Distal Phalanx, Side View 


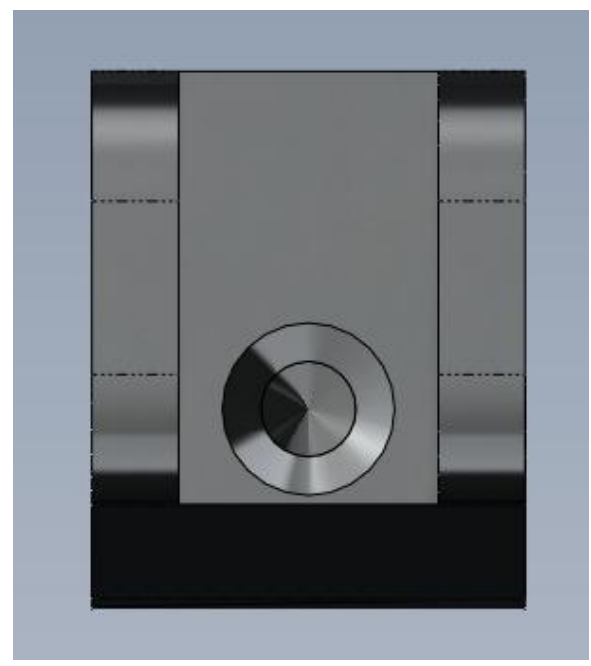

Figure 17: Distal Phalanx, Back View

The distal phalanx is similar to the proximal version; however it contains a bend similar to the design of de Visseret. et. al. [10] which improves grip characteristics on multi-shaped objects. An isometric representation of the distal phalanx concept can be seen above in Figure 15. The tendon routing hole is blind and terminates at a transverse hole through which a pin can be inserted as seen in Figures 17 and 16 respectively. In this design, the tendon connection pin will be inserted through a loop crimped into the tendon cable which will allow for easy and rapid replacement of individual tendons. The phalange as a whole can be seen below in Figure 18 .

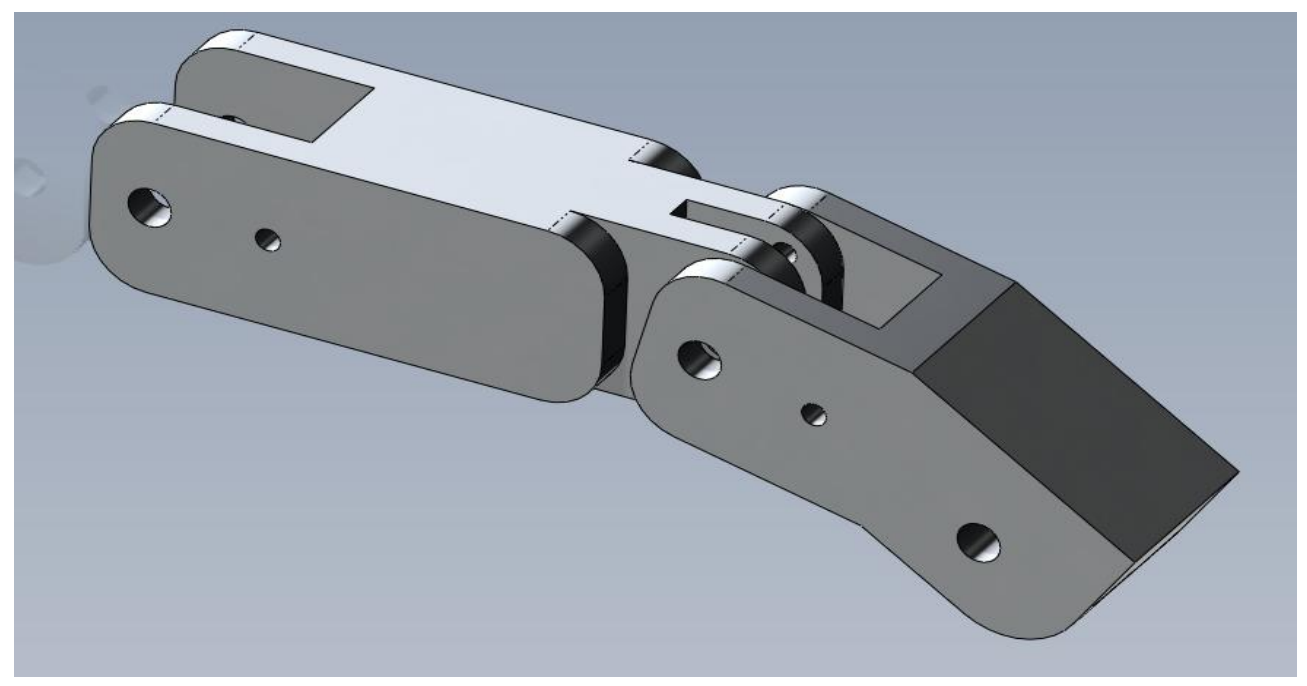

Figure 18: Phalange Assembly, Isometric View 
Anatomically, each phalange on the hand is a different length. Despite this, same length phalanges will be used for all four digits in order to reduce machining time and costs, but also to limit the quantity of replacement parts the challenger will need to carry to ensure replacement of damaged parts is possible. If all four phalanges had unique dimensions, the challenger would need to carry four times as many finger parts with him to ensure the same number of replacement cycles than if the phalanges were of similar length. This reduced burden would allow for the extra space to be used for vital equipment necessary for the given mission.

The failure method of most concern involves a transverse load applied at the tip of the phalange and causing a failure of the opposite attachment tab on the proximal phalanx. Force distribution and the expected failure points can be seen below in Figure 19.

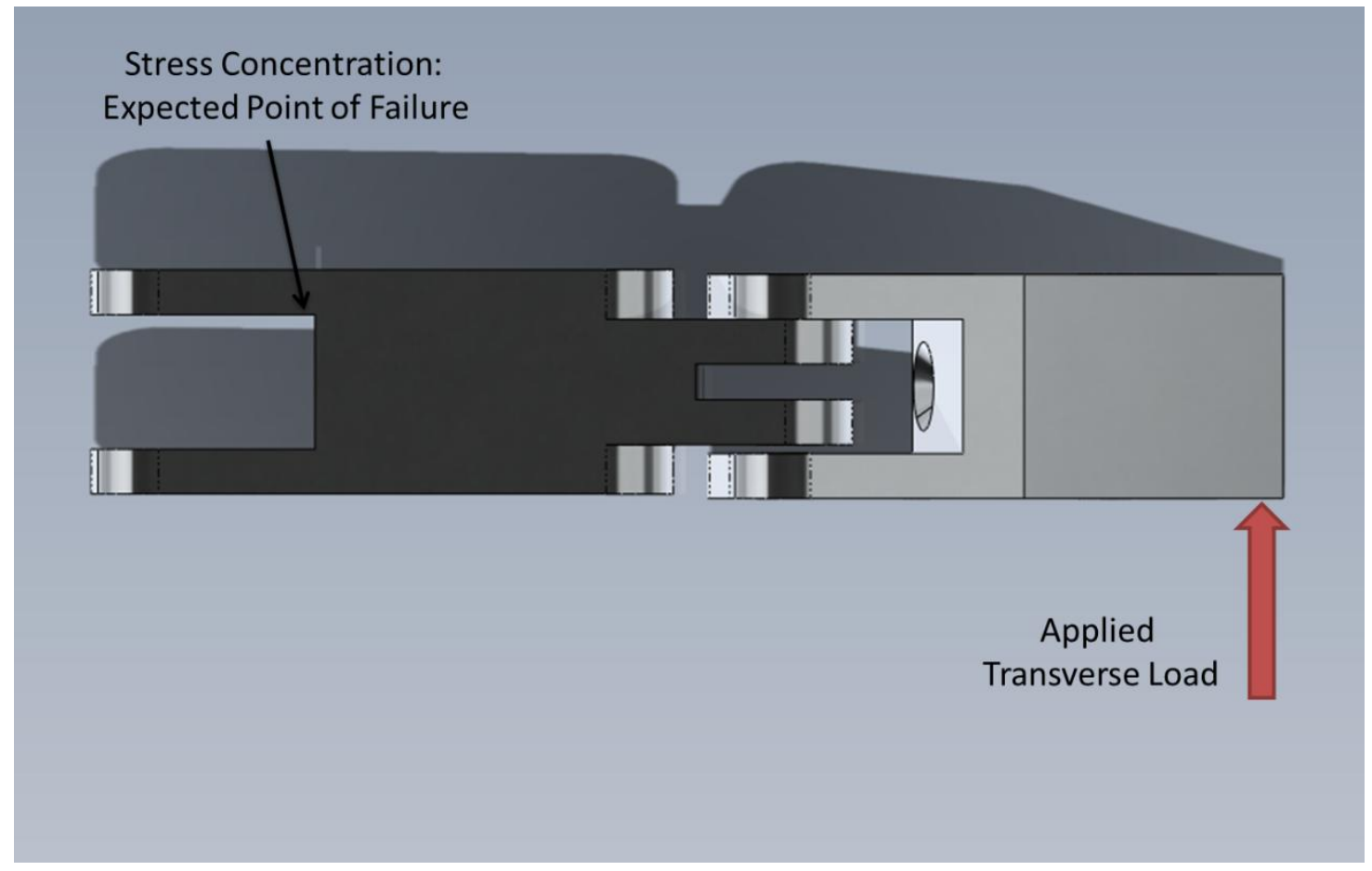

Figure 19: Transverse Loading of a Phalange and Expected Failure Point, Top View

In order to evaluate the force needed to cause this type of failure, cantilever beam theory can be used to approximate the stress state present. By approximating the length of the bean as the finger length and using cross sectional properties of the small tab which will break off post 
failure, a conservative estimate of the force needed to break the link can be obtained. The failure stress in this case was set to the yield strength of 6061 alloy aluminum. To do this, the following equation was used:

$$
\sigma_{y}=\frac{M c}{I}
$$

where $\sigma_{\mathrm{y}}$ is the yield stress, $\mathrm{M}$ is the experienced moment which is equal to the applied force times the length of the finger, $\mathrm{c}$ half the cross sectional height, and I is the cross section area moment of inertia. This resulted in an applied force of 55lb causing yield which at this juncture is adequate.

\section{2: Knuckle Attachment}

In the original design, the knuckle system had adjustable finger attachments which integrated directly into the attachment tab for the leather brace. While the presence of adjustable finger attachment lengths is desirable when designing for multiple users, it introduces weakness into the system. Another major advantage to the adjustability was the ability to disassemble and replace broken parts with ease. This aspect is highly important if the device or future iteration of the device will see combat environments. A CAD rendering of the knuckle bar concept can be seen below in Figure 20. 


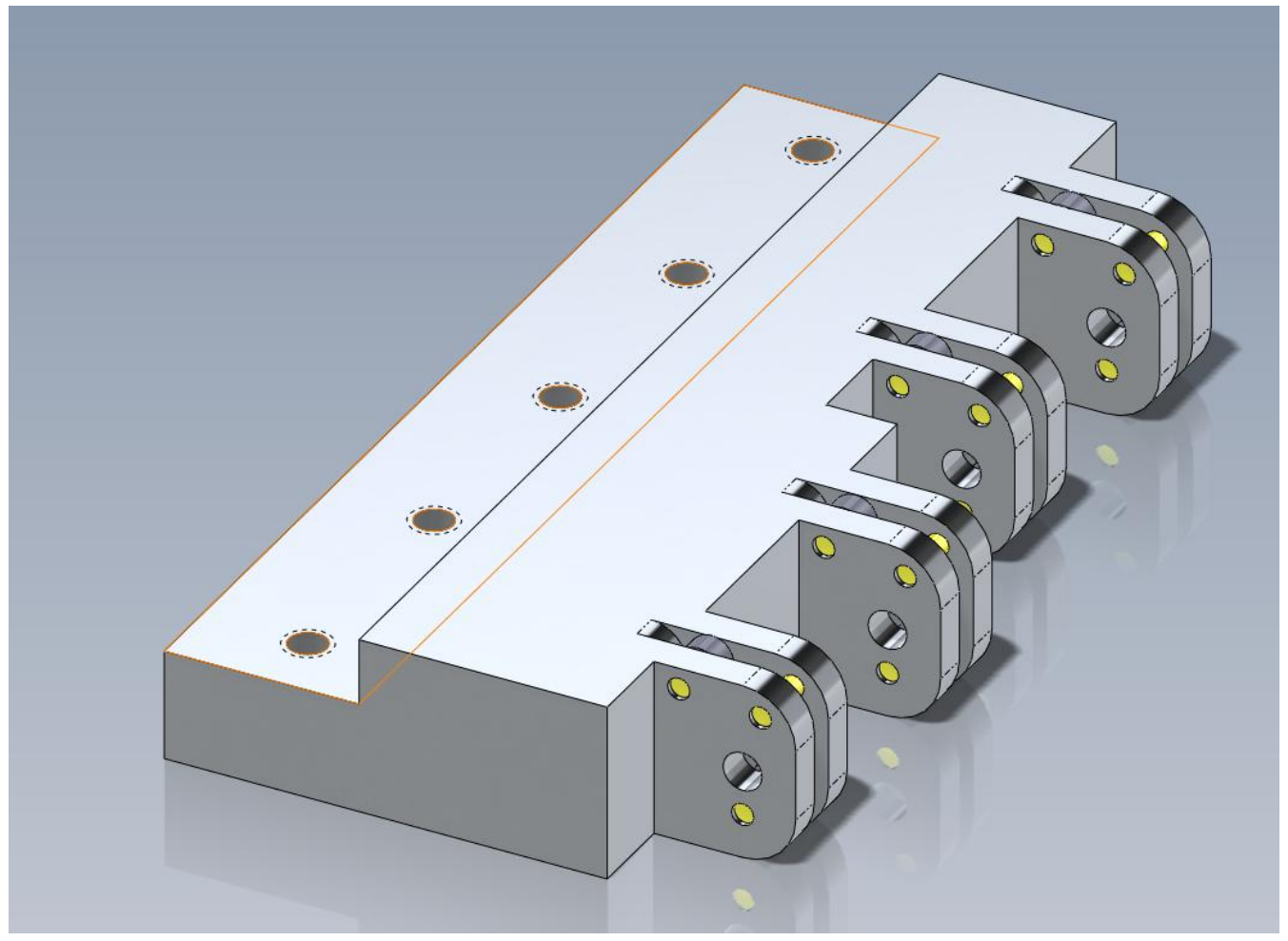

Figure 20: Knuckle Attachment Assembly

The knuckle bar, as shown above in Figure 20, has recessed lateral finger attachment tabs. This will cause the two lateral fingers (small and ring fingers) to sit back from the medial fingers causing the hand to appear more natural since all phalanges will be of similar length as discussed above. On each tab framing the knuckle pin are three holes with press fit pins. The top left and bottom pins have Delrin rollers placed in the tendon groove prior to press fitting, resulting in a pulley system that will allow the tendon to approach the fingers from the top, wrap over the top of the top pulley and around the bottom of the bottom pulley. This places the tendon in line with the routing holes in the phalanges, but also cases the cable to clear the knuckle pin which reduces friction. The top right pin has no roller since it acts as a spring anchor point for finger extension once tension is released from the tendon. This part connects to the brace attachment tab, which will be called the 'palm' from now on, via five \#6-32 screws. This part was separated from the palm to allow for individual replacement in the event failure occurs, to allow for purchase of off the shelf sized material needing limited machining thus reducing cost, 
and to reduce the footprint of parts being carried as replacements. Pins and rollers will be placed permanently in the part prior to deployment, limiting reassembly steps necessary if this part needs replacement in the field.

\section{3: Palm}

The palm simple since its sole function is serving as an attachment tab to the leather wrist brace that will hold the device on. Major features are simple geometry shifts to facilitate the change in width from the wrist to the knuckles, and counter bore holes that screws will sit in to attach the knuckle and thumb housing. These features will be created using stock $1 / 8$ inch sheet 6061 aluminum alloy. A CAD rendering of the palm concept can be seen below in Figure 21 .

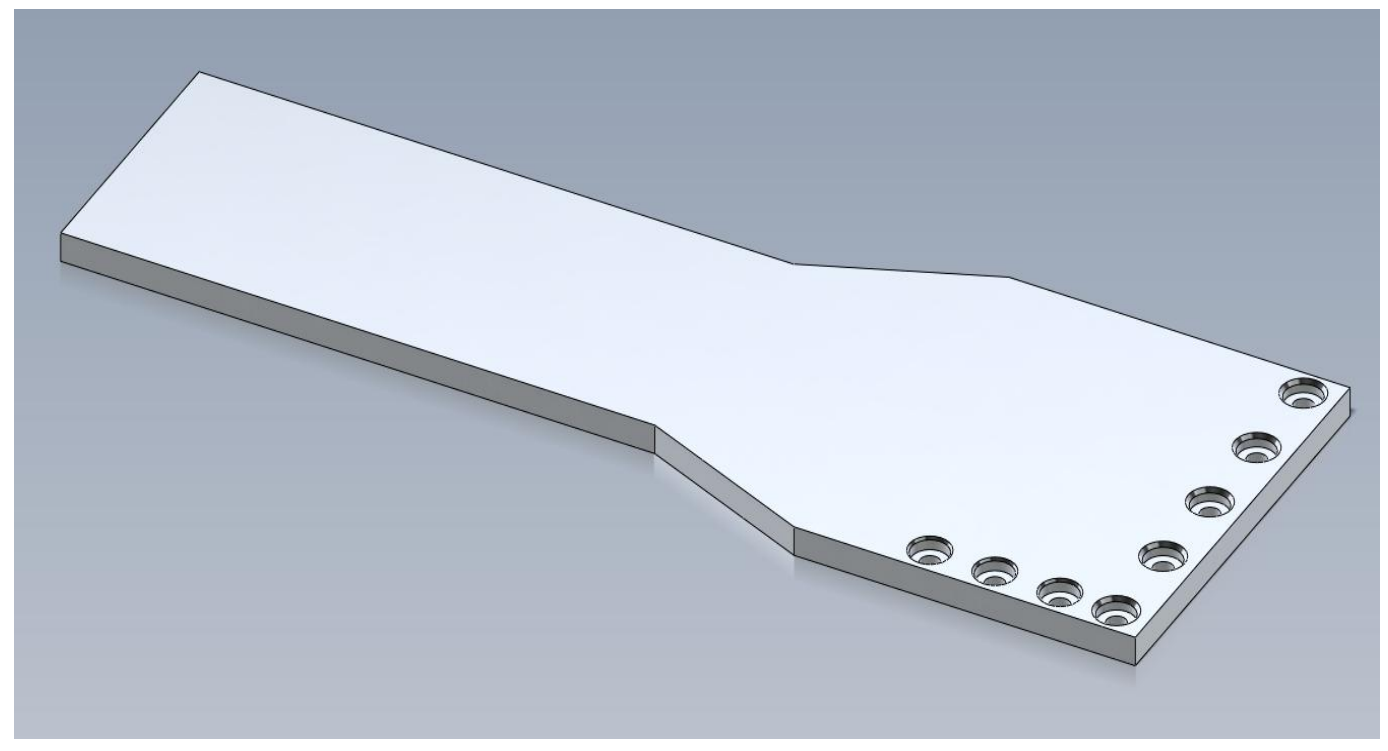

Figure 21: Palm, Isometric View

\section{4: Thumb Housing and Function}

The thumb housing and bar developed on the last hand iteration had sufficient functionality that a redesign is unnecessary. For this reason, the thumb from the last iteration will be used for this prototype, however the attachment scheme is different since the palm will be made from stock sheet metal as discussed above and not milled from a block like previous 
versions. This results in a simple attachment tab with three tapped \#6-32 holes on the top and two $1 / 4$ inch holes transverse to the tapped holes in the two gaps for attachment of the thumb housing which can be seen below in Figure 22.

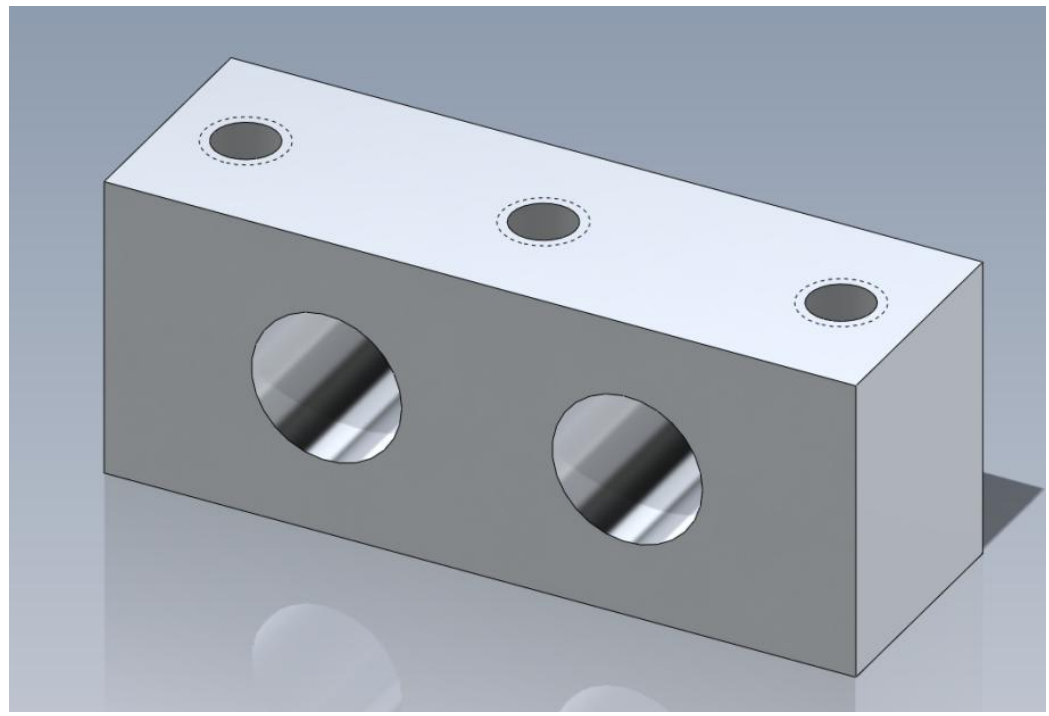

Figure 22: Thumb Housing Attachment Tab, Isometric View

A simple representation of the thumb housing and bar can be seen below in Figure 23.

This simplified model was created as a stand in during solid modeling for completeness.

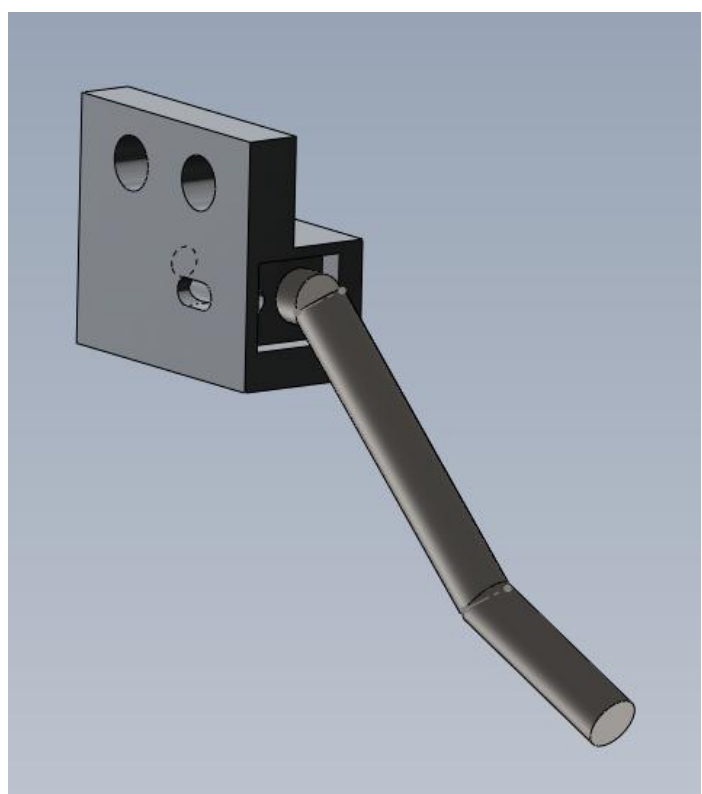

Figure 23: Thumb Housing and Bar Model, Isometric View 


\section{6: Tendon Control System}

The control system for the tendons will have two distinct parts; one for the finesse fingers, and one for the power fingers. In order to actuate both sets of fingers with one shoulder cable, the ratchet system for the power fingers must have a way to return the actuation cable while locking the finger side tendon in place. At this time, this will be accomplished using a custom cam for the actuation cable, a ratchet gear, and a set of custom pawls that interact with the ratchet gear. A concept mock up of this assembly can be seen below in Figure 24 .

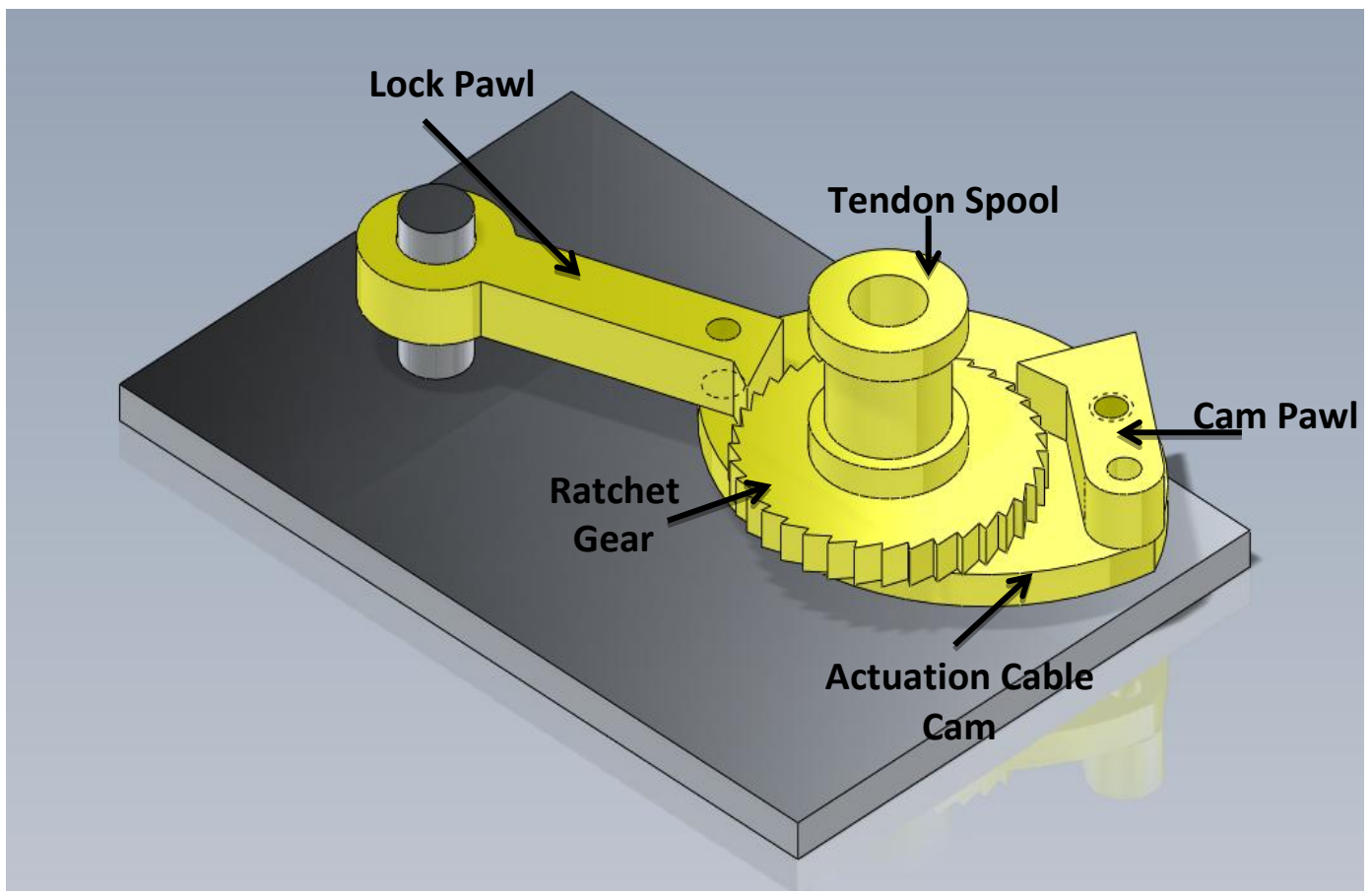

Figure 24: Tendon Lock System Concept

In this system, the actuation cable will attach to the cam underneath the cam pawl and be pulled back toward the back of the image in Figure 24. This will case rotation of the cam, which through the cam pawl will spin the ratchet gear and in turn the tendon spool. As the spool spins, it will wrap the power finger tendon around it, causing phalange flexion. Upon release of cable 
tension, the cam will return to its original position, and the cam pawl will ratchet over the sloped teeth. Since he lock pawl is in place, the gear and drum will not return with the cam, keeping the fingers locked in place until manual release of the lock pawl occurs by the user. No pictured are tension springs on the pawls that keep them pressed against the gear, or a torsion spring attached to the cam allowing it to return once tension is released.

Further exploration of this concept through FEA modeling and torque calculations will occur during manufacturing of the hand components.

\section{7: Manufacturing Processes}

Manufacturing of the parts discussed above will rely heavily on the use of a knee and column vertical mill, band saw, and drill press. When manufacturing the phalanxes, holes will be drilled using a drill press first to ensure no residual stresses are introduced as would happen if slots were cut first and though holes drilled second. The parts will then be inserted into a CNC mill for slot cuts and shaping in order to maintain high tolerances. The knuckle connector will be fabricated in a similar way to the phalanxes, however the slots will be milled using a manual mill. The palm plate shape will be formed on a band saw and holes will be drilled and counter bore drilled on a drill press post cutting. The thumb bracket will be shaped on a mill for outer tolerance control, then finished on a drill press.

Current plans for the lock and cam pawls from the tendon control system include band saw formation and hole formation with a drill press. The cam will be shaped via CNC mill due to the cured patterns on its outer geometry. Since these parts are still under design and modification, it is likely that the processing will be altered as well. 


\section{Chapter 4: Mathematical Simulations and Physical Testing Results}

\section{1: Maximum Tendon Tension Model and Physical Testing}

Characterizing the tension in the tendon cable system is important not only for specifying design criteria for geometry and material specification but also for user comfort and use since the cable system will interface directly to the worn shoulder harness. In addition, cable tension is the primary grip feedback conduit to the user since grip strength can be felt as cable resistance as discussed in the Introduction in the passive open hand section. While maximum force is important, it is also beneficial to understand how the cable tension changes as the fingers bend around an object since this trend will be what is felt by the user.

Initially, a simple static model of the distal link was analyzed to determine the tension required to generate a load that is in line with the tendon anchor bolt and acts normal to the angles grip surface. Load placement for this model can be seen below in Figure 25.

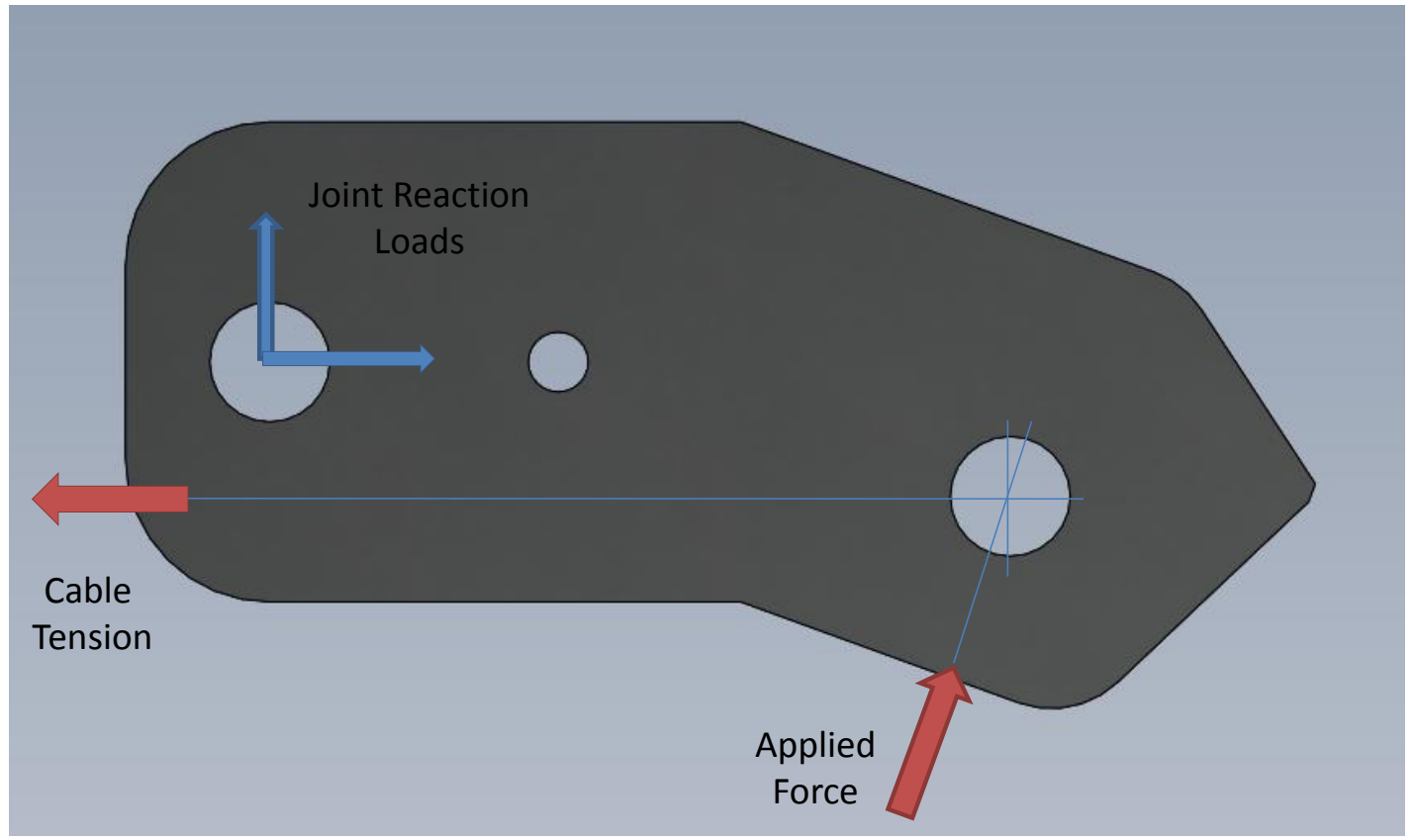

Figure 25: Basic Distal Tendon Tension Model 
By summing moments about the joint, it is possible to get required cable tension as a function of applied force. It was found that the tendon force was roughly seven times the desired output force; however this was rounded up to ten times to account for frictional losses.

While useful as an initial model to get a ballpark value, to fully understand the cable tension mechanics a model including both proximal and distal phalanxes as well as the knuckle was required since the previous model did not account for total finger bend. For this new model, dynamic rotating coordinate systems were employed to allow for force and length values to be transformed into a global coordinate system as each phalanx bends. The coordinate systems assigned can be seen below in Figure 26. $\mathrm{X} / \mathrm{Y}$ is assigned to the knuckle bar and represent the global coordinates. $X^{\prime} Y^{\prime}$ are relative to the proximal phalanx and move with it. $X " / Y^{\prime \prime}$ are relative to the distal phalanx and move with it.

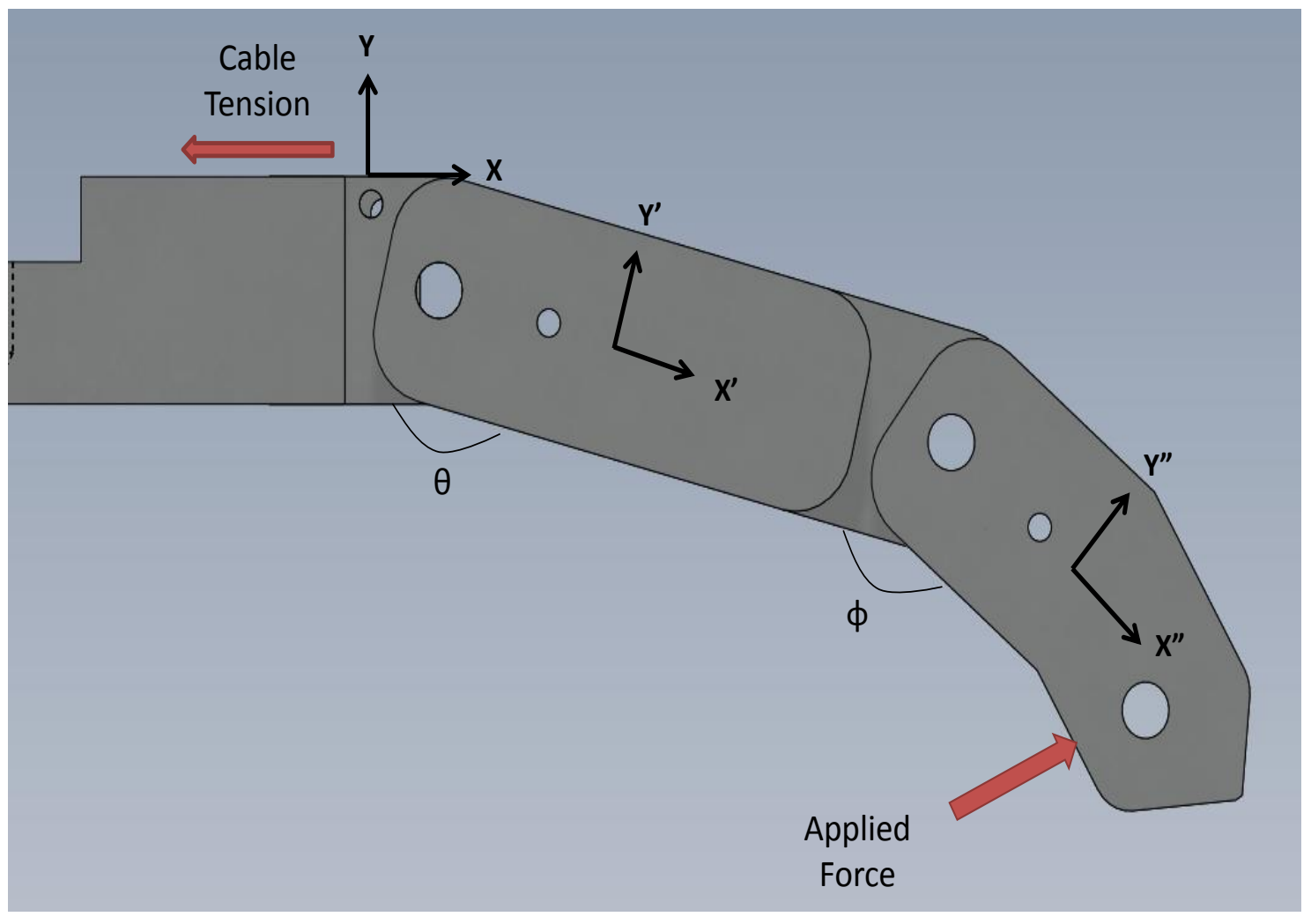

Figure 26: Full Finger Tendon Tension Model with Rotating Coordinate Systems 
For this calculation, a moment is summed about the knuckle bar/proximal phalanx joint. The rotating coordinate systems become important since the direction and $\mathrm{X} / \mathrm{Y}$ moment arms of the applied force change as the phalanxes bend at angles $\theta$ and $\varphi$. To begin, $X " / Y$ " must be related to $\mathrm{X}^{\prime} / \mathrm{Y}^{\prime}$ via trigonomic relationships based on the distal bend angle phi. It is helpful to visualize the two coordinate systems superimposed on each other for generation of this transform. Overlaid coordinates can be seen below in Figure 27.

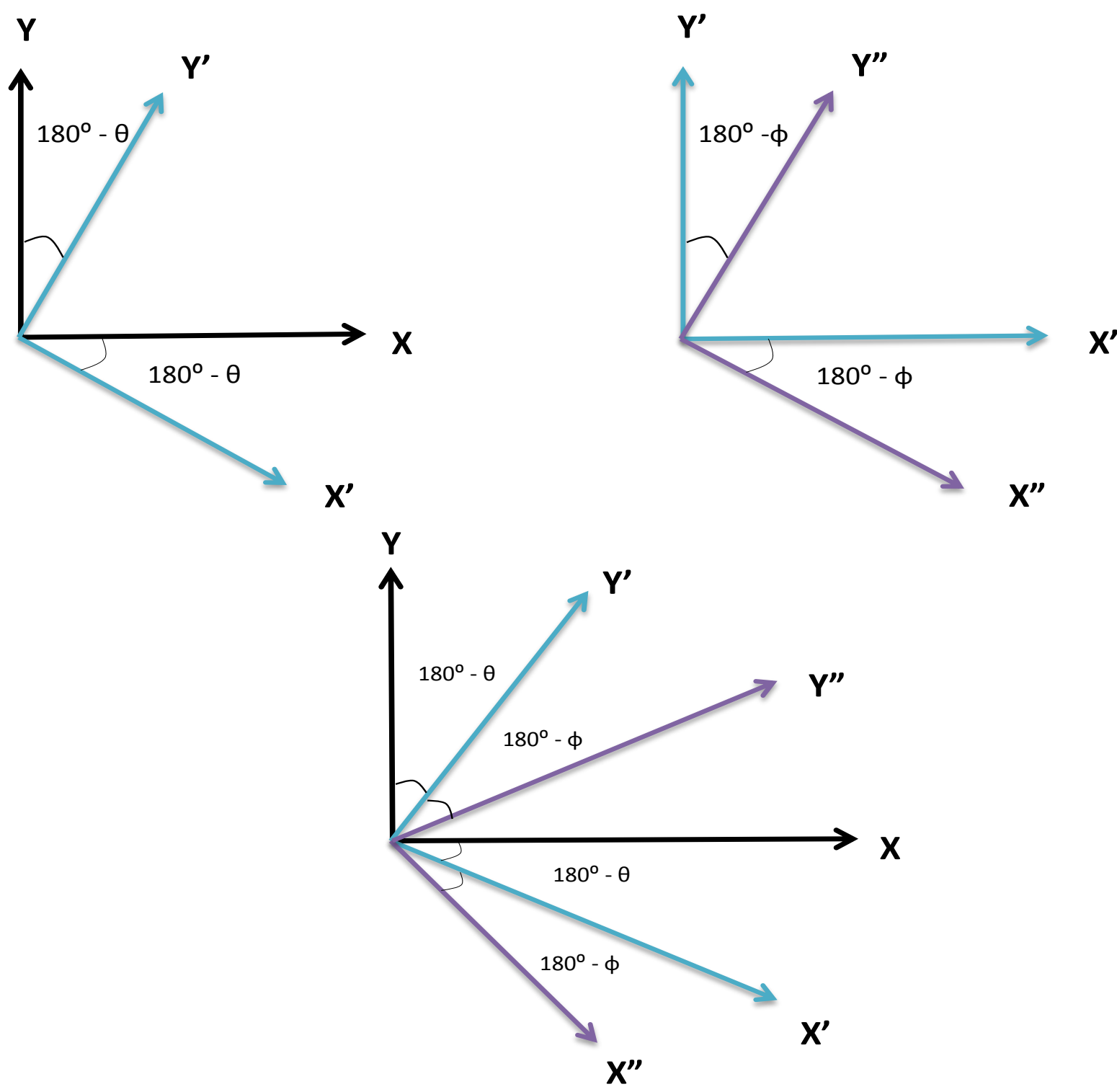

Figure 27: Coordinate Transforms for Cable Tension Model 
Forces or lengths which are constant relative to the $\mathrm{X}$ " $\mathrm{Y}$ " system can be written as follows in the $\mathrm{X}^{\prime} / \mathrm{Y}^{\prime}$ :

$$
\begin{gathered}
X^{\prime}=X^{\prime \prime} \cos \left(180^{\circ}-\phi\right)+Y^{\prime \prime} \sin \left(180^{\circ}-\phi\right) \\
Y^{\prime}=-X^{\prime \prime} \sin \left(180^{\circ}-\phi\right)+Y^{\prime \prime} \cos \left(180^{\circ}-\phi\right)
\end{gathered}
$$

The same relationships can be developed to transform $X^{\prime} / Y^{\prime}$ values into the global $X / Y$ system which follow:

$$
\begin{gathered}
X=X^{\prime} \cos \left(180^{\circ}-\theta\right)+Y^{\prime} \sin \left(180^{\circ}-\theta\right) \\
Y=-X^{\prime} \sin \left(180^{\circ}-\theta\right)+Y^{\prime} \cos \left(180^{\circ}-\theta\right)
\end{gathered}
$$

Values for $\mathrm{X}^{\prime} / \mathrm{Y}^{\prime}$ can then be substituted into the $\mathrm{X} / \mathrm{Y}$ transform equations to yield total transforms that will convert moment arms and force magnitudes from the $\mathrm{X}$ "/ $\mathrm{Y}$ " into the global $\mathrm{X} / \mathrm{Y}$.

By having things in terms of both theta and phi, it is possible to solve for the tendon tension for a range of bend angles. By solving for cable tension for all combinations of theta and phi, the worst case, or highest requires tension can be used as a design parameter for specification of tendon material strength and crimp strength for creating loops and fusing two strands as will occur at the ratchet. Values for a range of angles between 180 degrees and 140 degrees for theta and 130 degrees for phi can be seen below in Table 1. 
Table 1: Tendon Tension Model Results for Varying Angles

\begin{tabular}{|c|c|c|c|c|c|c|c|c|c|c|c|}
\hline & \multirow{2}{*}{ THETA } & Degrees & 180 & 175 & 170 & 165 & 160 & 155 & 150 & 145 & 140 \\
\hline & & Radians & 3.14 & 3.05 & 2.97 & 2.88 & 2.79 & 2.71 & 2.62 & 2.53 & 2.44 \\
\hline \multicolumn{2}{|c|}{ PHI } & & & & & & & & & & \\
\hline Degrees & Radians & & & & & & & & & & \\
\hline 180 & 3.14 & & 16.68 & 17.86 & 17.95 & 16.97 & 14.93 & 11.89 & 7.96 & 3.24 & -2.11 \\
\hline 175 & 3.05 & & 16.68 & 17.07 & 16.38 & 14.63 & 11.88 & 8.21 & 3.73 & -1.42 & -7.09 \\
\hline 170 & 2.97 & & 16.17 & 15.78 & 14.33 & 11.87 & 8.48 & 4.25 & -0.68 & -6.17 & -12.04 \\
\hline 165 & 2.88 & & 15.17 & 14.02 & 11.86 & 8.75 & 4.79 & 0.10 & -5.19 & -10.90 & -16.87 \\
\hline 160 & 2.79 & & 13.71 & 11.85 & 9.03 & 5.35 & 0.90 & -4.16 & -9.69 & -15.52 & -21.47 \\
\hline 155 & 2.71 & & 11.84 & 9.32 & 5.91 & 1.74 & -3.09 & -8.41 & -14.08 & -19.91 & -25.74 \\
\hline 150 & 2.62 & & 9.60 & 6.49 & 2.59 & -1.98 & -7.09 & -12.57 & -18.27 & -24.00 & -29.60 \\
\hline 145 & 2.53 & & 7.08 & 3.46 & -0.85 & -5.72 & -11.00 & -16.53 & -22.15 & -27.68 & -32.96 \\
\hline 140 & 2.44 & & 4.33 & 0.30 & -4.31 & -9.38 & -14.73 & -20.21 & -25.65 & -30.89 & -35.76 \\
\hline 135 & 2.36 & & 1.46 & -2.89 & -7.71 & -12.86 & -18.18 & -23.51 & -28.68 & -33.54 & -37.94 \\
\hline 130 & 2.27 & & -1.46 & -6.03 & -10.96 & -16.09 & -21.28 & -26.36 & -31.18 & -35.59 & -39.47 \\
\hline
\end{tabular}

\begin{tabular}{|c|c|c|}
\hline Maximum Tension & 17.95 & lbf \\
\hline Relative to Applied Force & 3.59 & \multicolumn{1}{|c}{} \\
\cline { 1 - 2 }
\end{tabular}

The first important thing to note about the results above in Table 1 is that for certain combinations of angles a negative tensile result is obtained (compressive). While the results are statically sound, these negative values have no real meaning in the finger system as the tendon cannot physically carry compressive loads. These results then represent angle combinations that cannot occur. This matches intuition on how the links will respond to a tensile load in the tension since they will be forced to bend together simultaneously. The maximum value was determined from the positive section by applying a MAX( ) function in excel to pull out the largest force value. This value was then divided by the used applied load of $5 \mathrm{lbf}$ to get a value for the maximum force in terms of the applied finger load. This allows for calculation of maximum tendon tension for any desired applied finger load. This value was calculated to be 3.59 , meaning it takes roughly three and a half times the force in the tendon to generate a desired finger force. This value is highly theoretical as it does not account for friction, so a ratio of 5:1 will be used instead, meaning it is expected that at most the tendon will endure five times the load being exerted at the finger tip. 
Below in Figure 28 is a three dimensional graphical representation of tendon tension based on the two bend angles. As expected, the maximum tension occurs when the bend angles between both phalanxes is small, resulting in a much smaller moment arm. As either angle shrinks (the finger bends) the load required to exert the $5 \mathrm{lbf}$ applied load shrinks since the mechanical advantage of the finger becomes greater as flexion occurs. This figure only contains positive results from Table 1 since these are the values that have physical meaning in the finger system.

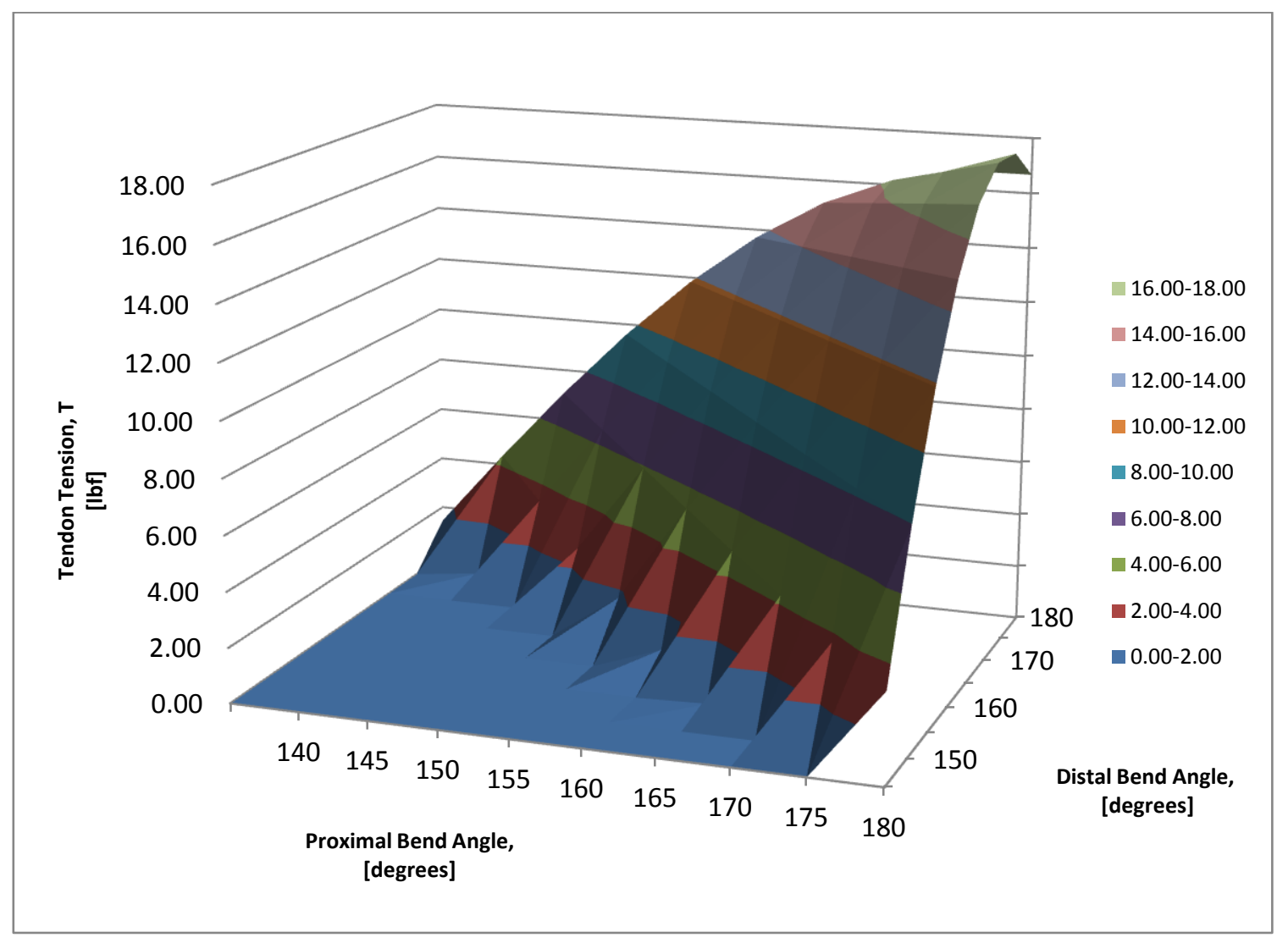

Figure 28: Tendon Tension Model Results as a Function of Proximal and Distal Bend Angle

Confirmation of the mathematical model was undertaken using alpha prototype phalanx parts and a knuckle bar that was partially completed but was cut out of tolerance leaving one usable attachment tab. Alpha phalanxes were created in order to determine if the computer code 
used to cut the parts was functioning correctly and if the chosen fixturing methods would result in an acceptable part. Use of the computer aided mill and fixturing protocols will be discussed later in the Phalanxes sub section of the Design Realization section. These parts also served as good testing material since failure of these pieces would match that of the final parts, yet would not result in a waste of material. Assembling these parts in a mock-up of a finger system also served to test whether the tendon routing scheme would be adequate, whether the finger extension concept would function as expected, and to test the validity of the mathematical model for tendon tension. The test parts can be seen assembled below in Figure 29.

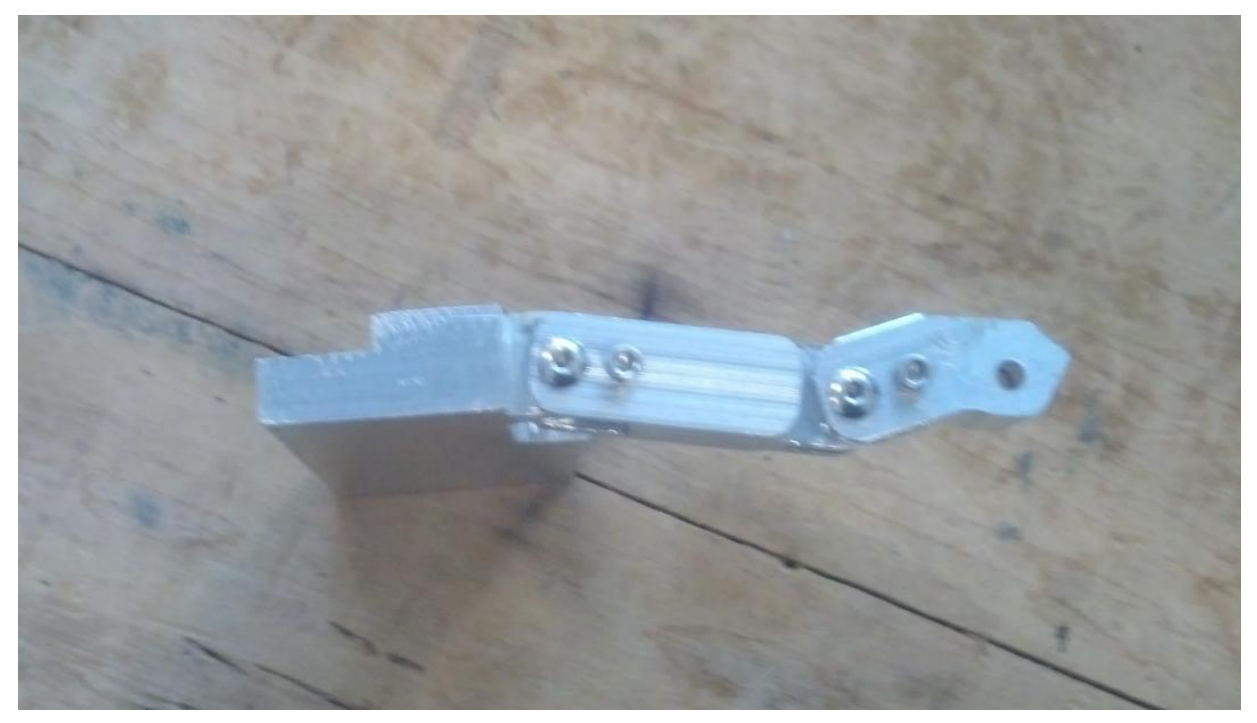

Figure 29: Alpha Finger Assembly for Testing of Tendon System

To verify the mathematical model, a 3lb weight was hung from tendon anchor hole and the assembly was locked into a vise upside down. A force scale was then attached to the tendon exiting the rear of the assembly, allowing for force measurements to be taken when lifting a known weight. This setup can be seen below in Figure 30. Additionally, an image of the scale during this test can be seen in Figure 31. 


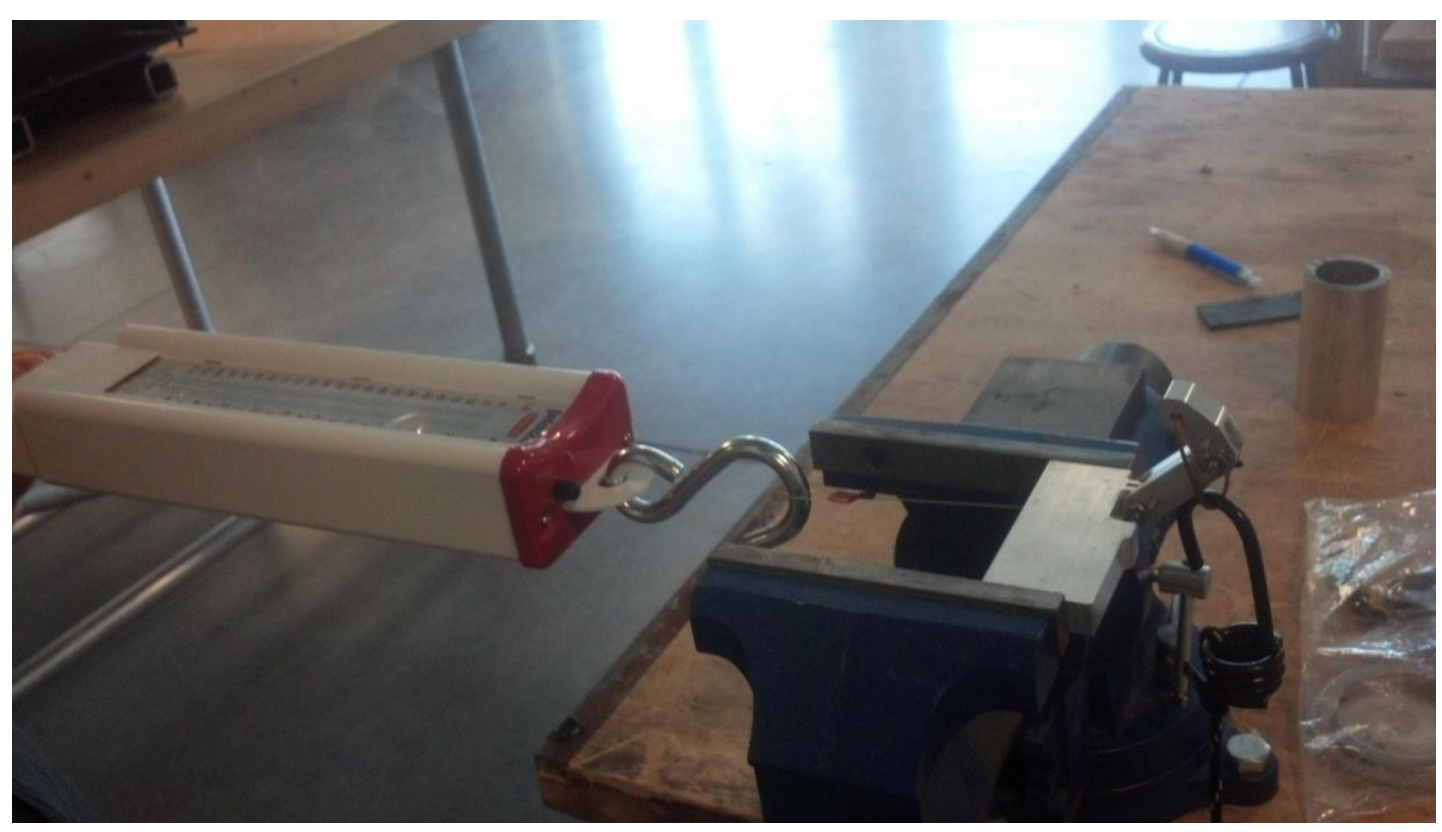

Figure 30: Tendon Force Physical Testing Setup
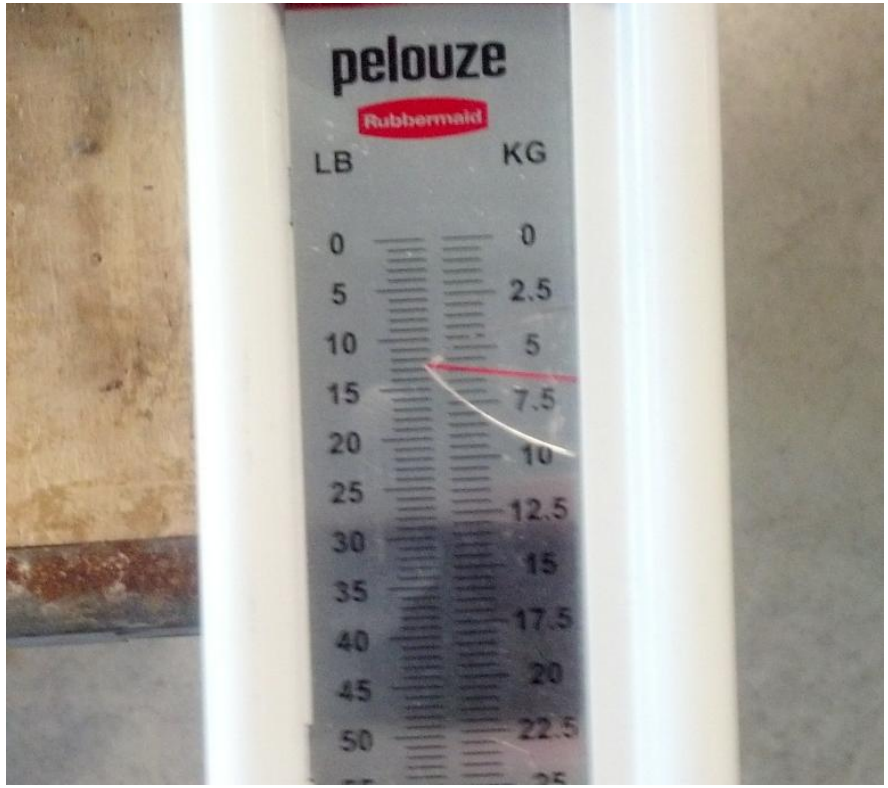

Figure 31: Force Scale Reading for Tendon force Physical Testing

As can be seen on the scale above, the $3 \mathrm{lb}$ weight required a tendon tension of roughly $15 \mathrm{lbs}$ when correcting the slant of the indicator needle. This yields a tension ratio of roughly 5:1 which matched mathematical predictions made above when accounting for friction. 


\subsection{1: Finite Element Modeling of Transverse Phalanx Failure}

As discussed briefly in the Phalanx sub section of the Design Concepts section, the most likely mode of failure in this links is a shear separation at a corner stress concentration on either the proximal phalanx or the attachment tab on the knuckle bar due to a transverse loading. These areas are concerning since their creation was with an end mill rather than a ball end mill. The difference is that the ball end mill will leave a known radius at the cut, creating a fillet that will help alleviate the stress concentration factor at the corner. The end mill on the other hand cuts that feature at an almost perfect 90 degrees, meaning the stress concentration factor in the corner is much higher, amplifying the stress seen in that region of the part much more. The use of the end mill was necessary due to the tooling available during fabrication since the radius on a ball end mill must be very small in order to leave enough clearance in the corner to allow for finger flexion to occur without binding of the mating part edge. Another region of concern is the knuckle pin holes on both the proximal phalanx and the knuckle tab, however the sharp angles necessary in the corners of the knuckle tab as previously discussed are believed to be severe enough to cause initial failure to occur there rather than at the holes.

This concern was primary in the drive to generate a finite element analysis (FEA) model in order to determine not only if the rudimentary calculation described in the Design Concepts section which predicted a yield force of $50 \mathrm{lbf}$ was accurate, but whether initial failure did indeed occur through the knuckle corner. ABAQUS CAE was used to create models of the proximal and distal phalanxes as well as a single knuckle tab to act as an anchor. These three parts were modeled individually and were brought together in the assembly as individual instances. Images of these parts can be seen below in Figure 32.

When modeling the mechanics of the finger system, selection of element type and class are important since it will play a heavy role in how results are determined and how much 
computing power will be required. For these models, shell elements and solid 3D elements were considered. Shell modeling represents the part as a thin section with the part thickness represented with a thickness value in the element specification. The weakness of shell elements is that they cannot predict stresses though a part's thickness since the thickness specified within the element is only for moment of inertia calculations. 3D stress elements on the other hand do have the ability to predict stress distributions through a part's thickness; however it requires having elements stacked though that thickness, causing the number of elements required to be much higher. The use of shell elements would allow for a much smaller element size for a constant computation power requirement since there would be no elements though a thickness. Unfortunately the stress through tab thicknesses are of concern for this model, requiring the use of 3D stress elements despite the extra computational power and thus model run time required to use them.

Of the 3D elements, a standard quadratic tetrahedral was chosen for its ability to create relatively even meshes around holes and into tight corners. Mesh quality can be seen below in Figure 32 underneath the corresponding model.


Figure 32: Finite Element Models and Meshes of Finger Components 
As can be seen, mesh distortion around the holes is minimal, meaning no partition lines were necessary to even out the element distribution. In addition it is standard practice to ensure at least three elements are present across the smallest thickness. This will be considered when determining seed size after the convergence study discussed below.

These parts were arranged in the assembly to accurately depict how they would interact with each other at full extension. And encastre boundary condition was applied to the rear of the knuckle part preventing movement or rotation in all three directions, essentially fixing it as a rigid member. The load was placed at the very tip of the finger, creating the largest moment possible. These features can be seen below in Figure 33 .

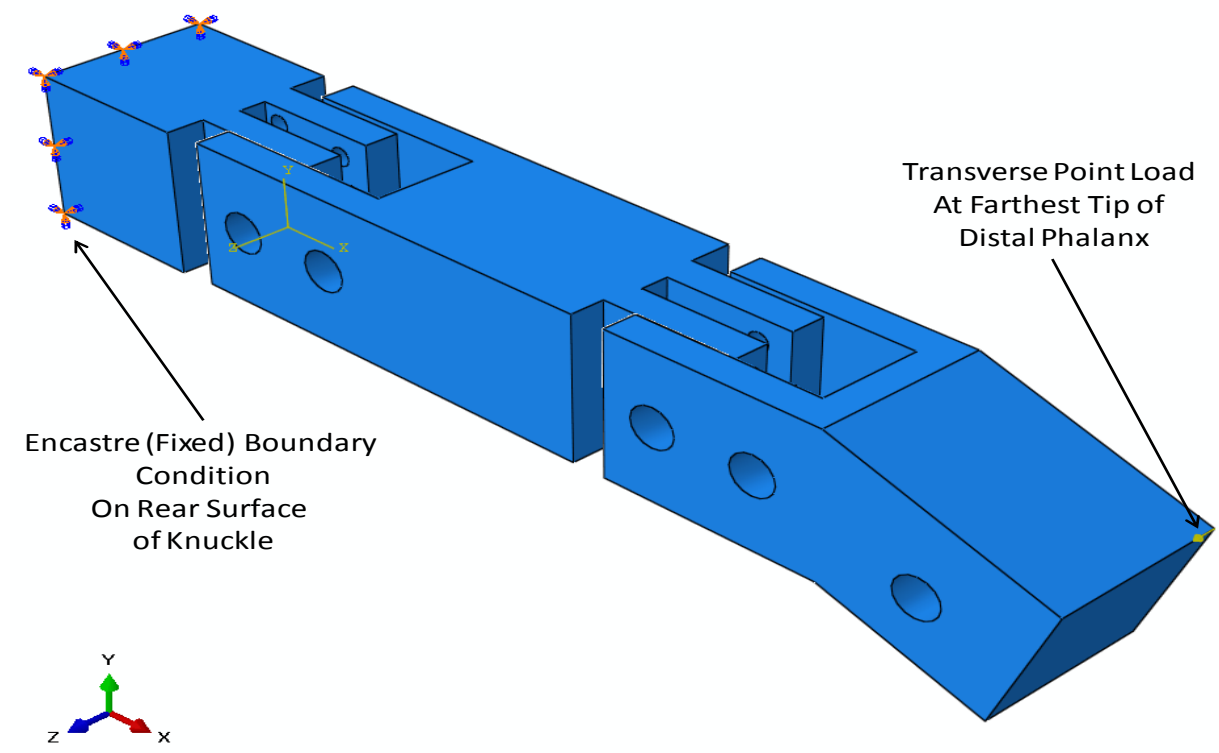

Figure 33: Finite Element Model Boundary Condition and Force Placement

The joint interactions between the three parts were modeled using a tie constraint between the joint pin holes, simulating a rigid pin locking the two parts together transversely. This modeling approach can be accurate for any material which the fingers could be made from since even if the 6061 aluminum used for the prototype is not strong enough and titanium is 
chosen for future iterations, stainless steel bolts can be used which have a yield stress of 70000psi as compared to the yield stress of pure titanium which is 40000psi (McMaster Carr product specifications). This means the surrounding material will yield long before the joint pin. In addition, a tie constraint between the attachment tabs and the side wall of the joining attachment groove was used to simulate the contact force between the parts during a transverse loading event. Placement of these constraints can be seen below in Figure 34.

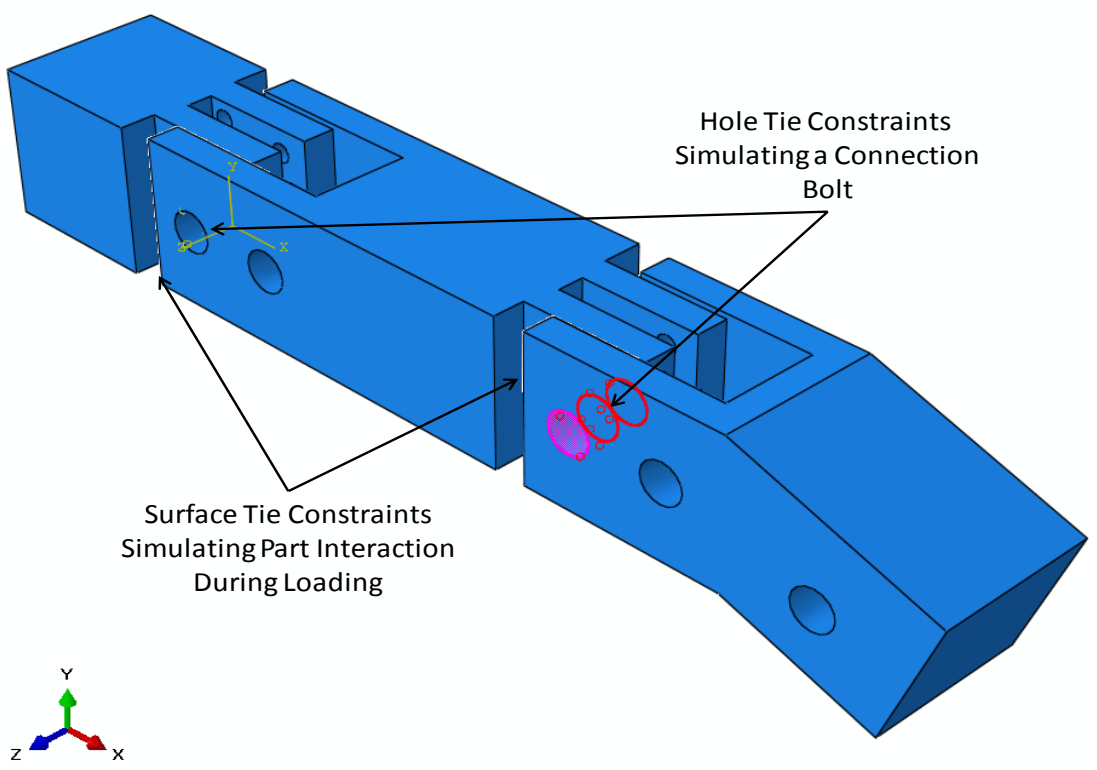

Figure 34: Finite Element Tie Constraints Used

Before running models to interpret results, a convergence study was undertaken to ensure that the number of elements used would not alter the results significantly. This is also a means to optimize use of computing power since increasing element numbers causes the run time to increase as well. To accomplish this, the element seed size was subsequently reduced once the von Mises stress was obtained for a specific node. Once the values cease changing significantly since increasing element numbers also increases accuracy, the model is considered to have reached convergence and actual model runs can begin. Below in Figure 35 the node used for the study is depicted. 


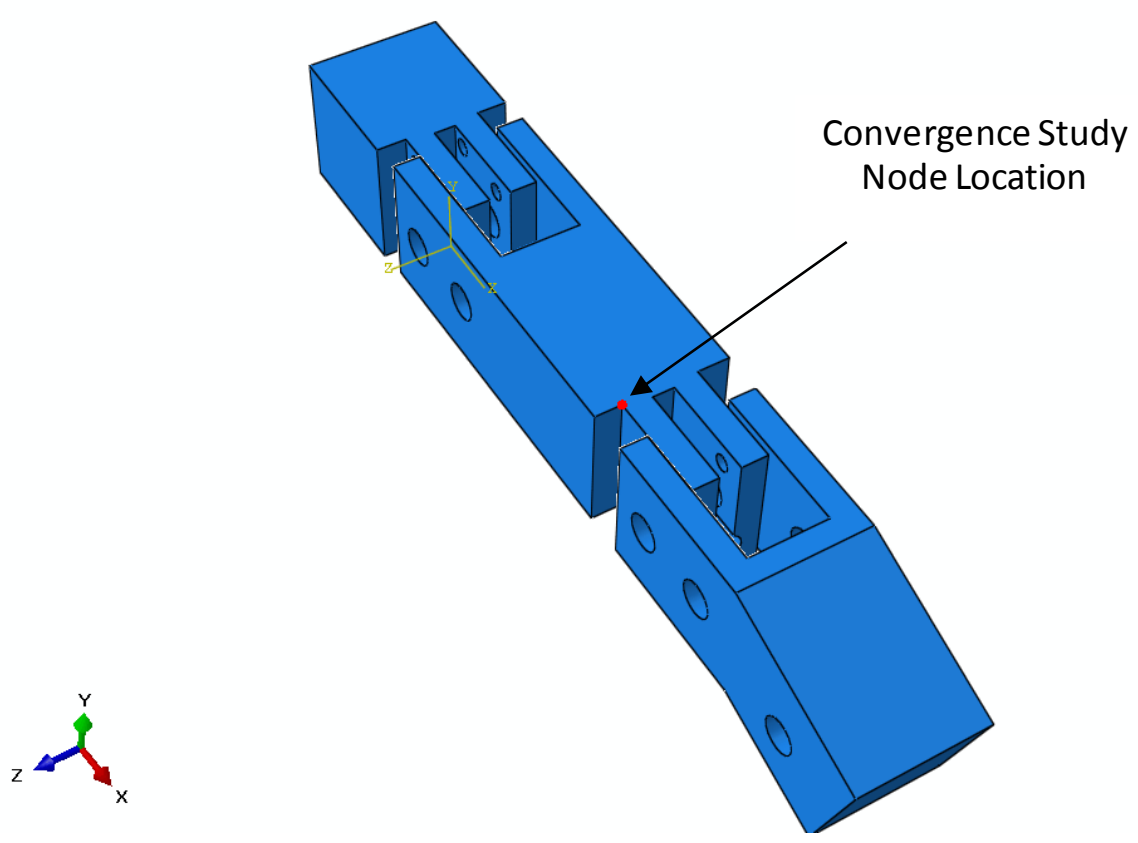

Figure 35: Finite Element Convergence Study Node Location

To run the study, .3in was used for the initial seed size and the model was run with an applied load of $40 \mathrm{lbf}$. The von Mises stress at the node indicated above was recorded, and model was run again with a smaller seed size. Results of the convergence study can be seen below in Figure 36.

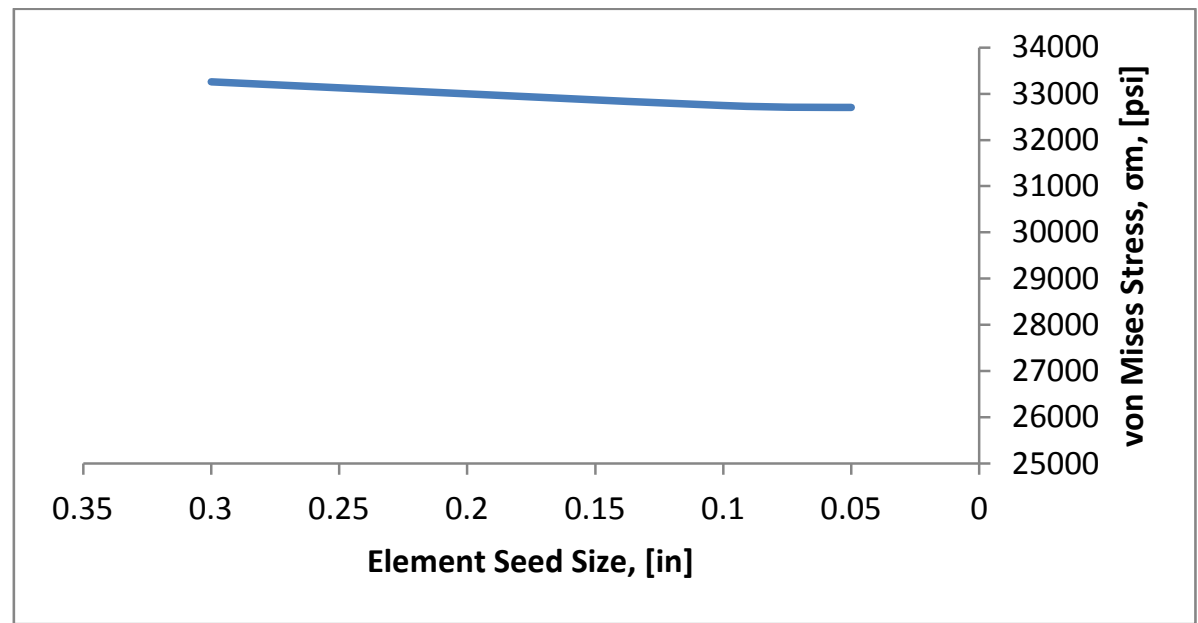

Figure 36: FEA Convergence Study Results 
As can be seen in Figure 36, the von Mises stress at the indicated node decreased steadily until a seed size of about 0.1 in where the stress began leveling off. Ultimately a seed size of 0.05 in was chosen despite the requirement to allocate additional ram to the model because at this size there were no distorted element warnings for the model, meaning result skew from poor mesh quality around holes was not an issue.

Interestingly, even though the convergence study was run at $40 \mathrm{lbf}$ which is lower than the $50 \mathrm{lbf}$ predated previously, the Mises stress predicted hovered near $33 \mathrm{ksi}$ which is extremely close to the yield strength of 6061 aluminum which is $35 \mathrm{ksi}$ (McMaster Carr product specifications). This is worrisome since the node location chosen for the study was not at a point which would experience maximum stress in the system. For this reason, the applied transverse load was reduced to $10 \mathrm{lbf}$ for the following model results.

In addition to verifying convergence, the initial model run was intended to determine key areas with the highest stress in order to target the sections which will be looked at for results comparisons. From this first model run, it was determined that the most aggressive stress zones exist on the proximal phalanx at the holes on the proximal and, and on the knuckle bar attachment tab at the corner discussed previously as well as the holes in the tab. These are indicated below in Figure 37. These zones are what was intuitively expected based on stress concentration theory.

Von Mises stress is a theoretical value based on the principle stresses in an object and is governed by the distortion energy theory. In this theory, if the combination of the three principle stresses reached a peak value, failure occurs in the part. This is determined by comparing the von Mises stress to the yield stress since the von Mises stress is a product of the principle stresses. Simply stated, if the von Mises stress meets or exceeds the yield stress of the material, failure occurs in the form of yielding. 


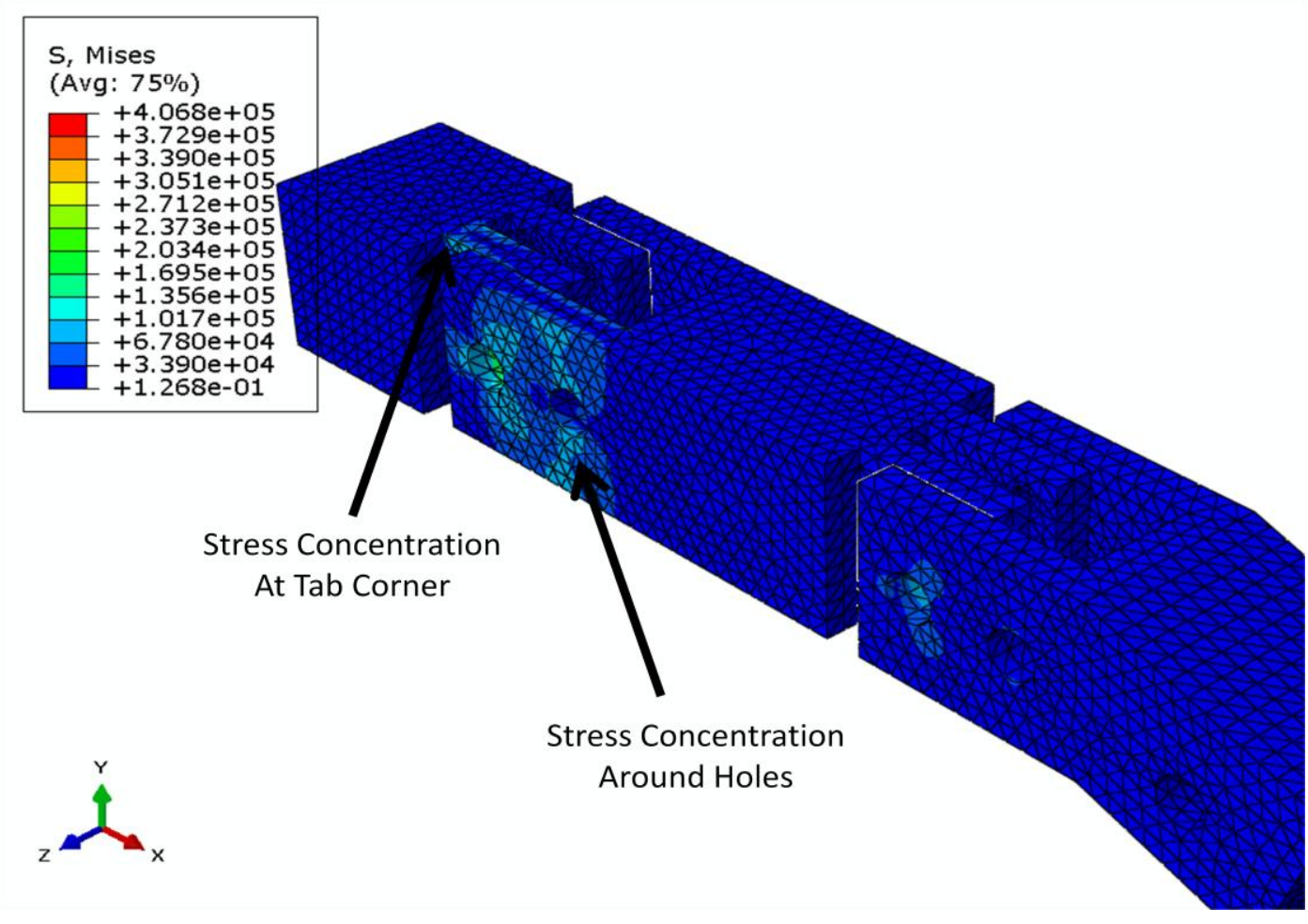

Figure 37: Locations of High Stress on Finite Element Model

Since the highest stresses are located on the knuckle tab, all following results will feature just the knuckle part. Two separate models were created, where the material of the parts was set as 6061 aluminum with an elastic modulus of 10E6 psi and a Poisson ratio of 0.3 , and the other where the material was set as titanium with an elastic modulus of 16.5E6 psi and a Poisson ratio of 0.3. Strangely, the difference in elastic moduli was not significant enough in order to change the von Mises stress on the knuckle. Results of these models can be seen below in Figures 38 and 39. Recall that the load used for these runs was $10 \mathrm{lbf}$. 


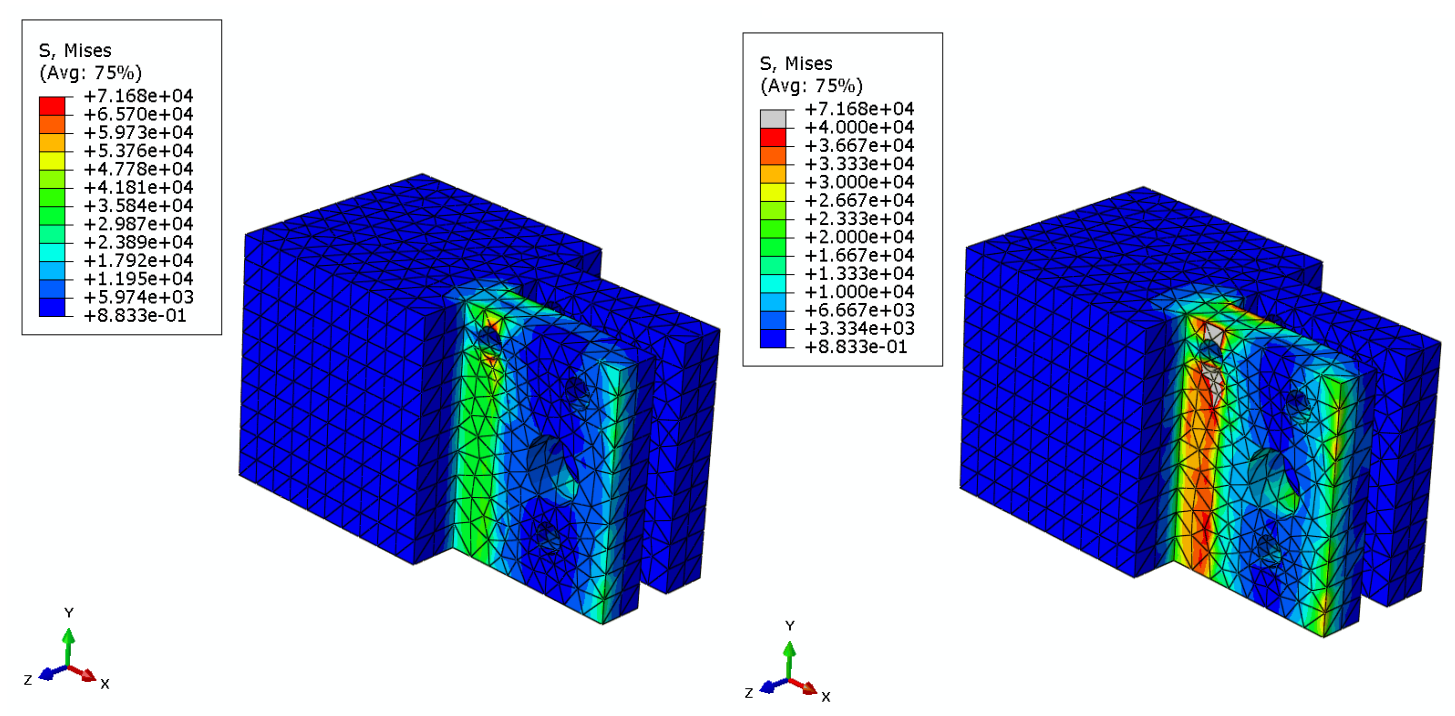

Figure 38: Aluminum Knuckle Finite Element von Mises Stress Results with 10lb Transverse Load

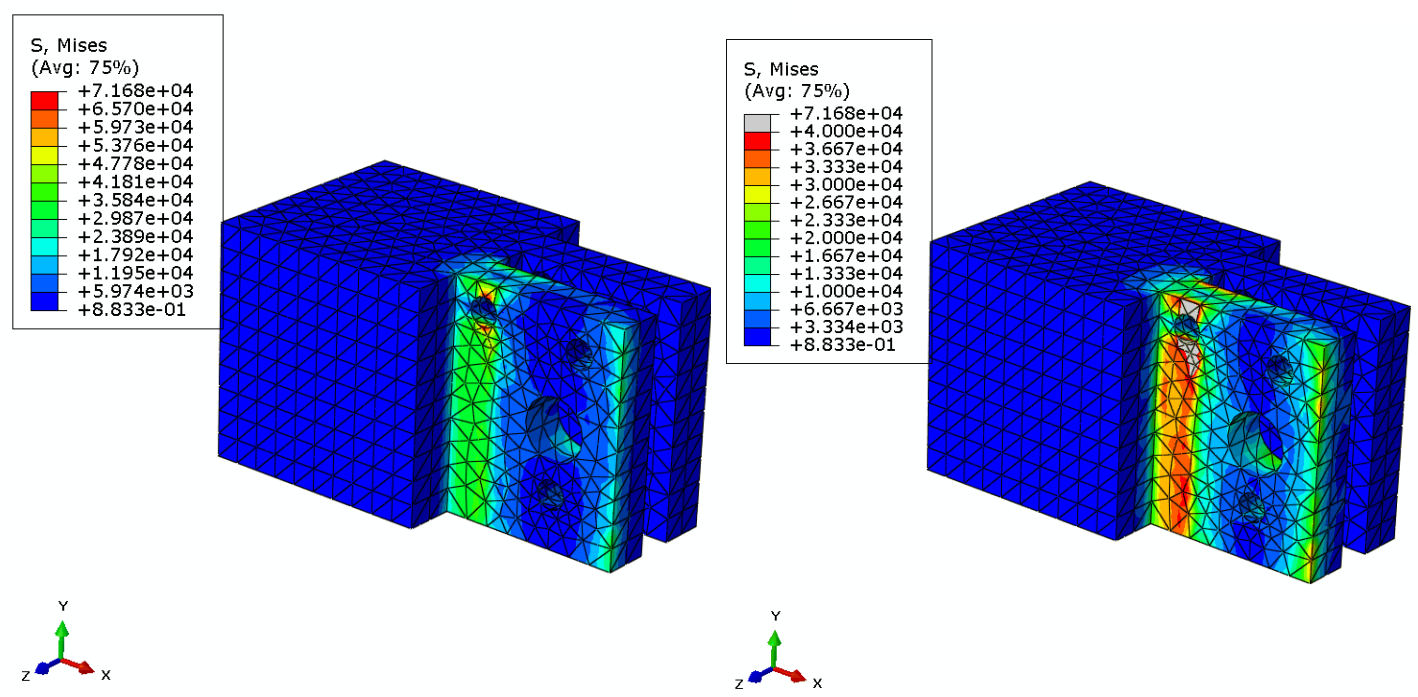

Figure 39: Titanium Knuckle Finite Element von Mises Stress Results with 10lb Transverse Load

As can be seen above, the maximum von Mises stress peaks at roughly $71000 \mathrm{psi}$ at the pin hole for the top tendon roller. This is not surprising since in this are the stress concentration induced by the hole are superimposing with the concentrations caused by the corner, amplifying the total effect. These results are worrisome since $10 \mathrm{lbf}$ of transverse load is not a sever loading, yet the finite element model is predicting failure since $71 \mathrm{ksi}$ is higher than the yield strength for 
both aluminum and titanium at $30 \mathrm{ksi}$ and $45 \mathrm{ksi}$ respectively. On a positive note, the stress in the corner as seen in the right image for both Figures 38 and 39 sit below these thresholds. Since the results from the finite element models produced strange results, physical testing was undertaken to verify the results.

\subsection{2: Physical Verification of Transverse Loading}

In physical testing was undertaken using the same parts used in the tendon tension model and increasing static weights. The parts were mounted in a vise such that flextion and extension of the finger would occur parallel to the ground, allowing for weights to be hung from the same loop sued in the previous test. An image of this setup can be seen below in Figure 40 .

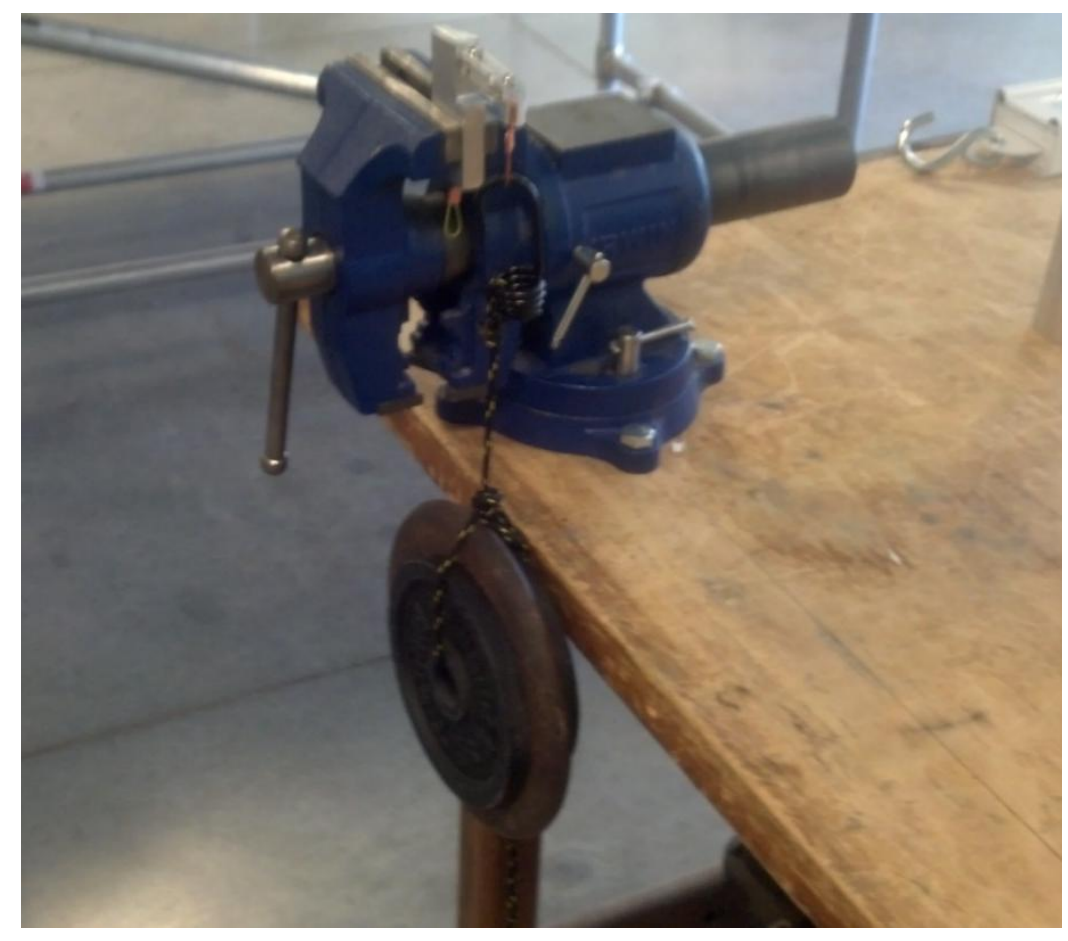

Figure 40: Transverse Finger Failure Physical Verification

Loads started at $3 \mathrm{lbs}$, then increased to $6,10,13$, and finally $16 \mathrm{lbs}$, which is higher than the load which the FE models predicted yielding of the material would occur. Interestingly, the parts did not fail, and the only deflection witnessed was due to improper tolerance on the alpha parts. An image of the finger under $16 \mathrm{lbs}$ of force can be seen below in Figure 41 . 


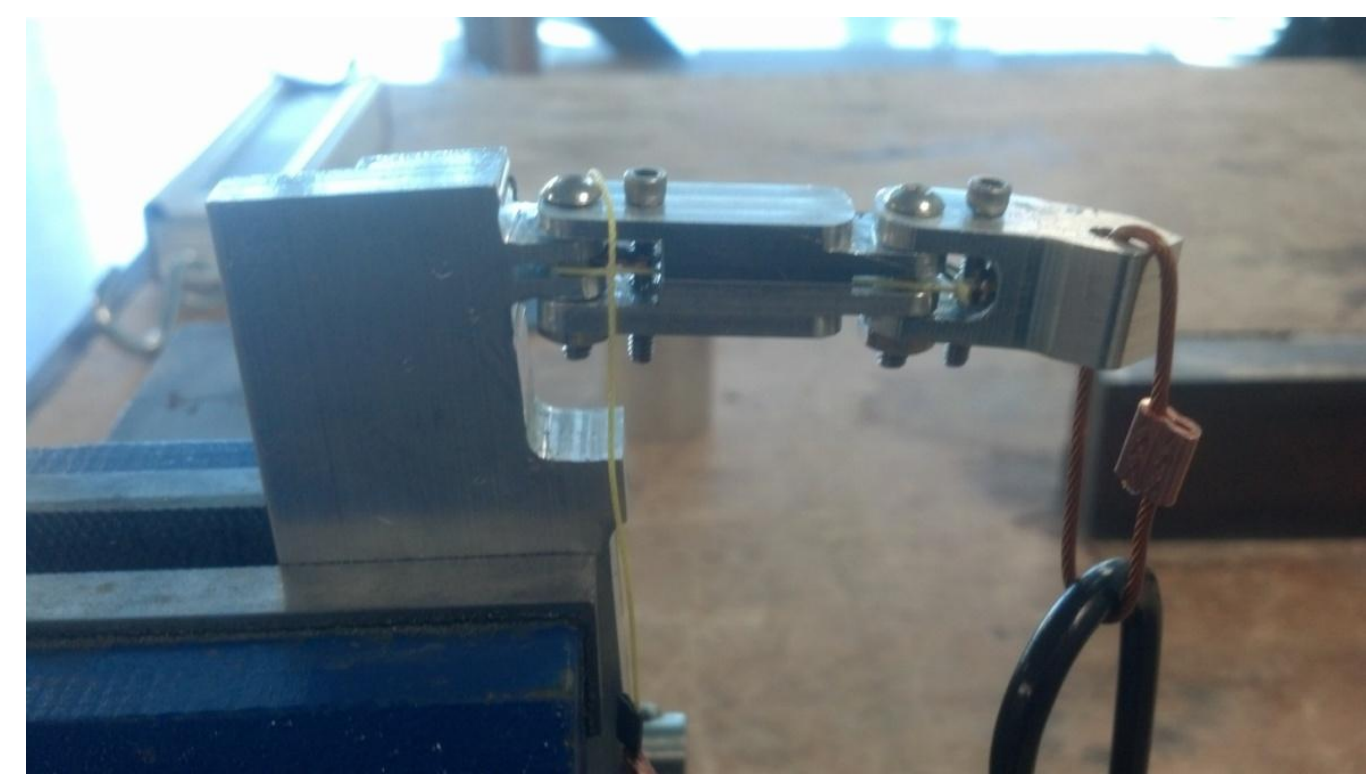

Figure 41: Physical Transverse Load Testing, 16lb Weight Deflection Image

Since the loads placed on the physical finger exceed that which the FEA model predicted failure, extra strength is being added to the system. This is most likely due to the press fit steel pins for the rollers, which prevent the hole from collapsing under load which was predicted in the FEA model. This will be discussed further in the Future Work section. 


\section{Chapter 5: Design Realization}

Ideally, minimal changes to design and manufacturing plans should be made from concept to realization; however these changes are always necessary since initial fabrication is fraught optimization of feature creation and removal of un-necessary processing steps and part

geometries. In the following section, part creation will be detailed with special emphasis placed on deviations from initial plans laid out in the above part sections.

Additionally, all parts were completed by polishing them fist with subsequently finer grit sand paper to remove burs and scratches in the metal surface caused by fabrication and buffed with a cloth buffing wheel attachment for a hand held Dremmel.

\section{1: HAAS VF2 Computer Aided Mill}

Before discussing the creation of each part individually, it is beneficial to discuss the CNC machine used for creation of most to the part features. A HAAS VF2 was used for all CNC operations on the knuckle bar, distal phalanx, and proximal phalanx. This machine is has three cutting axes with up to 10 tool holders, allowing for multiple cutting operations to be undertaken in a single fixturing. To the observer standing in front of the machine, the z-axis is up and down, the $\mathrm{x}$-axis is left and right, and the $\mathrm{y}$-axis is toward and away relative to the observer with positive directions indicated in Figure 42. 


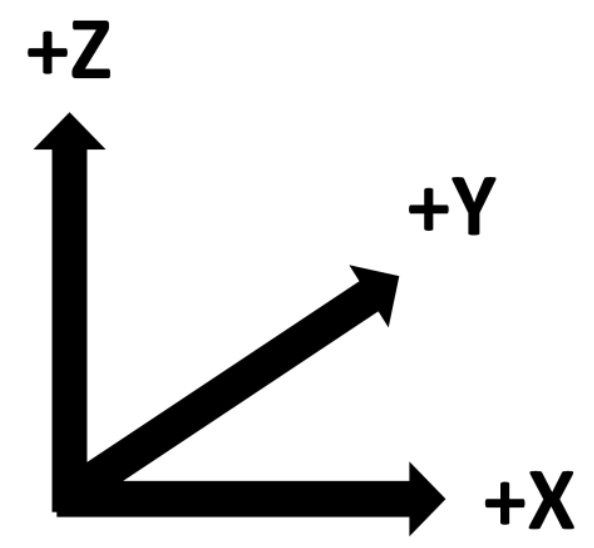

Figure 42: HAAS VF2 Coordinate System

Part fixture positions described in the following sub sections will be relative to this coordinate system.

\subsection{1: Phalanxes}

Manufacturing of the phalanx was undertaken as described above in the concept section. For both proximal and distal segments, total part lengths were cut from $0.5 \mathrm{in}$ by $0.5 \mathrm{in}$ bar stock for the proximal phalanx and 0.5 in by 0.7 in bar stock for the distal phalanx using a horizontal band saw. The finished length of these pieces are 1.70in and 1.24in respectively, meaning each raw section was cut by roughly 0.1 in longer than the finished length due since the band saw blade tends to cut at a slight angle due to saw construction and the inability to control tolerances to acceptable levels. Many "blanks" were cut in order to facilitate the creation of test pieces and as a buffer for potential mistakes being made during manufacturing resulting in a wasted piece. Each of the over long blanks was then faced to length on a knee and column mill by hand, preparing them for final cutting in the HASS VF2 computer controlled mill.

Changes were made to the knuckle pin setup to accommodate not only commercially available parts, but ease of breakdown and construction of the fingers themselves. Originally, the design called for headless clevis pins with e-clip retaining rings on either side as a means of 
holding the knuckle joints together. Due to anatomical and spacial constraints, the pins had to have very specific dimensioning. The desired pins would have a usable length between ring grooves $\mathrm{Lg}$ of 0.5 in to match the phalanx width, a diameter of no more than $1 / 8$ of an inch in order to limit hole size in the part, and a total length of no more than .60 in to prevent pin interaction between fingers and to reduce the likelihood of pins snagging on materials being gripped. The diameter of the pins could be no more than $1 / 8$ since the rule of thumb for hole placement is to have at least one radial length from hole side to part edge. Since the holes for the knuckle joints are places .15 in away from the part edge, this limits the hole to no more than .15 in in diameter since the hole placement should not be moved inward more due to phalanx link collisions during flexion.

Headless clevis pins are typically not made smaller than $1 / 4$ in, meaning either a clevis pin with a cotter pin anchoring would need to be used, or a different method of joint pinning would need to be explored. Since cotter pins would catch easily on fabric materials, the clevis pin usage was discarded in favor of threaded fasteners. By tapping threads into one side of the proximal attachment (outer wrapping groove) and widening the hole opposite and the mating hole on the distal attachment tab on the mating part, a threaded bolt can pass through the larger holes and thread into the tapped hole, fixing it in place. Since the hole on the distal tab of the proximal part is large enough for the bolt to pass through, the two parts are still able to rotate relative to each other. Solidworks renderings of these new parts can be seen below in Figure 43. Additionally, a point was added to the distal phalanx based on a discussion with the challenger in order to allow him to more easily pick up paper or other small objects off of a flat surface. This new feature can be seen in Figure 43 as well. 


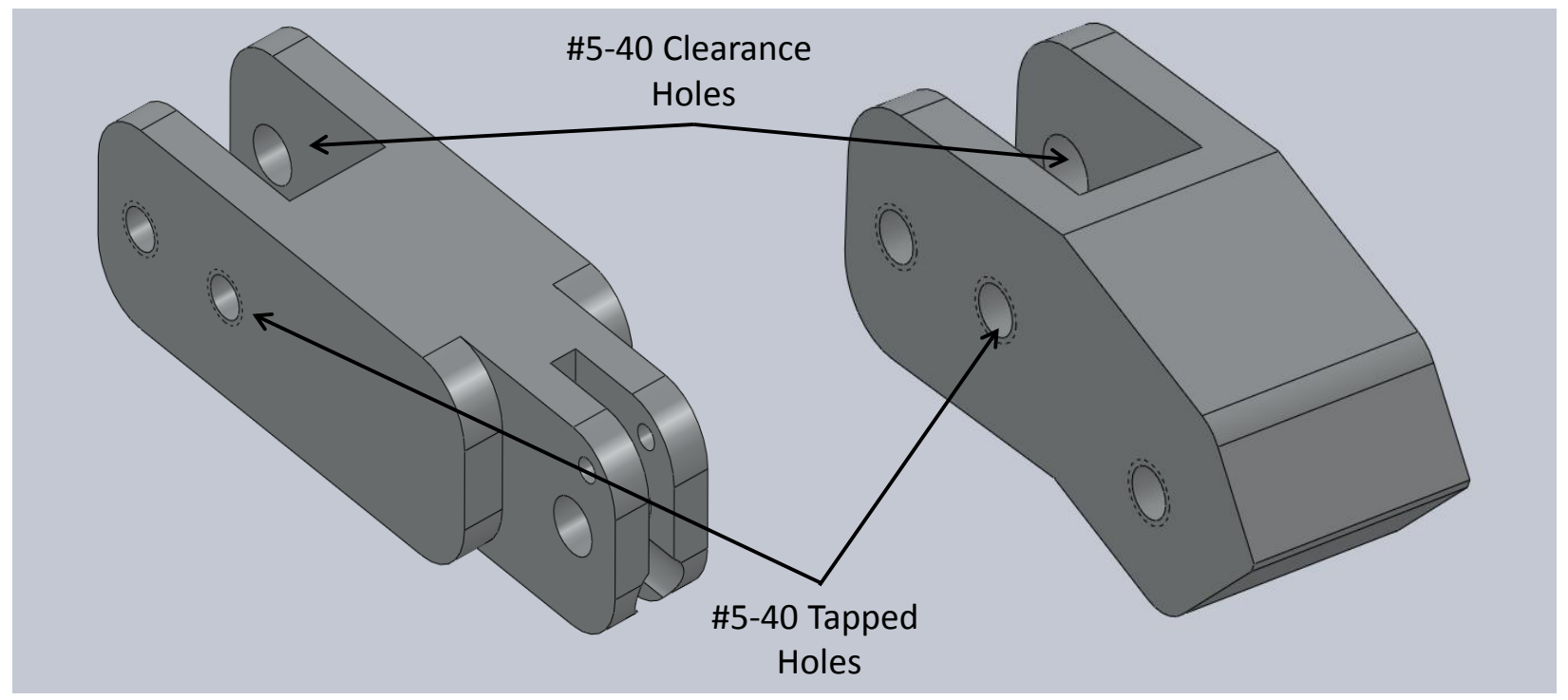

Figure 43: Proximal and Distal Phalanx Final Design Solidworks Rendering

Due to the unique geometry of each phalanx, fixturing of the blank pieces for cutting was unique to each section. In addition, to satisfy tight geometric tolerance on the hole positions it was desirable to use the HASS machine to make these cuts as well. Fixturing protocols followed for manufacture of the parts will be described individually below.

\subsection{2: Proximal Phalanx}

Creation of the proximal phalanx required three different fixturings in order to cut all of the features. First, the long axis of the phalanx is inserted into the vice along the $\mathrm{x}$ axis with parallel bars underneath ensuring that a minimum of 0.26in of clearance between the top of the part and the top of the vise is present in the $\mathrm{z}$ direction. This is important to ensure that the cutter will not run into the vise during processing. Once the vise it tightened, it is important to remove the parallel bars out from under the part since the knuckle and spring return holes will be drilled through the part during the first operation. For this operation, the part zero is located at the corner on the right side of the part and away from the operator (most positive $\mathrm{x}$ and $\mathrm{y}$ corner). This zero is indicated in Figure 44 which also shows the cuts made during this operation. 


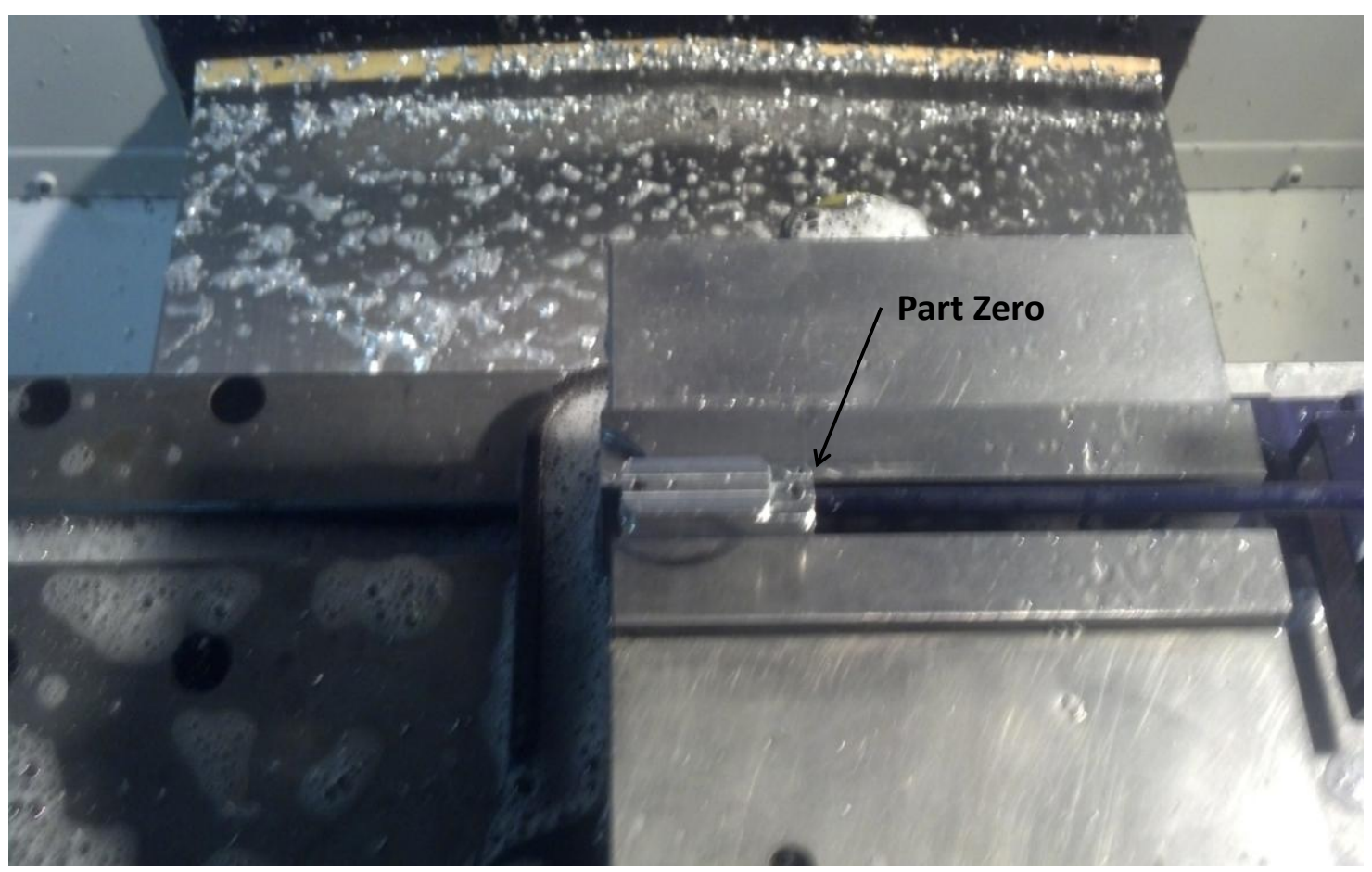

Figure 44: Proximal Phalanx CNC Operation 1 Fixturing

The second fixturing is almost identical to the first and is meant to cut the same features on the other side. To accomplish this, the part is removed from the vise and flipped 180 degrees along the longitudinal axis while keeping the distal side of the link in the positive $\mathrm{x}$ direction. The same parallel bars should be used from operation one to ensure adequate cutter-vise clearance. Parallels do not need to be removed during this operation since the holes have already been drilled.

The third and final fixturing is meant to cut the proximal groove for the knuckle bar joint as well as drill the tendon routing hole. For this fixturing, the distal section of the finger should be placed down in the vise in the negative $\mathrm{Z}$ direction, while the bottom of the link should face the positive Y. A new part zero is needed for this fixturing, however it should still be set to the right corner away from the operator once more. This corner is the most positive $\mathrm{X}$ and $\mathrm{Y}$ side. 
For all cuts on this part, a 0.25 in end mill, \#30 drill, \#38 drill, and a 0.125 in drill are needed. Post CNC, the slot in the distal section which allows the return spring to function was cut on a hand mill using a 0.072 in thick slitting saw on an arbor collet as depicted below in Figure 45. The final part can be seen below in Figure 46.

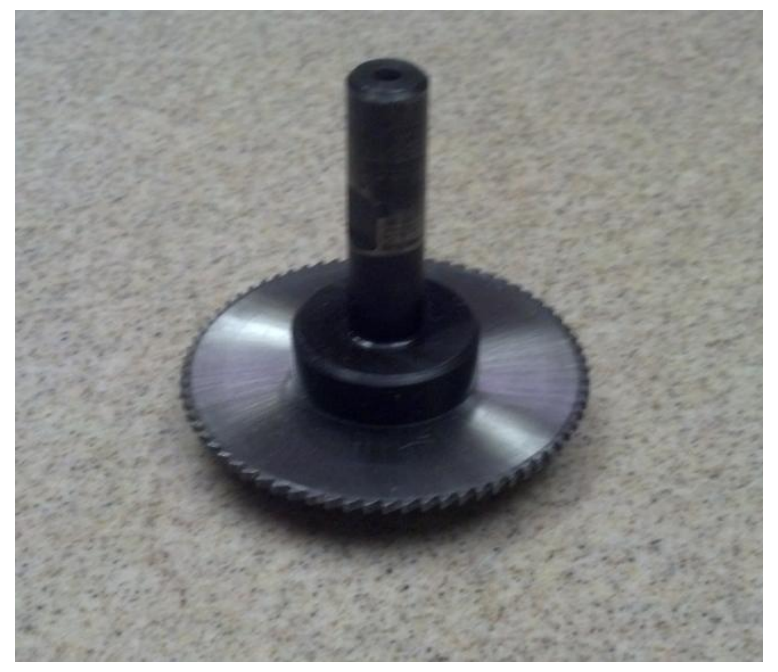

Figure 45: Slotting Saw on Arbor Collet

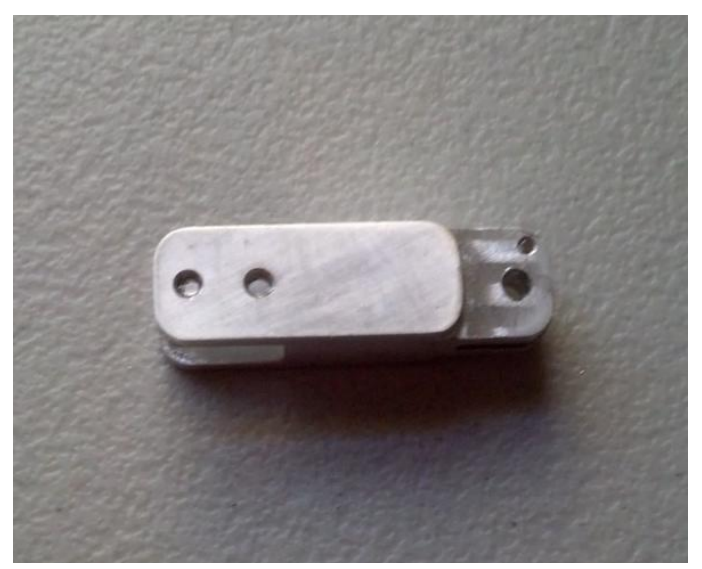

Figure 46: Proximal Phalanx Final Part

\subsection{3: Distal Phalanx}

For the distal phalanx, two operations were needed to cut the features. Fist, the blank is placed in the vise with the long axis facing up, and the .70in side running along the $\mathrm{Y}$ axis. Parallel bars should be used such that only $1 / 4$ of the total height of the part is held in the vise to 
prevent a cutter-vise interaction. The part zero for this fixturing is the same back right corner as discussed above in the proximal phalanx section. In this operation, the proximal slot for interaction with the proximal phalanx is to be cut, along with part of the bend profile and the distal side of the phalanx and the tendon routing hole. When the partially done phalanx is removed, there will be a chunk of material hanging out to one side which will become the bent down section on the distal end of the phalanx in the next operation. An image of the part after undergoing the first operation can be seen below in Figure 47.

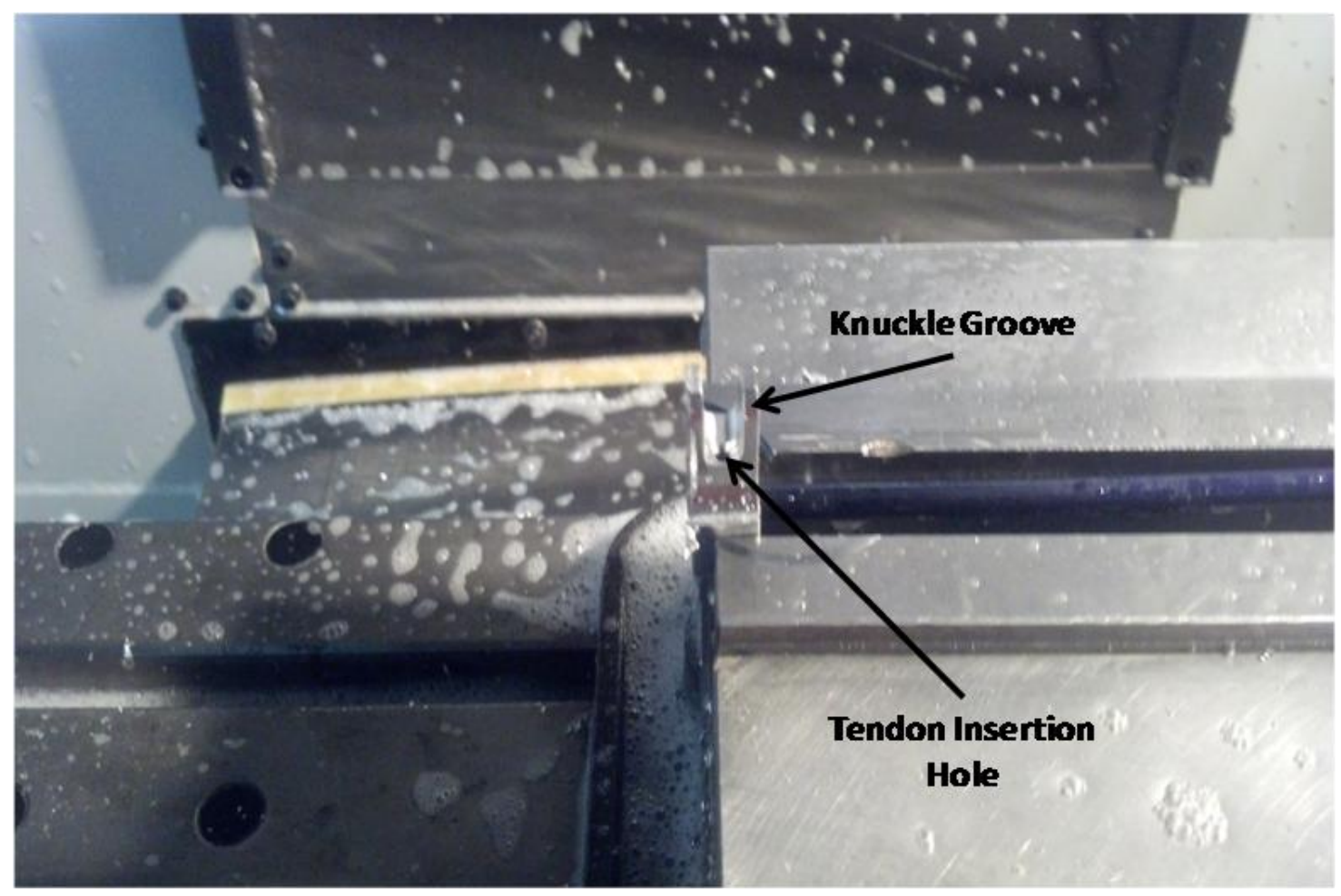

Figure 47: Distal Phalanx CNC Operation 1Fixturing

The second fixturing places the phalanx in the left side of the vise with the distal section pointing in the negative $X$. In addition, it is important that the bottom of the phalanx be placed facing away from the operator in the positive $\mathrm{Y}$ in order for the profile to be cut correctly. This mounting can be seen below in Figure 48. 


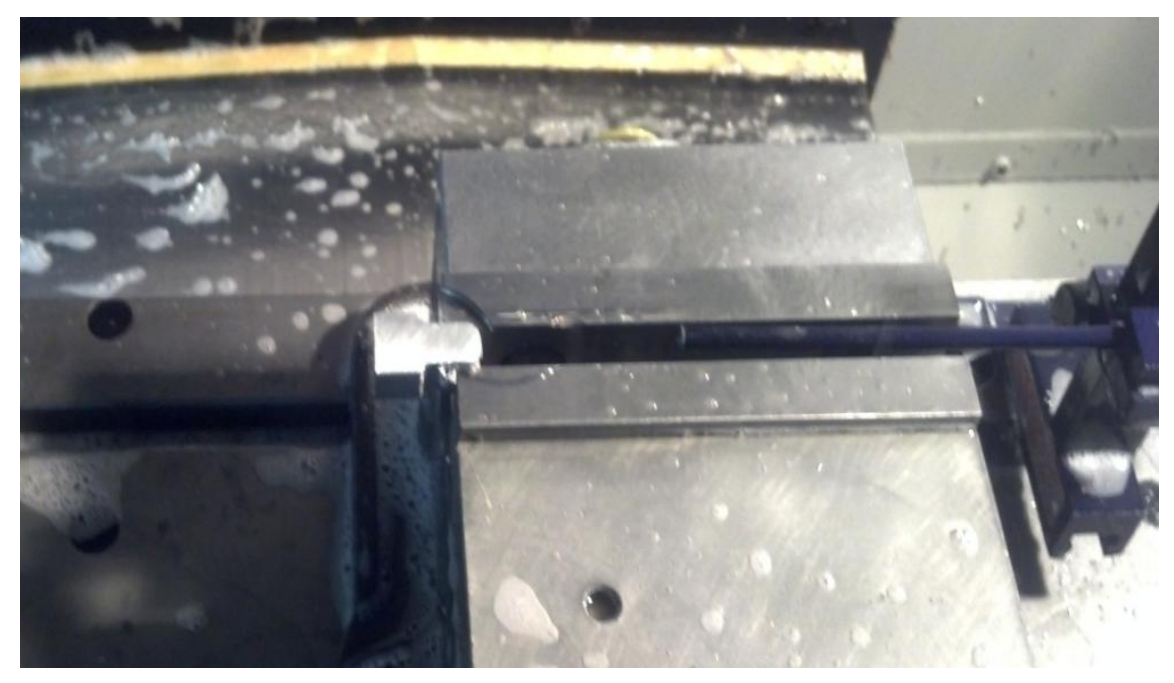

Figure 48: Distal Phalanx Operation 2 Fixturing

The part zero is to be again set to be back right corner of the part; then add 0.2 in to the $\mathrm{Y}$ value such that the zero plane is in line with the edge of the part overhang discussed above. If the zero is not altered by this $0.2 \mathrm{in}$, the profile is shifted by that much resulting in an incorrect piece depicted in Figure 49 as it compares to a correct part.

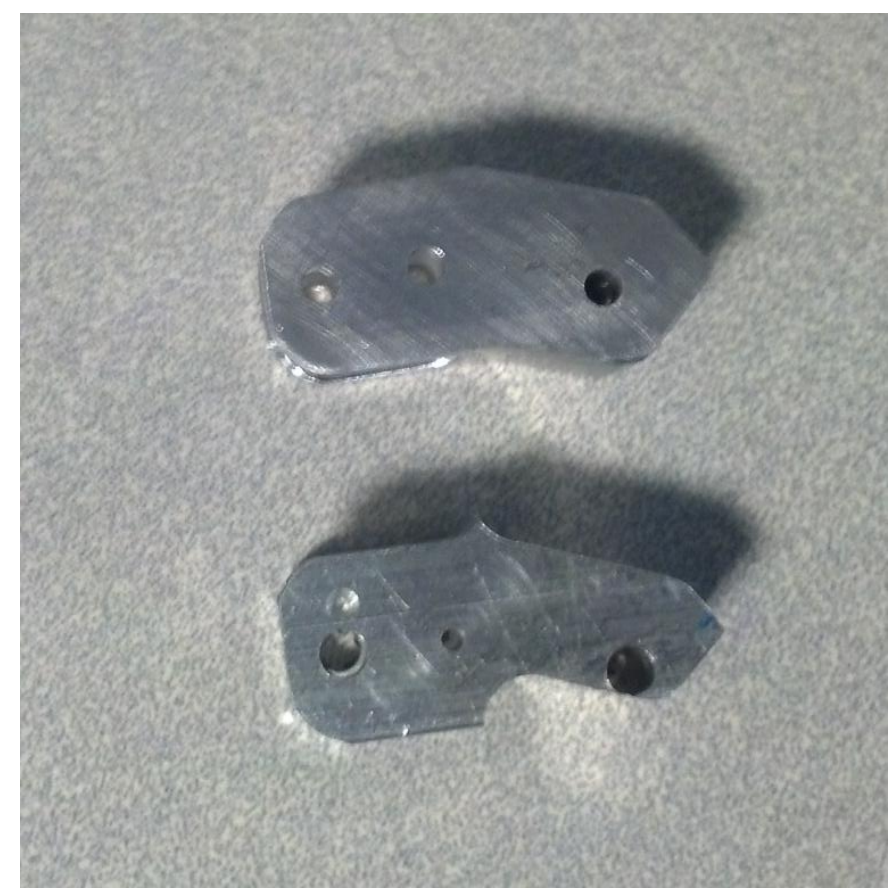

Figure 49: Distal Phalanx Failed Part and Correct Part 


\subsection{4: Phalange Extension System}

In the original design, small extension springs were to be used to cause the phalange to return from flexion to a natural open state when tension on the tendons was released. The draw of the springs was that they are easily obtained in large quantities and can be carried as replacement with little volume consumption in the pack. The total outer diameter of the springs was required to be limited to no more than 0.070 in since the width of the slot through which they must fit was created with a 0.072 in slotting saw as discussed in the Proximal Phalanx section. Ultimately springs of this size are not a feasible phalange extension mechanism since they are extremely difficult to manipulate without two hands, needle nose pliers, and a magnifying lens. Additionally, the loops that come preformed on the ends of the springs were not large enough to accommodate the $1 / 16$ in pin, requiring modification which compromised the integrity of the spring. This would make replacement of the spring in the field nearly impossible which is unacceptable based on the initial project requirements. For these reasons, the extension mechanism was altered to a line of 1/16 in diameter elastic with loops at either end. This alteration does not change the design of the phalanx holes, but makes replacement of the mechanism much easier. The total un-stretched length of the elastic from loop end to loop end was set as the distance from the distal attachment site up to the proximal press fit pin, then back to the distal attachment site. An image of the elastic with the formed loops can be seen below in Figure 50. Instructions on insertion of the elastic band into the finger system can be found below in section 5.7. 


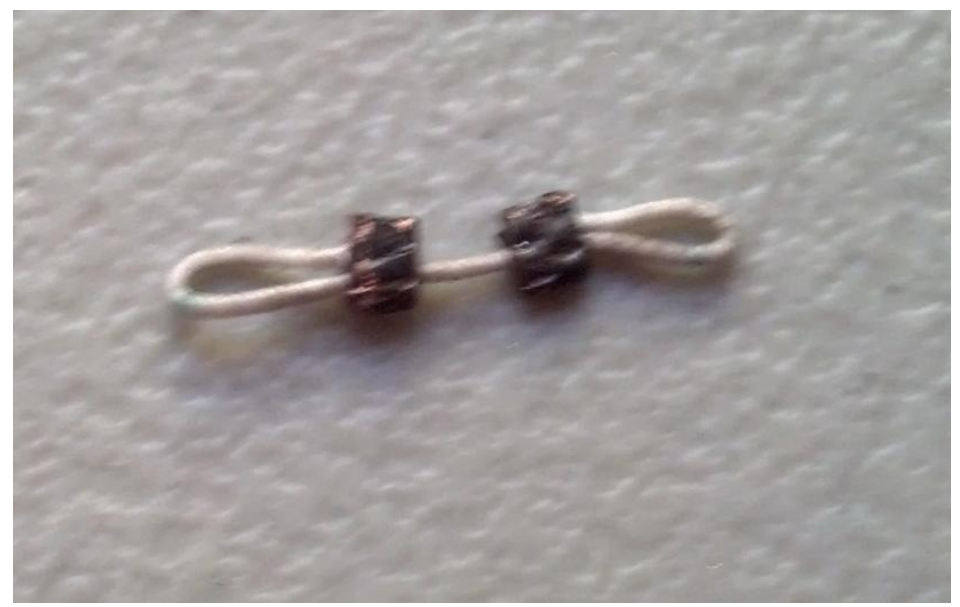

Figure 50: Elastic Extension Band

\section{3: Knuckle Attachment}

The creation of the knuckle bar was a combination of hand milling and CNC milling. To start, the rough overall dimensions were cut using a horizontal band saw out of .5in by $1.75 \mathrm{in}$ stock. The cuts lines for the band saw were intentionally large when compared to the final dimensions since the saw cuts at a slight angle and tolerance control is not sufficient.

This blank was then faced on a hand mill such that its rectangular dimensions measured 3.1 in by $1.65 \mathrm{in}$ with the thickness being the stock $0.5 \mathrm{in}$. Once total length tolerances were adequate, the slot on the proximal side that the palm plat is to sit in was milled out by hand. The part was then removed from the mill and drilling indentations were created on the new slot surface using calipers and a spring loaded center punch for the \#6-32 tapped holes. These holes were drilled using a drill press, and tapped by hand.

Next, the part was taken to the HAAS VF2 machine for creation of the knuckle attachment tabs. Originally, these features were going to be created by hand milling, however the first attempt resulted in a incorrectly cut part with an unacceptable surface finish. The HAAS machine reduced total manufacturing time for the part considerably and resulted in far better tolerance and surface characteristics than was possible by hand, thus the manufacturing plan was 
changed. To fixture the part, the distal side was place down into the vise in the negative $\mathrm{Z}$ direction with the 3.1 in length oriented along the $\mathrm{X}$ axis. As with the phalanxes, the part zero was set as the back right corner. A .25in end mill was used to create the slots. The fixturing and cutting of these features can be seen below in Figure 51. After the operation was finished, a hand file was used to smooth out the fillets since the end mill creates jagged edges when cutting that surface using the $\mathrm{Z}$ axis.

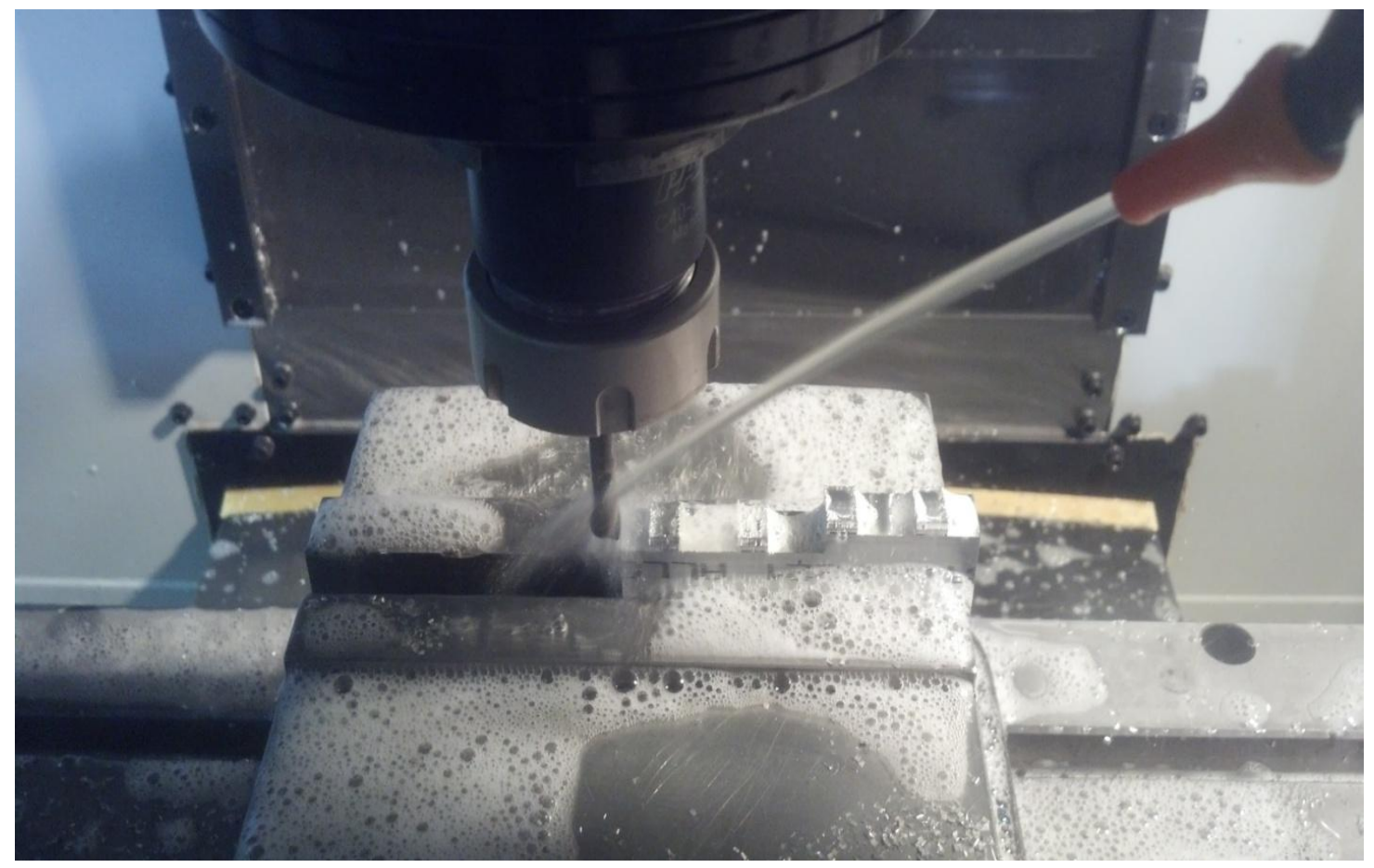

Figure 51: Knuckle Bar Attachment Tab CNC Fixturing

Once the part was brought to this point, further machining was suspended until testing of the tendon system using the first set of phalanxes and the failed knuckle bar was completed to ensure positioning of holes or other geometries did not need to change.

Once the tendon system was verified using the first knuckle bar part, the final knuckle bar was taken back to the HAAS VF2 for drilling of the knuckle holes and press fit pin holes. The CNC machine was to be used for these operations due to the small geometries and difficulty associated with maintaining tight tolerances with a hand marked drill lines and a drill press. To 
drill the holes, two fixturings were required; one to drill the holes on the medial tabs, and one to drill the holes on the lateral tabs. The 3.1 in length of the part was oriented up and down in the $\mathrm{z}$ direction, making the drilling surface perpendicular to the $\mathrm{Z}$ axis to allow cutter approach to occur.

Unfortunately during the first operation, the code input into the machine had an incorrect zero set causing the machine to dive the drill into the part, breaking the bit and causing damage to the part. Since the machine was under heavy demand by other project teams, completion of the holes was not feasible with the HAAS and instead was forced to be completed using a drill press. This resulted in a change to the press fit roller pins in the final product that deviates from the actual part design. Due to the damage caused by the crashing of the drill, the holes for the center medial tab could not be drilled well since their placement is based on the placement of the outer tab holes as the drill must run through the outer tab to reach the inner tab. This fabrication issue will be addressed in the Future Work section to come. Due to misplacement of the holes caused by walking of the drill bit in the drill press, only pin holes for the anchor of the finger extension springs were used, leaving the tendon to wrap over the top of the knuckle bolt. While not a match for the current design, this scheme still mimics the function of the design since time was not available for re-fabrication of a new knuckle bar. An image of the Drilling operation can be seen below in Figure 52. 


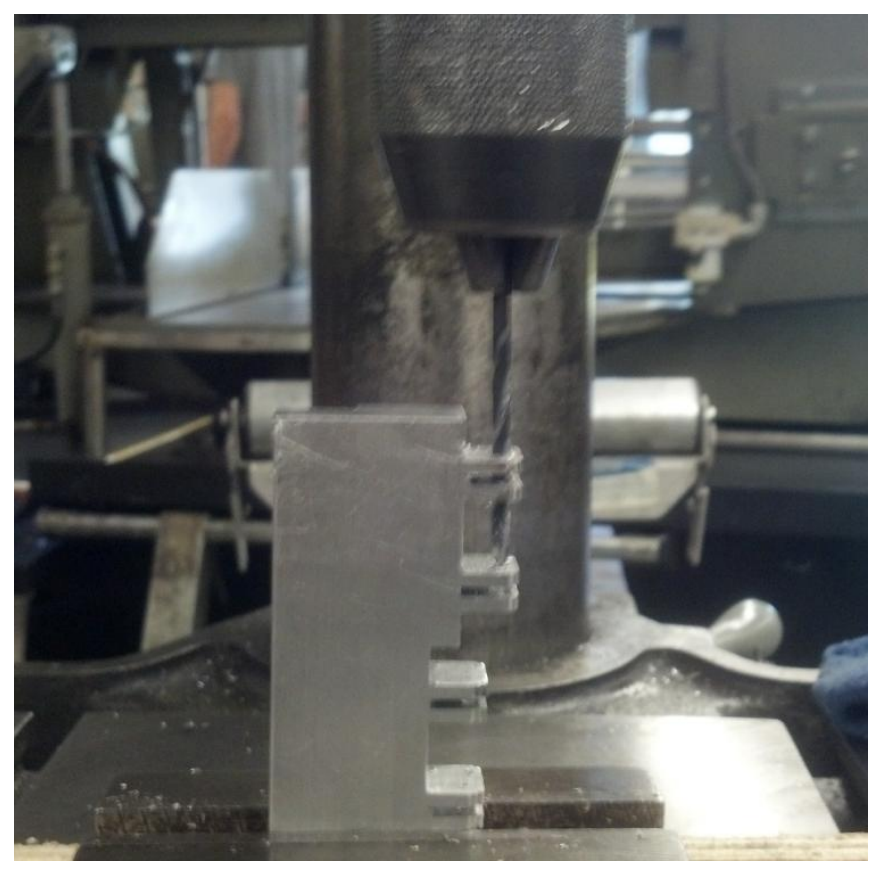

Figure 52: Knuckle Bar Hole Drilling Operation Fixturing

Once the holes were drilled, the knuckle bar was taken to a hand mill where the tab slots which will hold the Delrin rollers and the spring return system were cut wit the slotting saw mounted on an arbor collet as described in the Proximal Phalanx section.

With the holes drilled and deburred and the slots cut, Delrin rollers and pins were to be inserted into the part to create the final assembly knuckle assembly. As indicated in the drawing package in Appendix B, these press fit parts are required to be completed prior to sending off of any knuckle sections into the field since this process cannot be conducted outside the shop. Pins were cut to length using a Dremmel with a cut off wheel and a hand file to round any edges and for minor length modifications. The pin was then placed and pressed into place using pliers and a small C-Clamp. An image of the final knuckle bar can be seen below in Figure 53. 




Figure 53: Knuckle Bar Final Part

\section{4: Palm}

Manufacturing of the palm was straight forward and did not deviate from the initial plan. First, cut lines were sketched out on a piece of stock 1/8in sheet aluminum with calipers and a Tsquare. To create the shape, one side of the stock material was used as a datum and a vertical line was drawn 3.1in away from that edge to create the larger distal section. The total length of the part was also marked, creating a rectangle with the maximum dimensions. For the smaller proximal rectangle, .55 in was measured from each side to create the 2.0 in wide section which is meant to interface with the leather wrist strap. The total length of that section was measure and vertical lines were run from the proximal edge to that length. The edges of the distal and proximal sections were joined, creating the angled section. These lines can be seen below in Figure 54. 


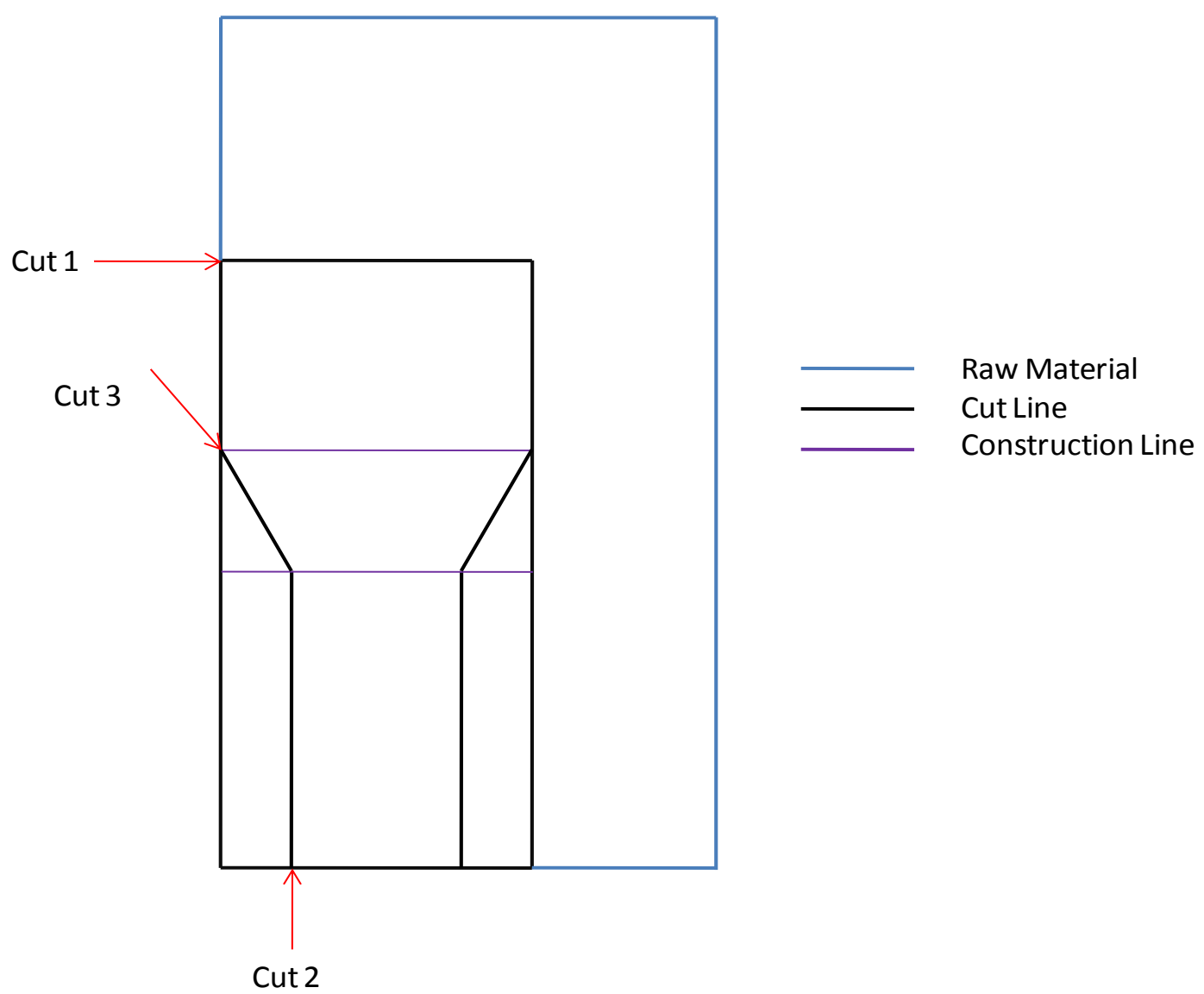

Figure 54: Palm Cut Line Layout and Cut Order

All cuts for the shape of the palm were carried out with a vertical band saw using a surface fixed parallel block to ensure cut lines were straight. First, the large outer rectangle was cut from the side of the raw material as indicated above by cut-line 1. Next, the lines which reduce the width of the proximal side were run up to the construction line marking the required length indicated by the cut 2 direction arrow. Last, the angled sides were created by starting the cut on the outer side at the end of the wide section at the distal end and running it toward the termination of cut-line 2 as indicated by the cut 3 arrow. This creates the general shape allowing for deburring, filleting, and final length alteration on a bench grinder.

Once the outer shape was created, the 8 holes at the distal end for connection of the palm and thumb attachment tab were laid out using calipers and a hole guide was created using a spring loaded center punch. This prevents the drill bit from walking sideways when the hole is started, 
keeping the hole tolerance in line when drilled with a drill press rather than a mill. Once these hole guides were finished, the part was inserted into the receiver sleeve of the leather wrist brace in order to map out the connection holes. These could not be generated using measurements since the leather brace was handmade and the connection holes were not awled into the leather with tolerances in mind. To create hole guides a pensile was used to mark the entire hole diameter on the metal using while it was within the leather brace. The palm plate was then removed and the center punch was used to create a hole guide in the center of the mark. The palm at this stage of fabrication can be seen below in Figure 55.

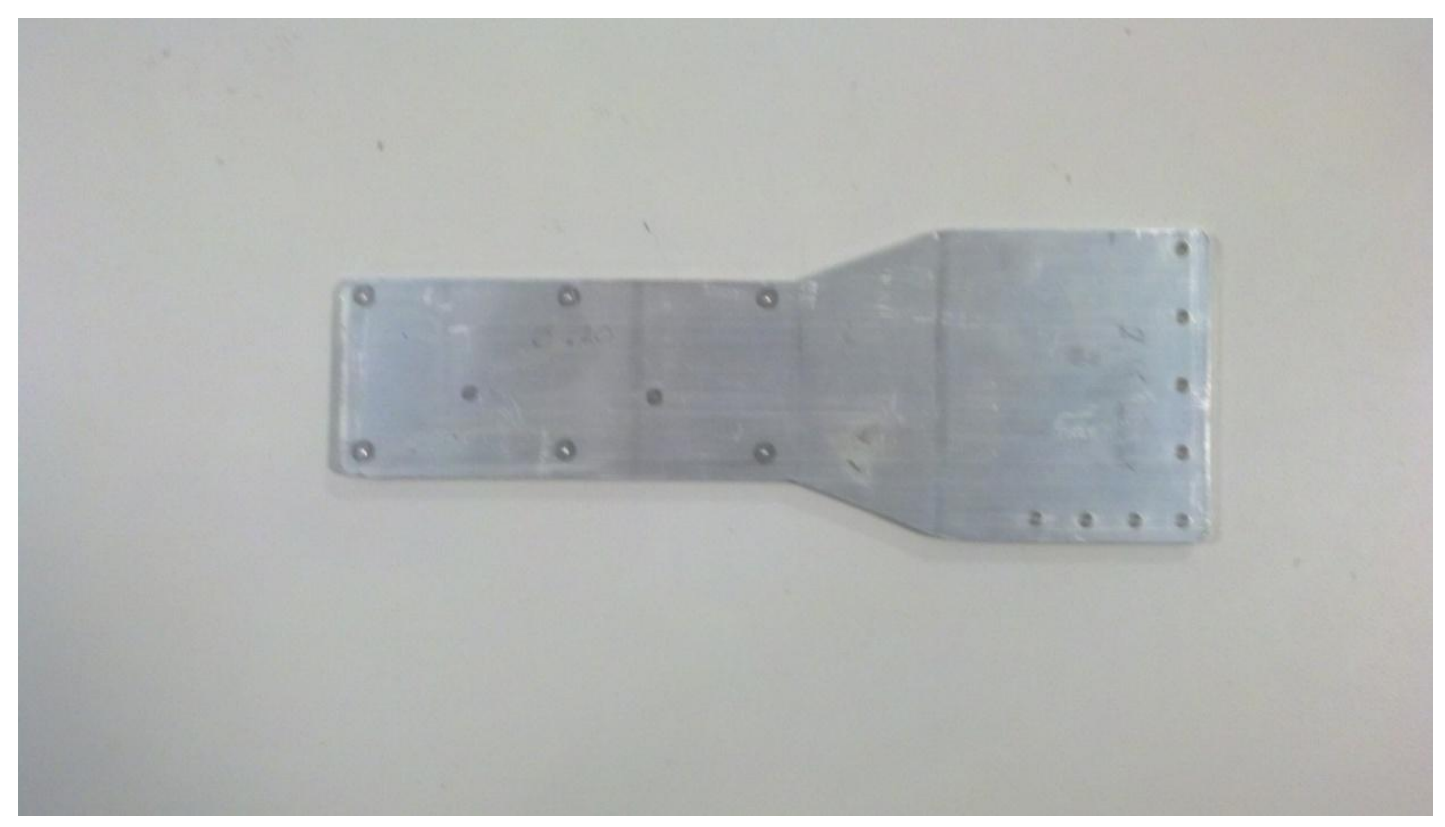

Figure 55: Palm with Distal Holes Drilled and Hole Guides for Leather Brace Attachment Laid Out

Once the eight bolt holes were drilled, counter bores were drilled over them with a 9/16 two flute end mill in order for the \#6-32 socket end cap screws being used to bolt the knuckle bar and thumb housing bracket in place to be seated into the part slightly. This minimizes the bolt foot print extending out from the top of the palm helping to reduce the chance that they will snag on something or interfere with the tendons which will run just over them. 


\section{5: Thumb Housing and Function}

Since the thumb mechanism from the previous iteration of the SEAL hand was used for this prototype, a simple mounting block was necessary to connect the thumb housing to the palm which interfaces with the custom leather wrist strap. This piece was unnecessary on the previous hand since the palm section was cut from a large piece of metal which encompassed a hanging bracket for the thumb housing and the knuckle attachment sites themselves. Since an important design consideration for this prototype was the ability for major components to be disassemblable, it was undesirable to have a permanent attachment tab fixed to the palm. In addition since welding the piece would have altered the strength in the heat affected zone, milling of a large block of raw material to create the tab would not only have been costly in machine time, tooling, and material, but a vast majority of the metal volume purchased would be cut away, wasting it.

Fabrication of this piece was straight forward and did not require the use of CNC operations. To start, $0.5 \times 0.5$ in stock bar stock was cut slightly long a horizontal band saw much like the start of the phalanx blanks. In keeping with the phalanx creation process, the part was then placed in a hand mill and faced such that the length was within tolerance. The side orthogonal to this length was then faced down to a width of .4 in as shown on the part drawing in the appendix. Upon completion of milling, the two 1/4in through holes were drilled perpendicular to the shorter side, and the three \#6-32 tapped holes were first drilled then tapped by hand. Rough edges were filed and the part was then bolted to the palm and the thumb housing was attached to the tab via the existing bolts from the last project iteration. An image of the final part can be seen below in Figure . 


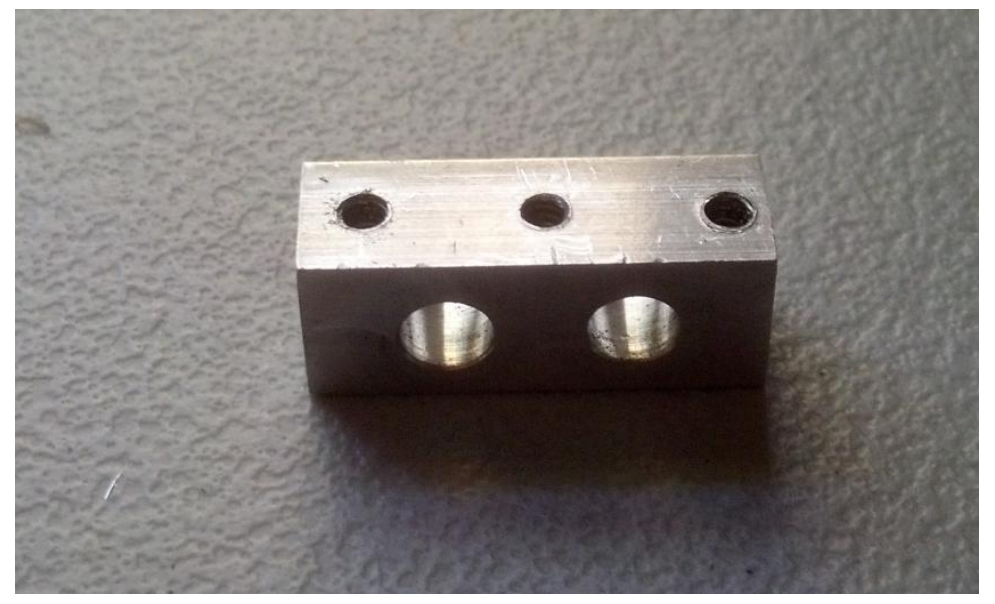

Figure 56: Thumb Housing Attachment Tab Final Part

\subsection{1: Tendon Control System}

The realization of the tendon control system turned out to be far different than conceptualized. While the initial design had merit, there were a few characteristics of the design that warranted a change. First among the issues is the ability to replace functioning components of the ratchet in the field. This is key since combat is a situation in which it is impossible to predict every situation and stress a component will endure, meaning things will break. To combat this, easily replaced components like the locking pawls were designed to be weaker than their surrounding mechanisms ensuring failure would occur there. This however does not account for situations in which stresses are applied in ways that do not occur from device use. For instance, if the devise gets pinned under rubble or takes a hit from enemy fire, even though failure was designed into specific components, these outside impacts could still likely destroy other parts. This is a major problem, especially for pieces like the ractchet gear - tendon drum part since these require a press fitting over a bearing to be operational and this type of repair cannot be undertaken in the field. 
Additionally, creation of replacement parts for the original mechanism design would be costly since they are almost entirely custom pieces, and their footprint when carried in a pack would be much larger than other off the shelf items that with alteration could be used to meet the design criteria.

For these reasons, it was decided to not pursue to ratchet design discussed above in the Design Concepts section. Instead, a tie down pulley mechanism was purchased to determine if it could be modified to work with the shoulder harness actuation of the prosthetic. This part has the advantage of being an easily accessible mass produced part with a small number of moving parts relative to the previous design thus reducing potential failure points, and would have a much smaller foot print not only on the device but as a replacement part in a pack. This part would also be easy to replace since it has only two connection points to the device; the tendons and cord which would anchor on the back of the devise and to the side, run through the pulley, then connect to the harness cable. This would create a mechanical advantage of 2:1 where the output tendon force would be double the force exerted on the device by the user. A concept image for this set up cab be seen below in Figure 57.

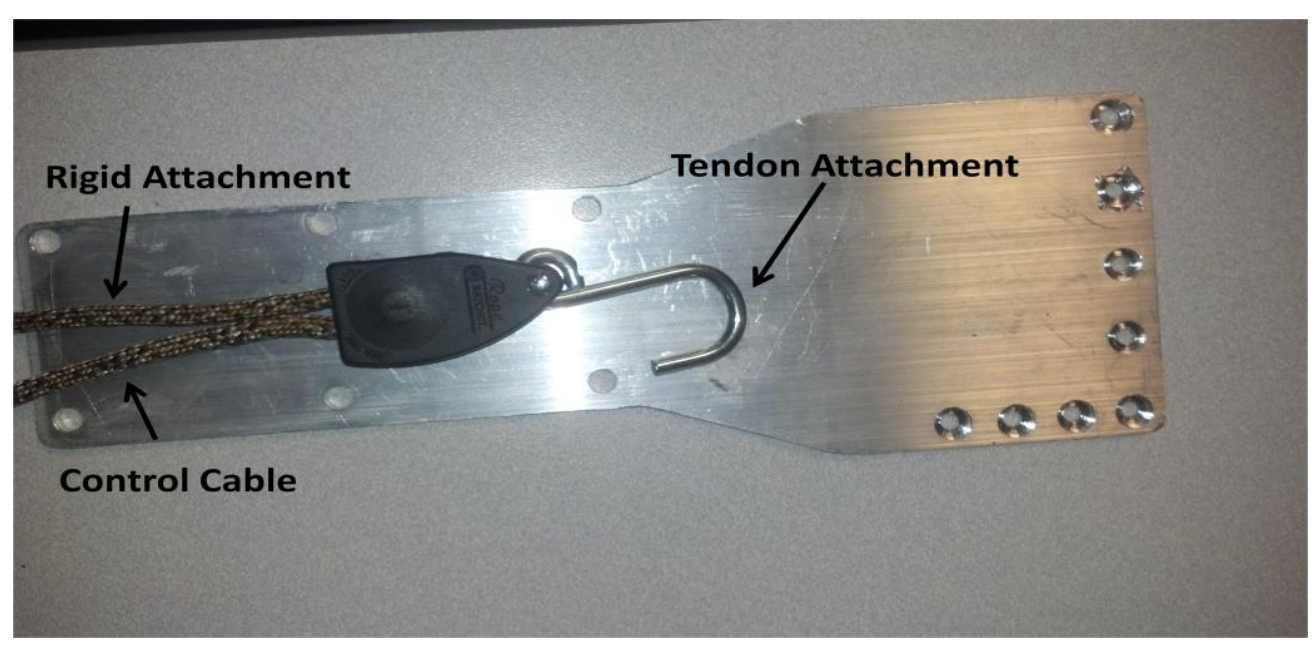

Figure 57: Pulley Concept for Tendon Control 
This particular ratchet uses beveled gripper gears to press a rope that comes with the devise against a lock plate preventing the rope from returning in the opposite direction. A small lever is depressed to release the lock, allowing the rope to freely move back in the opposite direction.

While this ratchet will produce a locking feature, it does not allow for subsequent shrugs to further continue finger flexion since the cable on the shoulder harness does not have the ability to reset its grip on the rope extending from the ratchet. Without this return function, when the shrug is relaxed the pull cable will simply go slack while the ratchet holds the finger at their current flexion amount. While useful for locking, this does not cover the full functionality that the original ratchet mechanism design covered, meaning a new mechanism had to be explored.

To rectify this problem, a different type of tie down was explored with consists of a come along ratchet the spins a spool drum with subsequent pulls on the ratchet lever. While this mechanism will not add the mechanical advantage of the pulley idea above, it will allow for a reset of the harness cable that will allow the user to reset their pull length, giving them more cable length to generate force with. Additionally, this style of ratchet also locks the tendons in place similar to the previous ratchet. An image of this ratchet can be seen below in Figure 58. Discussion of how the tendons will interface with this ratchet can be found below in section 5.6.3. 


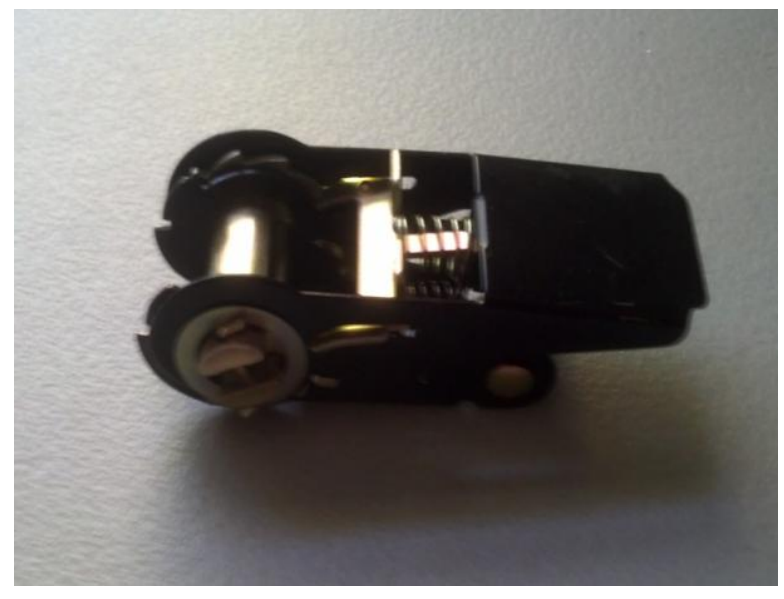

A) Ratchet in Closed State

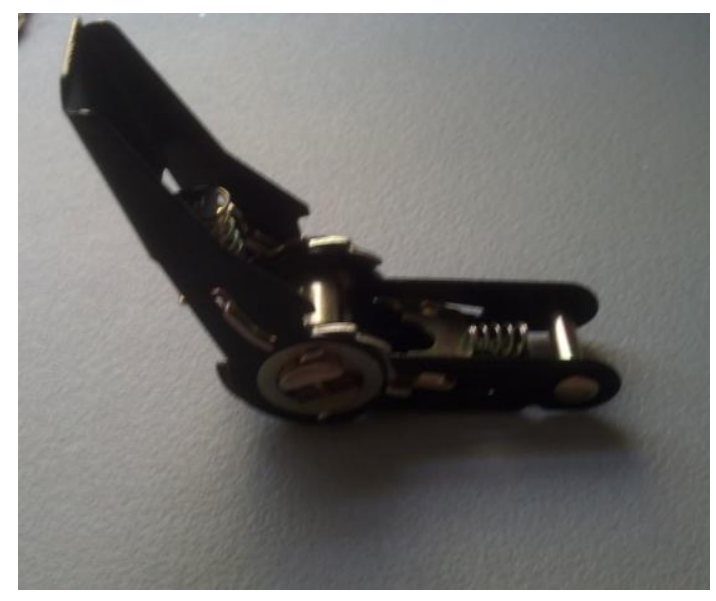

B) Ratchet in Opened State

Figure 58: Cyclic Tie Down Ratchet in Closed and Open States

\subsection{2: Ratchet Attachment Plate}

This ratchet must be fixed to the prosthetic to function since a rigid base from which to pull against is needed to move the spool. To do this, a plate was made using the same $1 / 8$ in material that the palm part is made from that goes over the top of the leather brace and uses the proximal four bolts securing the palm in place to fix it to the brace. An image of this part can be seen below in Figure 59. 


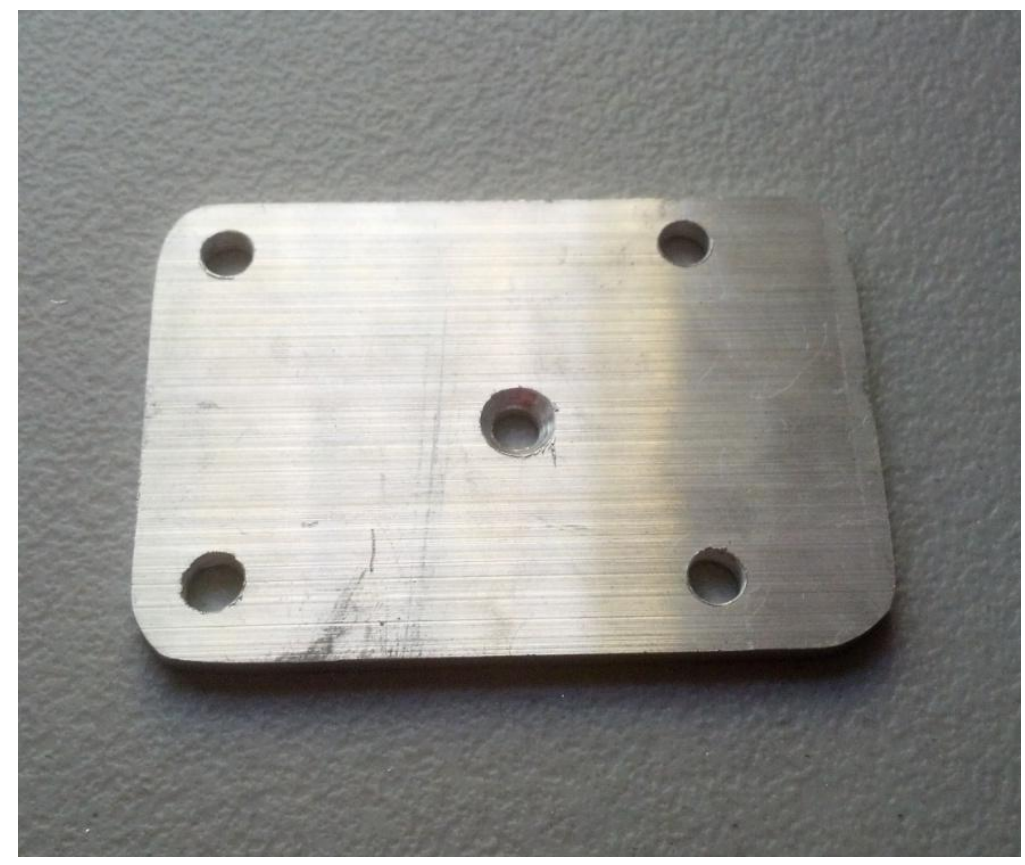

Figure 59: Tendon Ratchet Mounting Plate Final Part

\subsection{3: Tendon Material and Routing}

Based on results from the tendon tension model discussed previously, 100lb test line was chosen in order to ensure tensile failure will not occur for the expected range of tension in the tendon accounting for friction. Steel cable was considered for this application for its wear resistance and tensile strength, however degradation is worrisome based on the harsh outdoor environments the device might encounter. In addition, steel cable is not as easily bent and deformed meaning it will have more frictional losses from the finger to the ratchet and will be more difficult to route during replacement. For these reasons, fishing line was chosen for its resistance to damage during long exposure to aquatic environments. Multifilament spectra line was used since it does not elongate significantly under high loads and is more resistant to friction wear caused by rubbing on metallic parts. Additionally, this type of line is extremely easy to manipulate and work with and will not only take up less room in a pack than steel cable but can also be used in a survival situation if long coil is included in the repair package. 
For routing in the hand, a small loop of roughly 0.25 in diameter was created using double barrel fishing crimps cut with a Dremel to a relative thickness of 0.1 in. The line was pushed as close to itself as possible prior to crimping, and the section of crimp that was not containing any line was cut off to limit the footprint of the loop. An image of this loop can be seen below in Figure 60.



Figure 60: Multifilament Tendon with End Loop

This loop was then inserted into the tendon hole in the distal phalanx and anchored by inserting a \#5-40 machine screw into the most distal hole such that it goes through the loop in the tendon. It is then run through the proximal tendon hole, up through the knuckle interface, and run back to the ratchet. The end of the tendon was then run through the gap in the ratchet barrel and an automotive Dorman cable stop was fixed to the end exiting the ratchet drum. This cable stop allows the pretension of each tendon to be controlled individually. An image of the cable stops behind the ratchet can be seen below in Figure 61. 


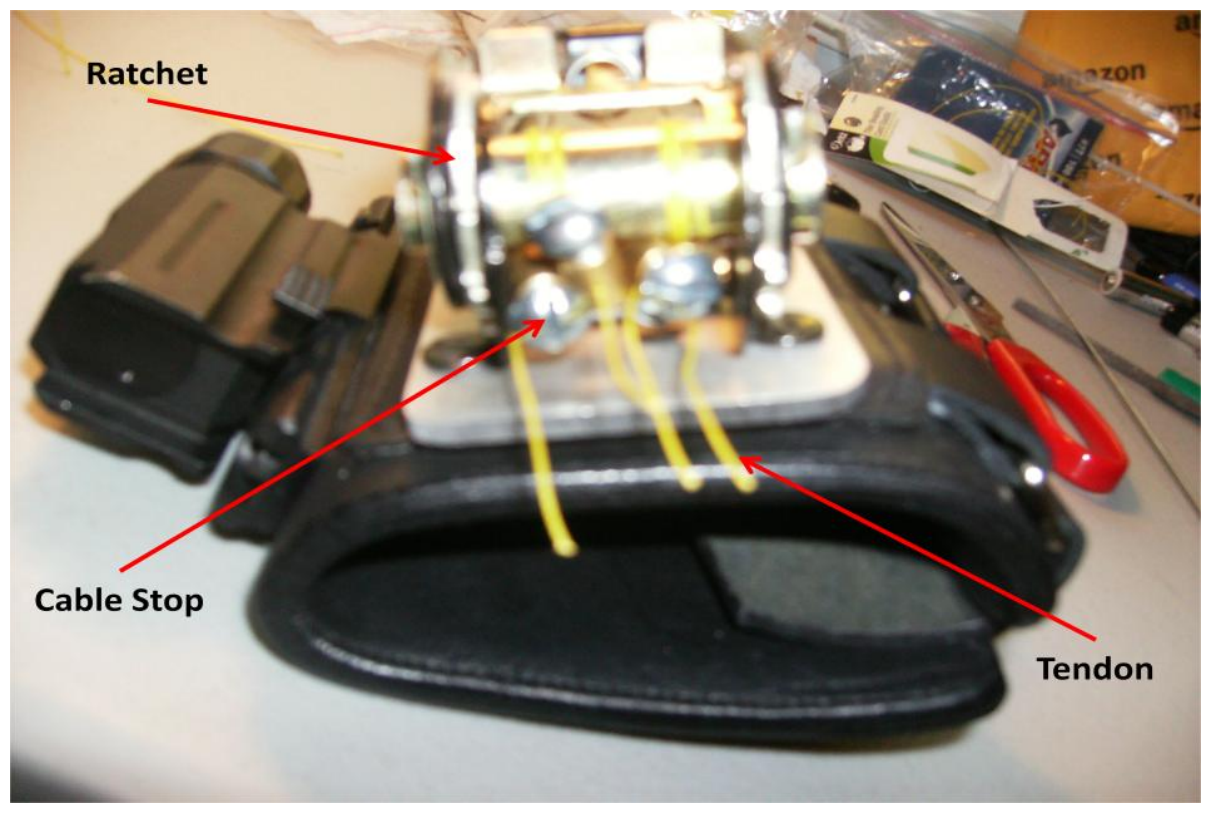

Figure 61: Cable Stops to Control Tendon Tension at the Ratchet

\section{7: Full Assembly and Construction Instructions}

Fully assembled, the hand can be seen below in Figure 62 .

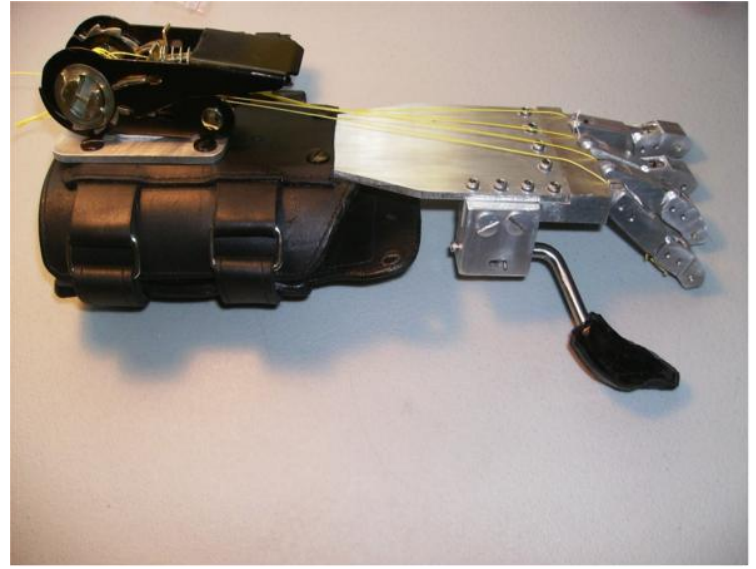

A

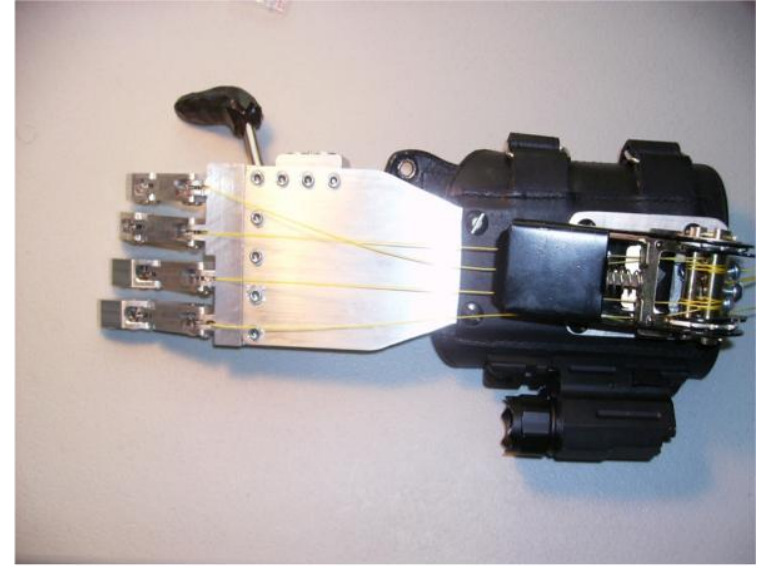

B

Figure 62: A) Complete Hand Prototype, Side View B) Complete Hand Prototype, Top View 
When fully disassembled, assembly order instructions are as follows:

1) Insert the proximal end of the palm plate into the receiver slot on the leather brace and line up the holes. Push the elevator bolts through the holes from within the brace with the blank head facing into the brace allowing the screw to be inserted from the top. Be sure to use the taller bolts on the proximal side in order to have post length for the ratchet plate. Insert screws into the distal two posts, leaving the proximal four blank as seem below in Figure 63.

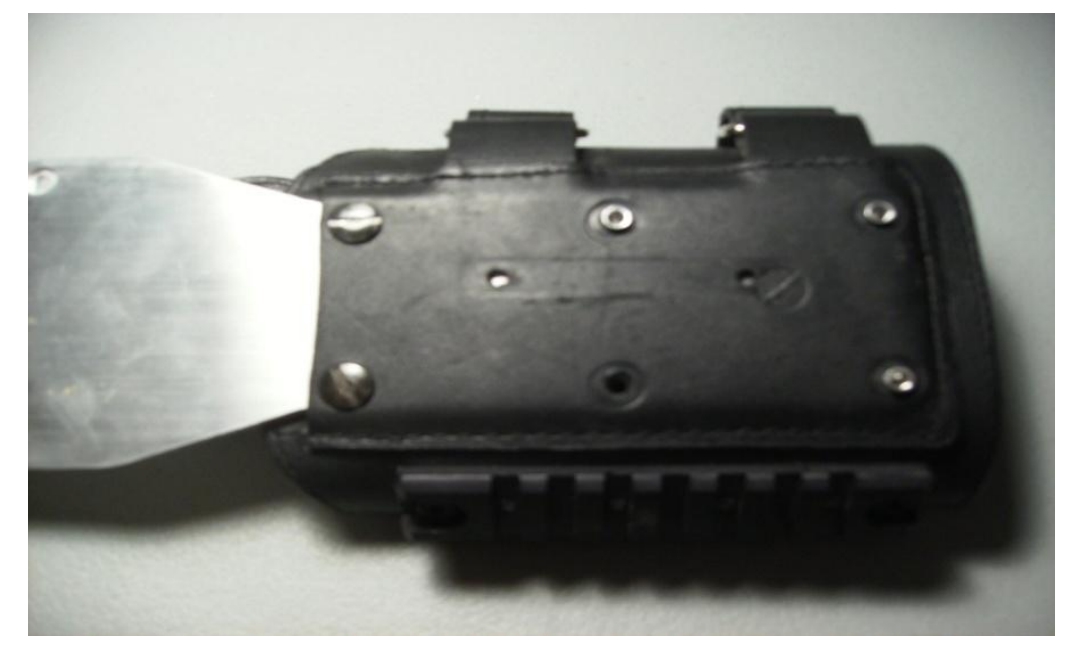

Figure 63: Palm Plate Attachment to Leather Brace

2) The ratchet plate center hole has a counter bore to allow the bolt that holds the ratchet down to sit flush with the plate surface. Insert the bolt through the hole and push the ratchet plate down onto the four exposed proximal posts with the head of the ratchet holder screw facing down into the leather. Insert the screws into posts to hold the ratchet plate and palm in place with the ratchet holder screw exposed facing up from the device as seen below in Figure 64. 


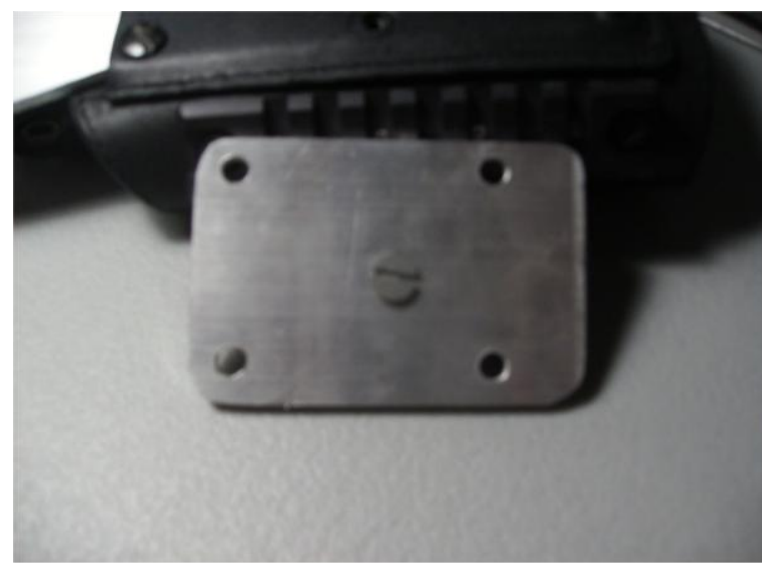

A

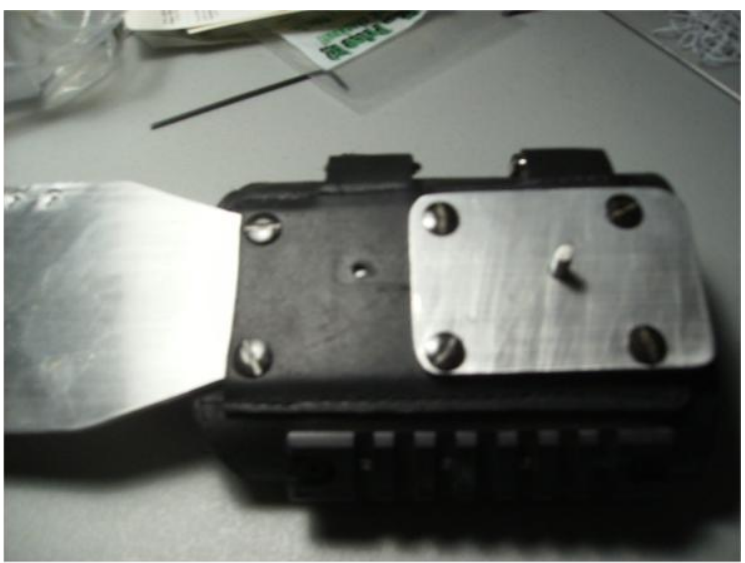

B

Figure 64: A) Ratchet Mounting Plate with Ratchet Mounting Screw Placed B) Ratchet Mounting Plate Fixed Above Palm Plate

3) Place the ratchet on top of the ratchet plate such that the lever faces forward on the hand and swings up and back when pulled. The pre-existing hole on the bottom surface of the ratchet is used for the ratchet holder bolt. Slip the ratchet over the bolt, thread the nut, and tighten it down fixing the ratchet in place.

4) Line up the thumb housing mounting tab with the medial holes on the palm and insert three \#6-32 cap screws. Tighten the screws to secure the tab An image of the parts together can be seen below in Figure 65.

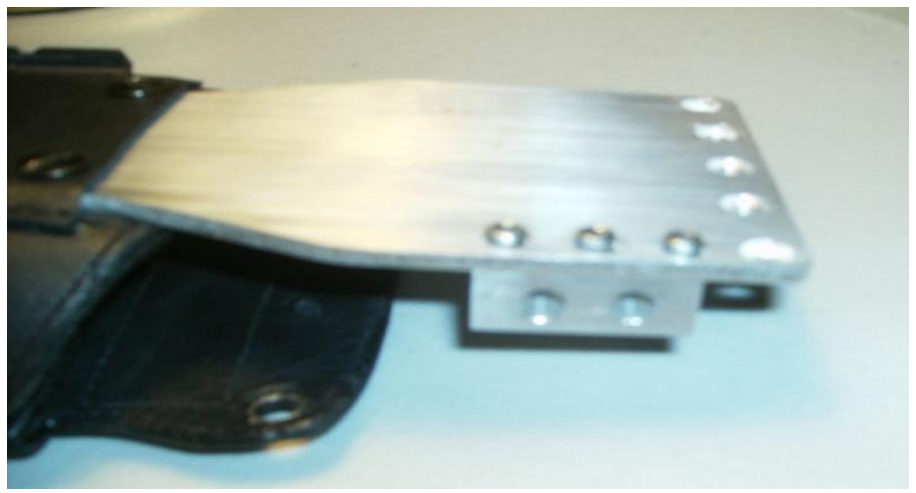

Figure 65: Thumb Housing Attachment Tab Connected to Palm

5) Line up the thumb housing mechanism from the previous project iteration with the two $1 / 4$ inch holes in the thumb housing attachment tab and push the elevator bolts through from 
the back such that the exposed threaded posts are exposed on the medial side of the device. Insert the screws into the posts and tighten with a screw driver to fix the thumb in place. The attached thumb can be seen below in Figure 66.

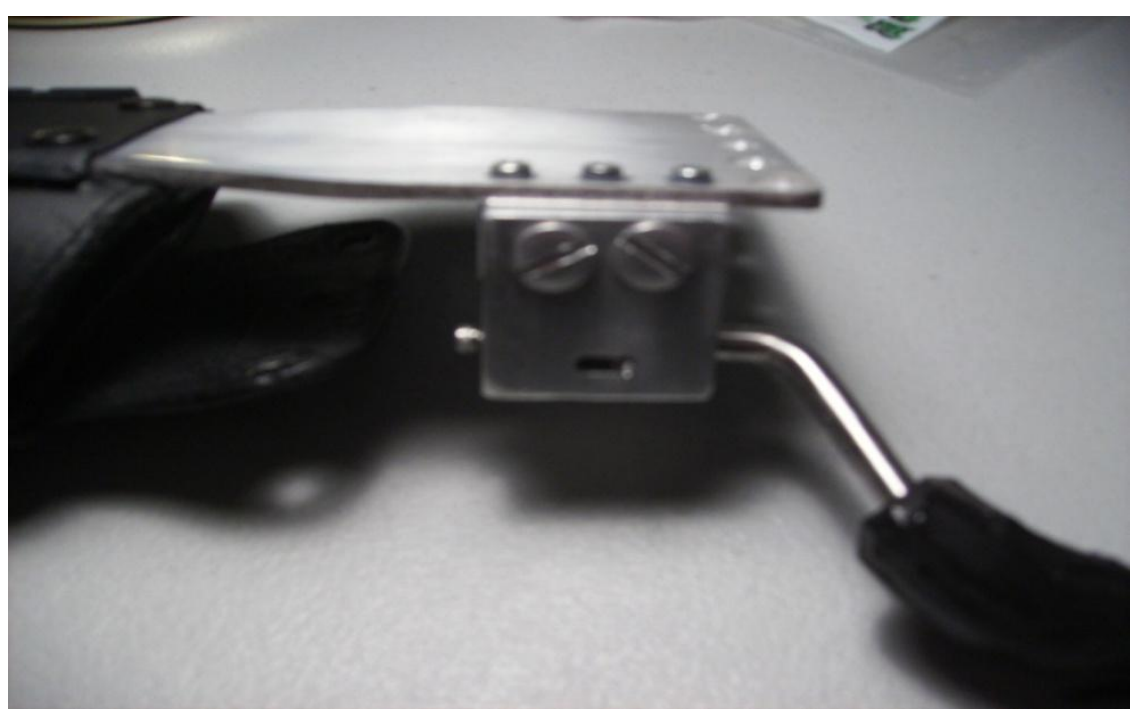

Figure 66: Thumb Mechanism from Previous Iteration Attached to Device

6) Prior to attaching the phalanges to the hand, assemble them with the following instructions:

a. Insert the looped end of a tendon into the tendon hole on a distal phalanx and push it to the end of the channel. If the loop does not open, insert a small object like a dental pick of pen into the tendon anchor hole to widen the loop to allow the anchor bolt to pass through. Insert a \#5-40 machine screw into the lateral side of the phalanx anchor hole and thread it into the other side such that the screw runs through the tendon loop, fixing it in place.

b. Run the exposed end of the tendon through the tendon routing hole on the proximal phalanx and pull it through such that the proximal phalanx attachment tab sits inside the distal phalanx attachment slot with the knuckle holes aligned. Insert a \#5-40 machine screw into the lateral side of the distal phalanx knuckle hole such that it passes through the proximal phalanx attachment tab and threads 
into the medial side of the distal phalanx. Tighten the screw ensuring that it is snug but that there is no binding of the phalanxes as them move relative to each other.

c. Place one loop of the elastic extension band in line with the remaining hole on the distal phalanx such that the loop is inside the attachment gap. Push a \#5-40 machine screw into the extension hole on the lateral side such that it passes through the loop of the elastic extension band but does not come into contact with the threaded medial side. Pass the loop over the press fit pin in the top of the proximal phalanx attachement tab the through the slot allowing it to exit below the pin and running toward the extension hole on the distal phalanx. Pass the remaining loop over the exposed screw such that it is anchored in the same way as the first loop. Thread the screw into the medial side of the distal phalanx, fixing the elastic extension band in place such that it stretches when the phalanxes bend relative to each other in a flexion motion.

d. Repeat steps 'a' through 'c' for the remaining three phalanges, creating four identical sets. An image of the phalanxes attached can be seen below in Figure 67.

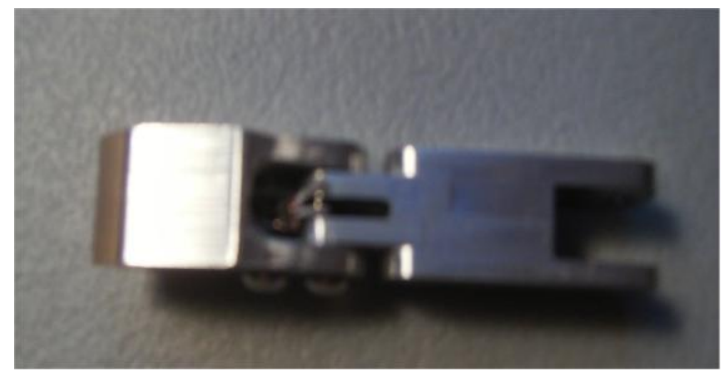

A

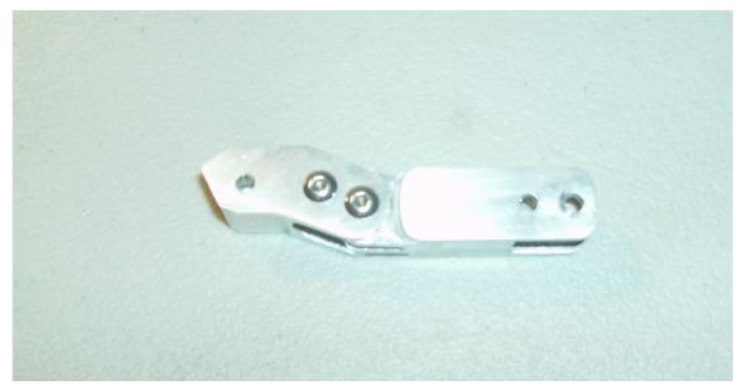

B

Figure 67: A) Assembled Phalange Top View B) Assembled Phalange Side View

7) With the phalanges assembled, attachment of the phalanges to the knuckle bar can occur. Finger must be attached medial to lateral due to how the attachment tabs on the knuckle 
bar are situated. In order to seat the knuckle screw, insert a shortened \#5-40 machine screw into the lateral side of the proximal phalanx such that the end of the screw does not extend past the tab. Push the phalange onto the knuckle bar attachment tab and line up the knuckle holes with the screw head up against the adjacent tab. Once the holes align, push the screw through the hole and up to the threads. Using an alan wrench, tighten the screw by inserting the wrench through the knuckle hole on the adjacent tab such that the wrench lines up with the screw. Attachment of the medial phalange can be seen below in Figure 68.

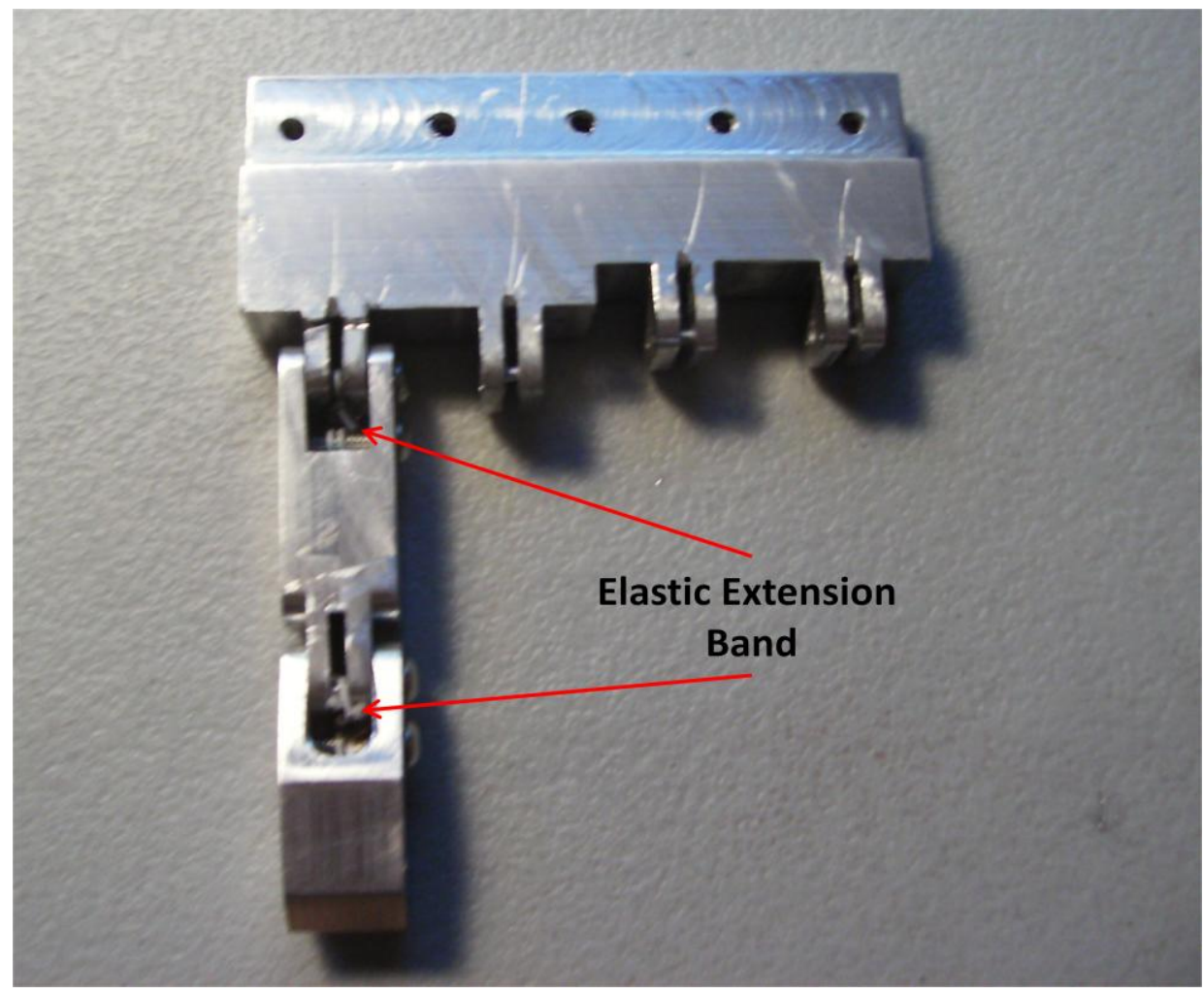

Figure 68: Medial Phalange Attached to Knuckle Bar

8) Run elastic extension bands in the same way they were run on the phalanges in part 6 a.b, and c. The completed knuckle bar / phalange interfacing can be seen below in Figure 69 . 




Figure 69: Phalanges Attached to Knuckle Bar

9) Line up the knuckle bar attachment slot with the palm attachment holes and insert five \#6-32 cap screws and tighten them to fix the knuckle bar to the palm.

10) With the extension elastic placed and the phalanges screwed in place, run the tendons under the bottom roller and around the top roller such that the tendon exits the top of the knuckle bar and avoids the knuckle screw.

11) Run the tendons back along the palm and through the ratchet drum gap and out the back side of the ratchet. Push the end of the tendon through the cable stop hole and push the stop up the tendon and up against the ratchet drum. Pull the tendon taught until the phalange is in a desirable position and tighten the tension screw on the cable stop to lock the tendon in place against the cable stop. An image of the tendons exiting the knuckle channels can be seen below in Figure 70 . 


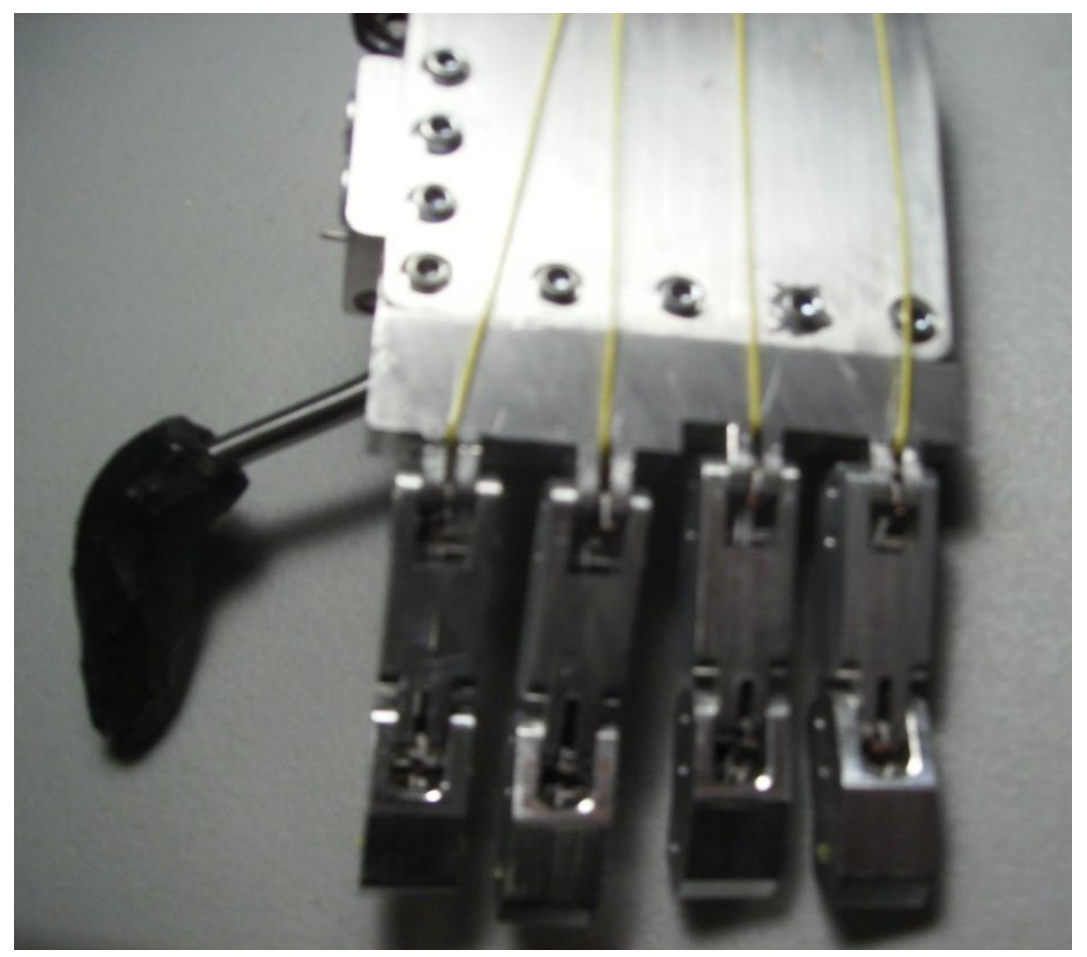

Figure 70: Tendons Run Through Knuckle Bar once it was Attached to the Assembly 


\section{Chapter 6: Future Work}

In the process of prototyping and testing the design discussed in this document, a few changes have been considered that there was no time to implement into the project before the end date. Discussion of these future changes to the current design will be discussed in the following sub sections.

\section{1: Knuckle Bar Redesign}

As discussed in the Knuckle Bar section above, the drilling of holes on the inner tabs was reliant on the holes being placed well on the outer tab since the bit was required to travel through the outer tab holes to reach the inner tab. This is a poor design choice since for the small pin holes, the drill bit has a tendency to wobble causing the holes to be positioned incorrectly and the hole to be off perpendicular. Additionally, having the knuckle bar as one piece reduces the reparability of the knuckles as a whole and makes attachment of the finger difficult. By splitting the knuckle bar into multiple pieces that bolt to together prior to bolting to the palm, the hole positioning problem is alleviated while allowing individual knuckles to be replaced without replacing the whole piece. It is recommended in future iterations to individual parts for the knuckle bar attachments. This shift in knuckle design will eliminate the need to attach the phalanges from medial side to lateral side as discussed in the assembly instructions. This is ideal since it prevents the need to remove all the phalanges from the device in the event that the most medial phalange happens to be the one that breaks.

\section{2: Finite Element Model Alteration}

As discussed in the finite element model section, the strength induced by the press fit steel pins was not accounted for in the model causing it to predict failure at a lower force than what was seen experimentally. Inclusion of these pins and how they interact with the proximal 
phalanx and knuckle attachment tab in the model should be undertaken to determine if they are indeed the cause of the added stiffness.

\section{3: Tendon Control System Testing and Completion}

The ratchet used for this prototype is much larger than the ratchet envisioned for the final product. Additionally, the finesse style fingers where the tendon is linked directly to the shoulder harness control cable was not implemented in this prototype. A smaller ratchet should replace the current ratchet and an additional attachment point on the control cable should be added for direct connection of the tendons. The smaller ratchet is important since the large model will have a higher chance of snagging on clothing or things in the environment the challenger might be in, causing a potential for hampering his movements. Use of a snow board binding ratchet or similar commercially available option is currently the best option for replacement of the prototype ratchet. This type of ratchet is already designed for outdoor environments and has a return spring built into it for lever return.

It is important to ensure the ratchet will move the strap in the correct direction. The currently possessed bindings ratchet causes the strap to move forward when the ratchet is oriented as it would be mounted on the hand such that the shoulder cable would pull the ratchet lever back. This type of ratchet would also bring the line of action of the tendons closer to the palm plate. By altering the pulley system in the knuckle bar such that the tendon runs straight back through the knuckle through a hole similar to the routing hole in the proximal phalanx which will run the tendon underneath the palm. Angled routing holes can then be into the palm to allow for the tendons to move above the palm gradually, eliminating the sharp change in height caused by the current roller design in the knuckle bar. The elimination of this sharp transition will also greatly reduce friction in the system, reducing the necessary shoulder harness tension. Additionally, this will protect the tendons from above since they are currently exposed from above. Prior to this 
implementation however it is critical that verification that this alteration will not interact with the user's residual limb which would

\section{4: Phalange Assembly and Replacement}

Assembly of the phalanges and attaching them to the knuckle bar during assembly of the hand revealed a great deal about flaws in the design. From initial brainstorming, key design considerations for the product were the user's ability to replace parts on the device in a quick manner and individually in the field. When assembling the device, it became very apparent that the extension bands are too small to manipulate easily even with two hands at a table with a light source and not in the wilderness. Going along with the discussion of splitting up the knuckle bar into individual components, it became apparent that the phalange with the extension method and tendon routing should go to the user pre assembled. This will also allow broken phalanges to be replaced individually without the removal of any other phalanges unlike current disassembly laterally to medially due to the one piece knuckle.

By having the phalange pre assembled, the user will be able to easily replace the broken component with just a simple set of screw driver and hex tools that will most likely be in their tool package anyway. While this will cause an increase in the volume requirement for carrying extra parts, it is crucial for total function of the device.

\section{5: Phalange Extension Method}

Phalange extension in the original design was accomplished by extension springs with outer diameter of 0.062in to fit inside the 0.072in slot in the knuckle attachment tab and the 
attachment tab on the proximal phalanx. The main reason the springs were eliminated in favor of the elastic band method discussed previously was due to the difficulty in replacing the springs in the field with one hand. Once completed, it was determined that the elastic design suffered from the same shortcoming as the springs. Additionally, the elastic method was not strong enough as built to support both the proximal and distal phalanx at the knuckle bar. This could be rectified by shortening the total length of the band for the knuckle bar band, however this additional prestretch will reduce the fatigue life of the band enormously since the stress range of the band will be much higher. For this reason it is recommended that the extension spring design be revisited, especially in light of the previously discussed recommendation that the phalange system come as a single unit.

The springs originally purchased for this purpose were off the shelf parts keeping with the goal of only using parts that are easily obtainable for better replacability. Unfortunately, there is not a large selection of springs with 0.062 in outer diameter such that the unstretched length of the spring is similar to the distance between the attachment points when the phalange is in extension. It is recommended that a more thorough search of spring be undertaken, and if necessary ordering of custom sized springs to suit the hand geometries. It would also be beneficial to conduct fatigue life studies on potential springs to ensure adequate life expectancy if the equipment is available to do so.

An additional option that has not yet been explored for this device which can be used to cause phalange extension after the release of tension on the tendons are sealed gas pistons. These can be made in very small sizes and used hydraulic force to return the piston back to steady state once a deflecting force is removed. This type of solution is desirable due to the highly customizable nature of the piston such that spring constant can be altered simply by changing the static volume and pressure of the fluid within the cylinder. Additionally, this type of mechanism is built to withstand an enormous number of cycles, making it ideal from a fatigue perspective 
when considering the large length change necessary for phalange flexion and extension when compared to both springs and elastic.

\section{6: Hyper-extension Blocks}

The design had hyper-extension blocks intentionally left out in order to allow the user to force hyper-extension of the finger in order to get them around large objects. This is similar to how natural finger can slightly hyper-extend at the most proximal knuckle. Once the device was assembled, it was determined that the extension mechanism could not be finely tuned enough for the phalanges to sit at 180 degrees at steady state. For this reason, semi rigid hyper-extension blocks are recommended. This will prevent the phalanges from opening to far due to the extension springs, but will allow them to be forced open slightly more by the user. This could be accomplished using a small sheet of metal that is rigid enough to withstand the force exerted by the extension springs but will deform in the elastic region when pushed to allow slight hyperextension without ruining the block. 


\section{Works Cited}

[1] S.-y. Jung, S.-k. Kang and I. Moon, "Design of Biomimetic Hand Prosthesis with Tendondriven Five Fingers," in 2nd Biennial IEEE/RAS-EMBS International Conference on Biomedical Robotics and Biomechatronics, Scottsdale Arizona USA, 2008.

[2] H.-M. Schmidt and U. Lanz, Surgican Anatomy of the Hand, Thieme, 2003.

[3] "ASSH Hand Anatomy," American Society for Surgury of the Hand, 2009. [Online]. Available: http://www.assh.org/Public/HandAnatomy/Pages/default.aspx.

[4] D. H. Plettenburg, "Basic Requirements for Upper Extremity Prostheses: The Wilmer Approach," in 20th Annual International Proceedings IEEE Engineering in Medicine and Biology Society, 1998.

[5] N. M. Lopez, F. di Sciascio, C. M. Soria and M. E. Valentinizzi, "Robust EMG sensing system based on data fusion for myoelectric control of a robotic arm," BioMedical Engineering OnLine, 2009.

[6] C. Pylatiuk, S. Schulz and L. Doderlein, "Results of an Internet Survey of Myoelectric Prosthetic Hand Users," Prosthetics and Orthotics International, vol. 4, no. 31, pp. 362-370, 2007.

[7] J. Yang, E. P. Pitarch, K. Abdel-Malek, A. Patrick and L. Lindkvist, "A multi-fingered hand prosthesis," Mechaniosm and Machine Theory, vol. 39, pp. 555-581, 2004.

[8] G. Smit, R. M. Bongers, C. K. Van der Sluis and D. H. Pletternburg, "Efficiency of voluntary opening hand and hook prosthetic devices: 24 years of development?," JRRD, vol. 49, pp. 523-534, 2012.

[9] R. Doshi, C. Yeh and M. LeBlanc, "The Design and Development of a Gloveless Endoskeletal Prosthetic Hand," Rehabilitation Research and Development, vol. 35, no. 4, pp. 388-395, 1998.

[10] H. de Visser and J. L. Herder, "Force-directed design of a voluntary closing hand prosthesis," Journal of Rehabilitation Research and Development, vol. 37, no. 3, pp. 261271, 2000.

[11] T.E. Company, Ergonomic Design for People at Work, Wiley, 2003. 
[12] T. Bionics, iLimb Ultra Service and Fitting Manual, Touch Bionics INC, 2011.

[13] R. INC, "BeBionic 3," RSLSteeler, March 2013. [Online]. Available: http://bebionic.com/the_hand.

[14] O. B. inc, Otto Bock Upper Extremity Prosthesis Catalog, Otto Bock Inc, 2013. 
Appendix A: Bill of Materials

\begin{tabular}{|c|c|c|c|}
\hline Part Description & Unit Price & Units & $\begin{array}{l}\text { Total } \\
\text { Cost }\end{array}$ \\
\hline Multipurpose Aluminum (Alloy 6061) 1/8" Thick, 6" Width, 3' Length & $\$ 26.78$ & 1 & $\$ 26.78$ \\
\hline $\begin{array}{l}\text { Multipurpose Aluminum (Alloy 6061) 1/2" Thick X 3/4" Wide X 6' } \\
\text { Length }\end{array}$ & $\$ 24.53$ & 1 & $\$ 24.53$ \\
\hline Multipurpose Aluminum (Alloy 6061) 1/2" Square, 6' Length & $\$ 14.88$ & 1 & $\$ 14.88$ \\
\hline $\begin{array}{l}\text { Multipurpose Aluminum (Alloy 6061) 1/2" Thick X 1-1/4" Width X } 3 \text { ' } \\
\text { Length }\end{array}$ & $\$ 20.26$ & 1 & $\$ 20.26$ \\
\hline $\begin{array}{l}\text { White Delrin }{ }^{\circledR} \text { Acetal Resin Tube Tight-Tol. 1/8" OD X 1/16" ID, 3' } \\
\text { Length }\end{array}$ & $\$ 3.30$ & 1 & $\$ 3.30$ \\
\hline Miniature 12L14 Drive Steel Shaft 1/16" OD, 24" Length & $\$ 13.29$ & 1 & $\$ 13.29$ \\
\hline $\begin{array}{l}1045 \text { Medium Carbon Steel High-Strength Rod 1/8" Diameter, 3' } \\
\text { Length }\end{array}$ & $\$ 12.57$ & 1 & $\$ 12.57$ \\
\hline $\begin{array}{l}\text { Arbor for Slitting Cutter 1/2" Shank Dia for 1/2", 5/8", 3/4", 7/8", 1" } \\
\text { Hole Dia }\end{array}$ & $\$ 29.57$ & 1 & $\$ 29.57$ \\
\hline $\begin{array}{l}\text { 18-8 SS Button Head Socket Cap Screw 5-40 Thread, 1/2" Length, } \\
\text { Packs of } 50\end{array}$ & $\$ 3.07$ & 1 & $\$ 3.07$ \\
\hline $\begin{array}{l}\text { General Purpose High-Speed Steel Hand Tap Taper, 5-40, H2 Pitch } \\
\text { Diameter, } 3 \text { Flute }\end{array}$ & $\$ 6.13$ & 1 & $\$ 6.13$ \\
\hline $\begin{array}{l}\text { Gen Purp Black-Oxide HSS Jobbers' Drill Bit Wire GA 30, 2-3/4" Oal, } \\
\text { 1.4" Drill Depth, 135Deg Point }\end{array}$ & $\$ 1.56$ & 2 & $\$ 3.12$ \\
\hline $\begin{array}{l}\text { Gen Purp Black-Oxide HSS Jobbers' Drill Bit Wire GA 29, 2-7/8" Oal, } \\
\text { 1.5" Drill Depth, 135Deg Point }\end{array}$ & $\$ 1.56$ & 2 & $\$ 3.12$ \\
\hline $\begin{array}{l}\text { Gen Purp Black-Oxide HSS Jobbers' Drill Bit Wire GA 53, 1-7/8" Oal, } \\
0.8 " \text { Drill Depth, } 135 \text { Deg Point }\end{array}$ & $\$ 1.56$ & 2 & $\$ 3.12$ \\
\hline Powerpro Braided Line 150 -Yard Yellow - 100Lb Test & $\$ 19.99$ & 1 & $\$ 19.99$ \\
\hline $\begin{array}{l}\text { American Fishing Wire Double Barrel Crimp Sleeves, Black Color, } \\
\text { Size 7F8, } 0.068 \text {-Inch Inside Diameter, 25-Pieces }\end{array}$ & $\$ 7.99$ & 1 & $\$ 7.99$ \\
\hline $\begin{array}{l}\text { Music Wire Extension Spring, Steel, Inch, 0.063" OD, 0.011" Wire } \\
\text { Size, 0.25" Free Length, 0.34" Extended Length, } 1.09 \text { lbs Load } \\
\text { Capacity, } 11.1 \mathrm{lbs} / \mathrm{in} \mathrm{S}\end{array}$ & $\$ 23.21$ & 1 & $\$ 23.21$ \\
\hline \multirow[t]{2}{*}{ Invincible Marine 6-Foot Ratchet Tie Down Straps, 2-Pack } & $\$ 12.69$ & 1 & $\$ 12.69$ \\
\hline & \multicolumn{2}{|c|}{ California Sales Tax } & $\$ 15.93$ \\
\hline
\end{tabular}

TOTAL

$\$ 243.55$ 


\section{Appendix B: Drawing Package}
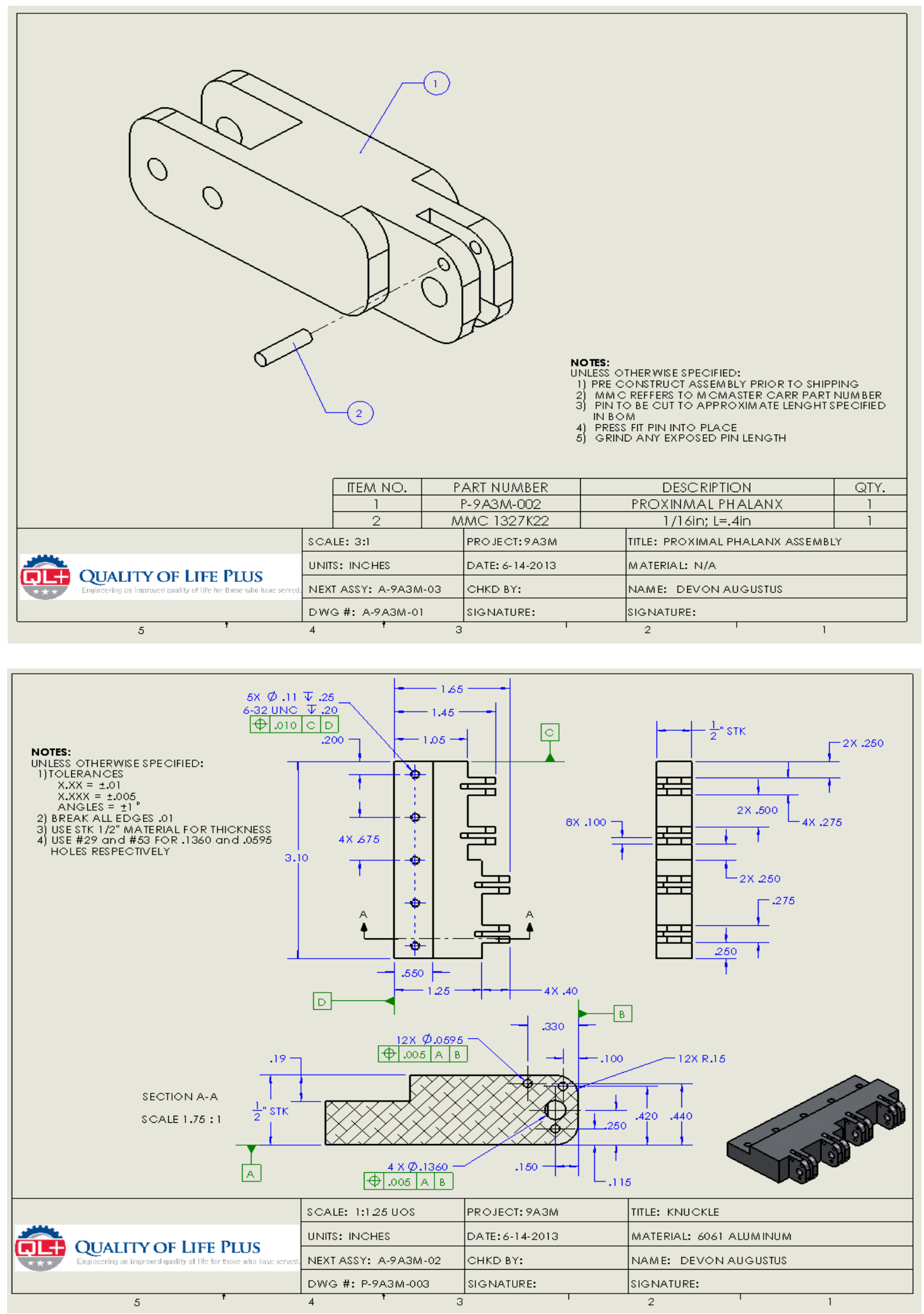


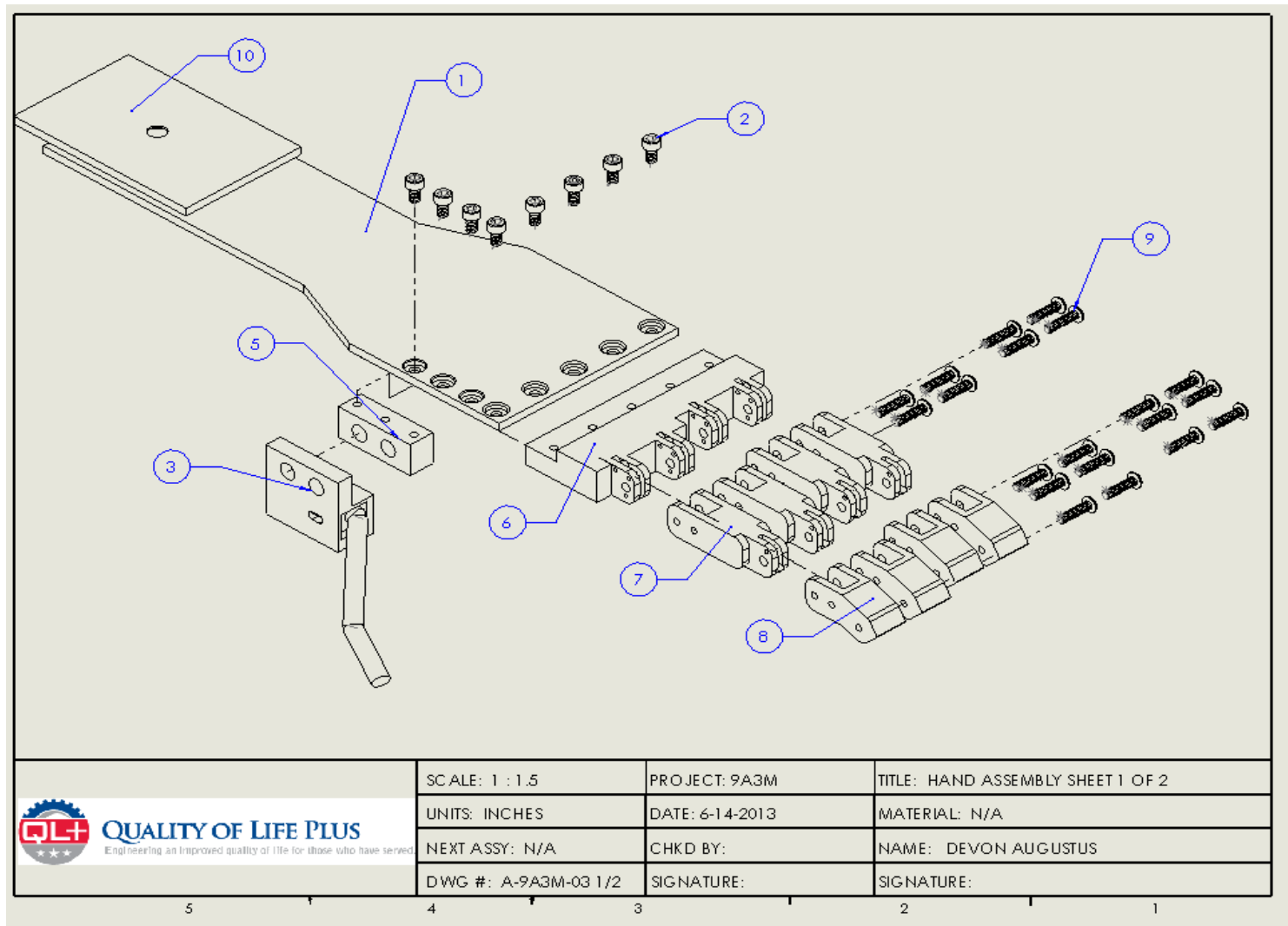

\begin{tabular}{|c|c|c|c|c|c|c|}
\hline \multirow{12}{*}{\multicolumn{2}{|c|}{$\begin{array}{l} \\
\text { NOTES: } \\
\text { UNLESS OTHERWISE SPEC } \\
\text { 1)THUMB PART DRAWIN } \\
\text { PROJECT: NAVYSEAL } \\
\text { 2) MMC REFER TO MC } \\
\text { 3) USE ELEVATOR BOLTS } \\
\text { FIX THUMB HOUSING }\end{array}$}} & $\begin{array}{l} \\
\text { D: } \\
\text { AVALIBLE FRO } \\
\text { NDER CARR PA } \\
\text { STM CAREVIOUS } \\
\text { THE PTTACHM }\end{array}$ & $\begin{array}{l} \\
\text { M PREVIOUS } \\
\text { RT NUMBER } \\
\text { PRO JECT TO } \\
\text { ENT TAB }\end{array}$ & 0 & 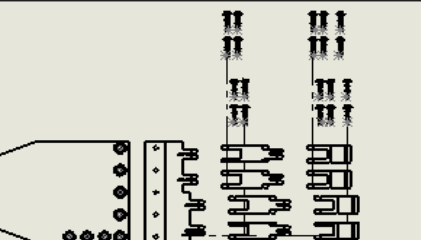 & \\
\hline & & IEM NO. & \multirow{2}{*}{\multicolumn{2}{|c|}{$\begin{array}{c}\text { PART NUMBER } \\
\text { P-9A3M-004 }\end{array}$}} & DESCRIPTION & QTY. \\
\hline & & 1 & & & PALM & 1 \\
\hline & & 2 & \multicolumn{2}{|c|}{ MMC $91251 \mathrm{~A} 144$} & \#6-32 SOCKET SCREW & 8 \\
\hline & & 3 & \multicolumn{2}{|c|}{ 1A2-P-011 } & THUMB HOUSING & 1 \\
\hline & & 4 & \multicolumn{2}{|c|}{$1 \mathrm{~A} 2-\mathrm{P}-012$} & THUMB BAR & 1 \\
\hline & & 5 & \multicolumn{2}{|c|}{ P-9A3M-005 } & THUMB HOUSING ATTACHMENT TAB & 1 \\
\hline & & 6 & \multicolumn{2}{|c|}{ A-9А $3 M-02$} & KNUCKLE ASSEMBLY & 1 \\
\hline & & 7 & \multicolumn{2}{|c|}{ A-9A3M-01 } & PROXIMAL PHALANX ASSEMBLY & 4 \\
\hline & & 8 & \multicolumn{2}{|c|}{ P-9A3M-001 } & DISTAL PHALANX & 4 \\
\hline & & 9 & \multicolumn{2}{|c|}{ MMC $92949 \mathrm{~A} 135$} & \#5-40 .5in MACHINE SCREW & 20 \\
\hline & & 10 & \multicolumn{2}{|c|}{ P-9 A3M-006 } & RATCHET MOUNTING PLATE & 1 \\
\hline \multirow{4}{*}{\multicolumn{3}{|c|}{$\frac{2+2}{4 ! *}$}} & SCALE: $1: 4$ & \multicolumn{3}{|c|}{ TITLE: HAND ASSEMBLY SHEET 2 OF 2} \\
\hline & & & UNITS: INCHES & DATE: $6-14-2013$ & MATERIAL: N/A & \\
\hline & & & NEXT ASSY: N/A & CHKD BY: & NAME: DEVON AUGUSTUS & \\
\hline & & & DWG \#: A-9 A3M-03 2/2 & SIGNATURE: & SIGNATURE: & \\
\hline
\end{tabular}



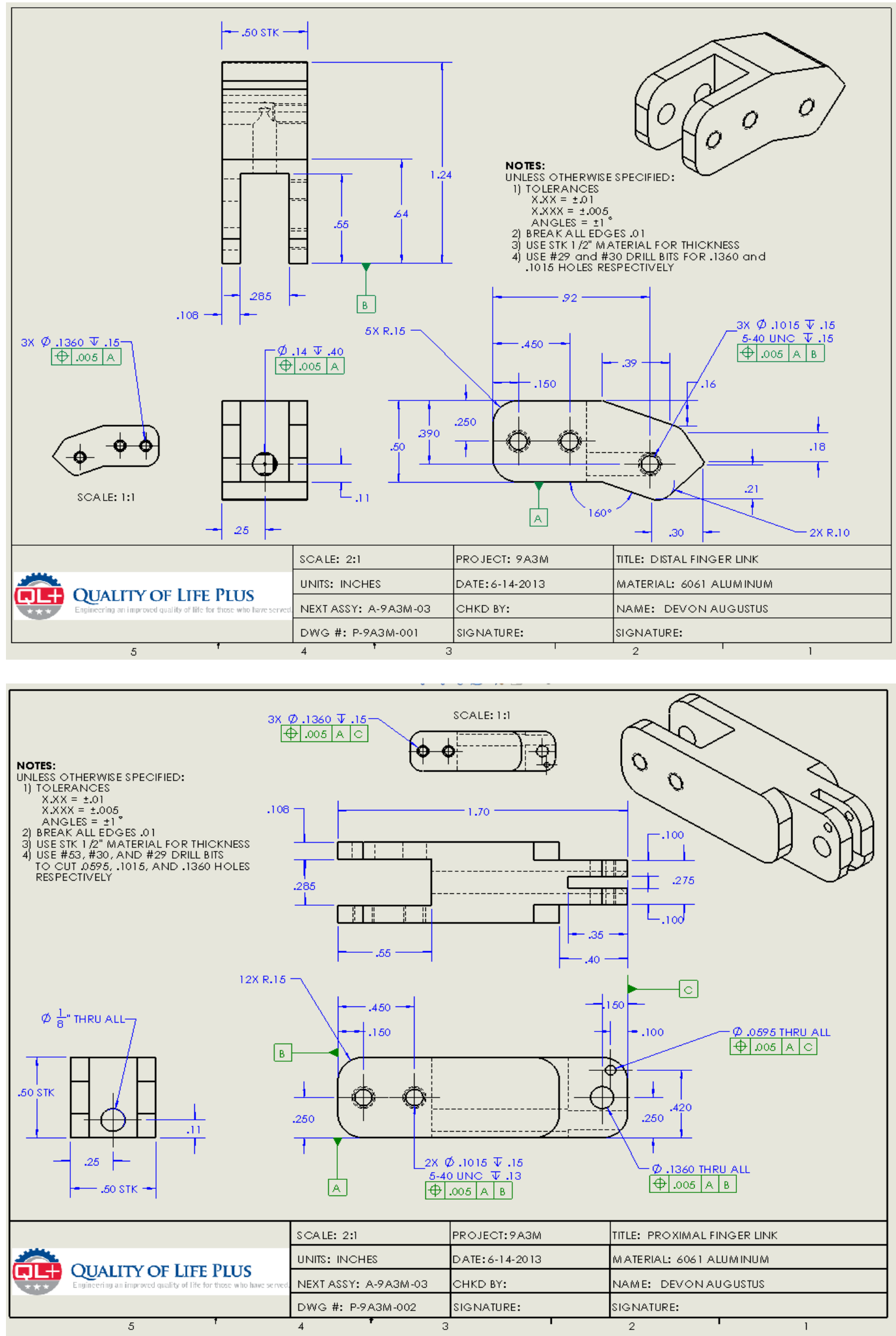

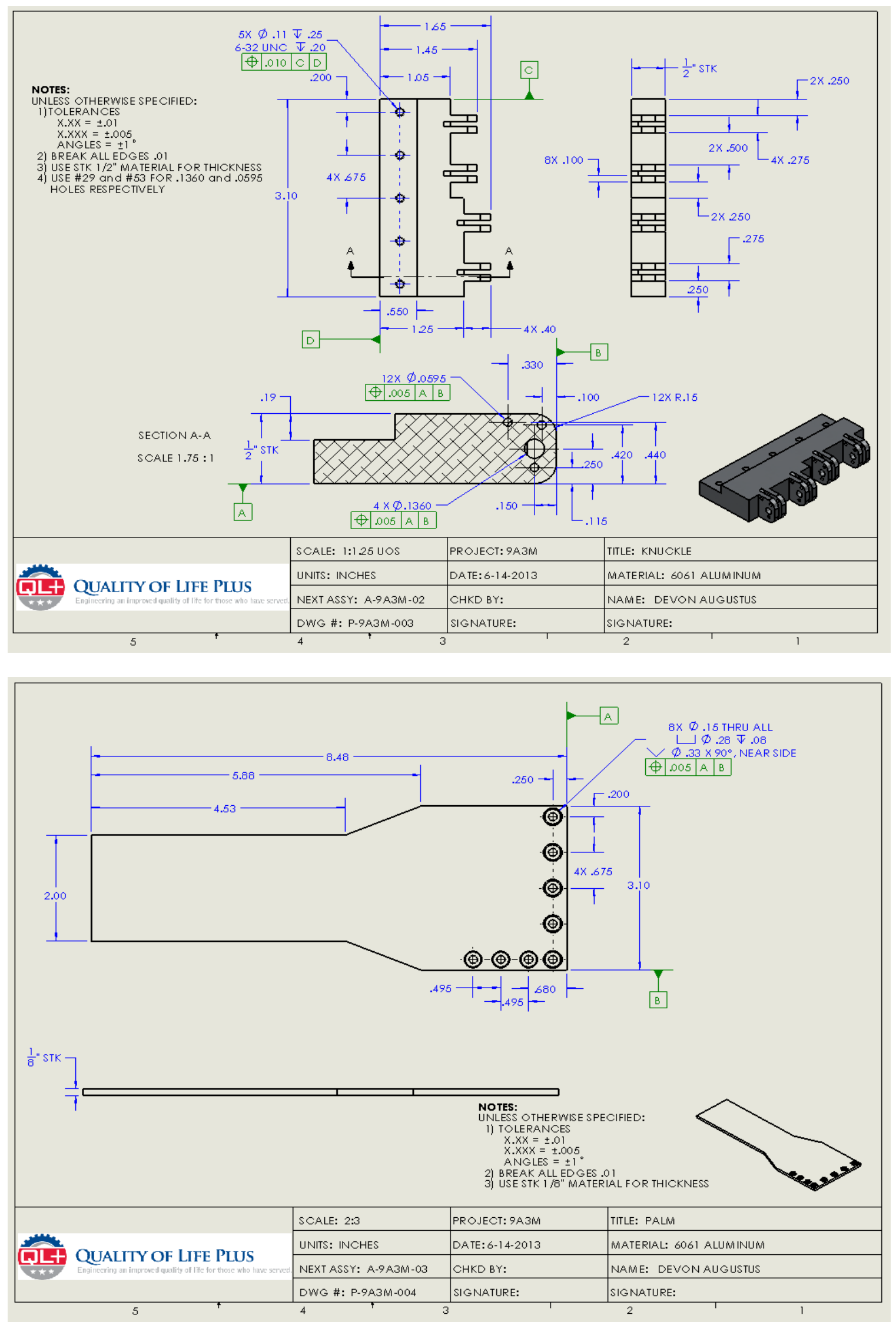

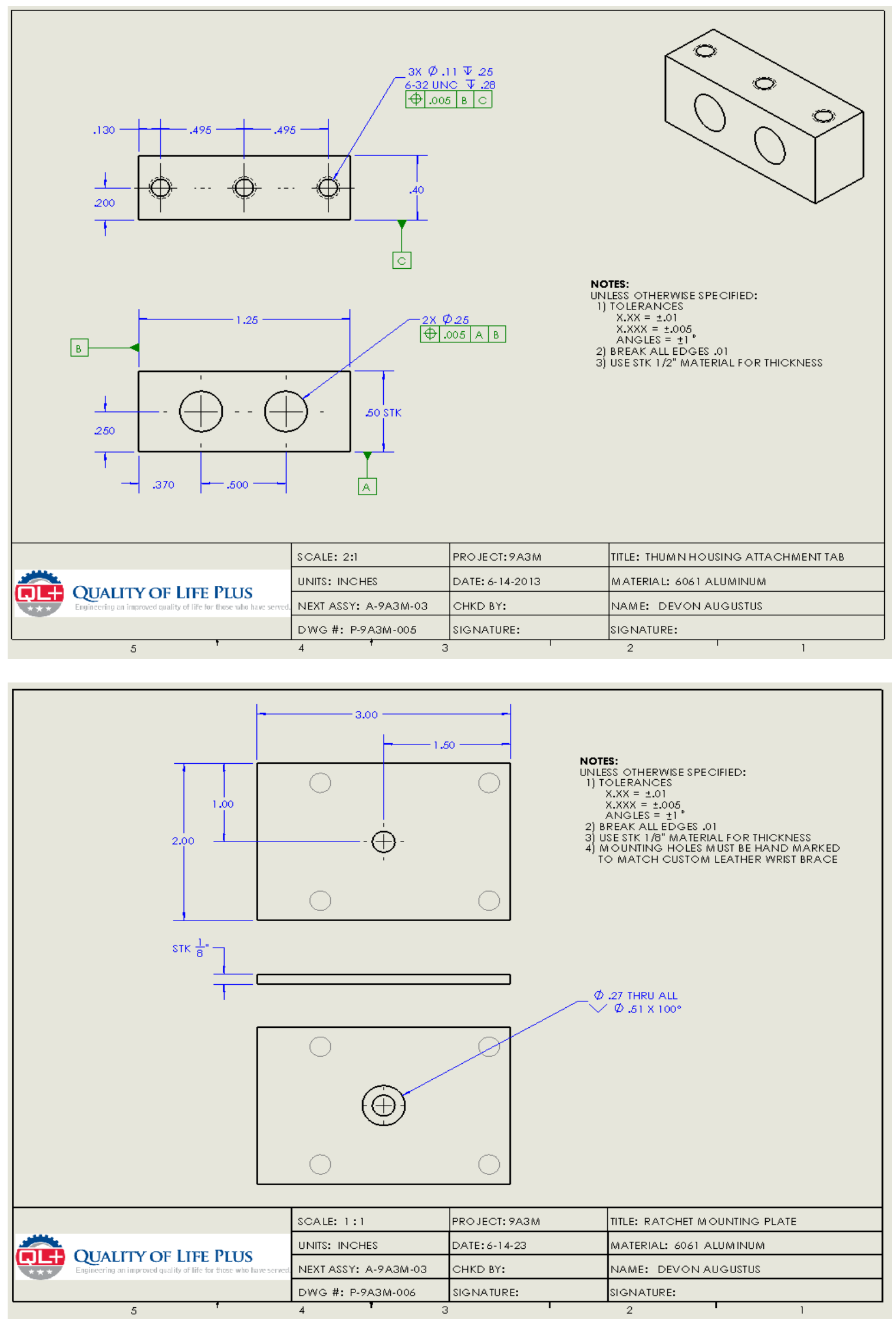